University of Louisville

ThinkIR: The University of Louisville's Institutional Repository

Electronic Theses and Dissertations

$12-2017$

\title{
An investigation of relationship correlates and predictors of cultural adjustment among missionaries.
}

Sarah Warren

University of Louisville

Follow this and additional works at: https://ir.library.louisville.edu/etd

Part of the Social and Behavioral Sciences Commons

\section{Recommended Citation}

Warren, Sarah, "An investigation of relationship correlates and predictors of cultural adjustment among missionaries." (2017). Electronic Theses and Dissertations. Paper 2844.

https://doi.org/10.18297/etd/2844

This Doctoral Dissertation is brought to you for free and open access by ThinkIR: The University of Louisville's Institutional Repository. It has been accepted for inclusion in Electronic Theses and Dissertations by an authorized administrator of ThinkIR: The University of Louisville's Institutional Repository. This title appears here courtesy of the author, who has retained all other copyrights. For more information, please contact thinkir@louisville.edu. 


\title{
AN INVESTIGATION OF RELATIONSHIP CORRELATES AND PREDICTORS OF CULTURAL ADJUSTMENT AMONG MISSIONARIES
}

\author{
By \\ Sarah Warren \\ B. A., Olivet Nazarene University, 2006 \\ M.A., Indiana Wesleyan University, 2008

\begin{abstract}
A Dissertation
Submitted to the Faculty of the College of Education and Human Development In Partial Fulfillment of the Requirements for the Degree of
\end{abstract} \\ Doctor of Philosophy \\ in Counseling and Personnel Services \\ Department of Counseling and Human Development \\ University of Louisville \\ Louisville, Kentucky
}

December 2017 



\title{
AN INVESTIGATION OF RELATIONSHIP CORRELATES AND PREDICTORS OF CULTURAL ADJUSTMENT AMONG MISSIONARIES
}

\author{
By \\ Sarah Warren \\ B. A., Olivet Nazarene University, 2006 \\ M.A., Indiana Wesleyan University, 2008
}

A Dissertation Approved on

November 28, 2017

by the following Dissertation Committee:

Dr. Lisa M. Hooper, Dissertation Chair

Dr. Detra Johnson, Committee Member

Dr. Ahmad Washington, Committee Member

Dr. Hongryun Woo, Committee Member 


\section{ACKNOWLEDGMENTS}

I am immensely grateful for the many individuals who have helped me through this long dissertation journey. First, thank you to my dissertation chair, Dr. Lisa M. Hooper. I am grateful for your guidance, wisdom, and patience, the priority you place on your students, and your willingness to work with me across continents. I am also grateful to my committee members, Dr. Detra Johnson, Dr. Ahmad Washington, and Dr. Hongryun Woo, for your support, expertise, and flexibility as I completed this dissertation process.

Thank you to Extreme Nazarene Missions and the Global Mission Department of the Church of the Nazarene for your kindness and willingness to assist me throughout the course of this project. Without your support, I would not have been able to complete this research study. I am grateful for the opportunity I have to be part of these organizations and the missions work that is being done around the world.

To my amazing family who has unconditionally loved, supported, and encouraged me through every step of this long journey - thank you for always believing in me and for teaching me to believe in myself.

And finally, to my Lord and Savior Jesus Christ, without whom none of this would be possible. To Him be the glory, forever and ever! 


\section{ABSTRACT \\ AN INVESTIGATION OF RELATIONSHIP CORRELATES AND PREDICTORS OF CULTURAL ADJUSTMENT AMONG MISSIONARIES}

Sarah Warren

November 28, 2017

While research on the cultural adjustment of expatriates has existed for decades, information related to the cultural adjustment of missionaries is considerably lacking (Kimber, 2012). Information on missionary cultural adjustment often has been extrapolated from the greater expatriate population, in spite of differences existing between missionaries and other expatriates (Navara \& James, 2002; 2005). This study examined the extent to which missionary relationships (with God, individuals from one's host culture, individuals from one's home culture, and other missionaries) correlate with and predict cultural adjustment among missionaries.

Participants were recruited from the Church of the Nazarene's Global Mission Department to complete an online survey consisting of the Sociocultural Adaptation Scale (SCAS; Ward \& Kennedy, 1999), the Spiritual Assessment Inventory (SAI; Hall \& Edwards, 1996; 2002), and the 2-Way Social Support Scale (SSS; Shakespeare-Finch \& Obst, 2011). The final sample included 101 English-speaking missionaries who have been serving for at least three months.

While results of the bivariate analyses did not find a correlation between cultural adjustment and overall level of relationship with God, there was a significant correlation 
found between cultural adjustment and the Instability subscale of the SAI, indicating that stability in one's relationship with God is positively correlated with cultural adjustment. Results also indicated a significant correlation between cultural adjustment and missionaries' relationships with individuals from their host culture. Additional bivariate analyses did not indicate a significant correlation between cultural adjustment and missionaries' relationships with individuals from their home culture or cultural adjustment and relationships with other missionaries.

Results of a multiple regression analysis indicated a significant positive relationship between cultural adjustment and the independent variables of relationship with God, individuals from one's host culture, individuals from one's home culture, and other missionaries. Further analysis indicated that missionary relationships with host nationals made a significant contribution to the multiple regression model, but no other variables had a significant impact on cultural adjustment.

This study adds to the limited research on missionary cultural adjustment, providing information on the cultural adjustment process that can be used to increase the likelihood of missionary success in transitioning to a new cultural environment. 


\section{TABLE OF CONTENTS}

\section{PAGE}

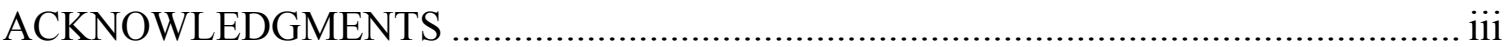

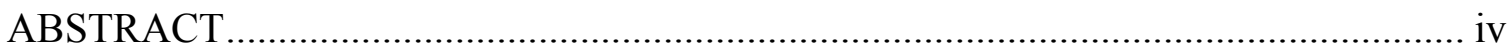

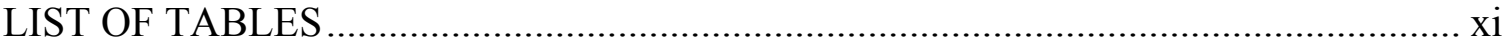

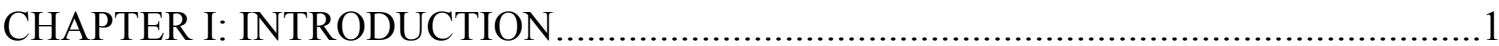

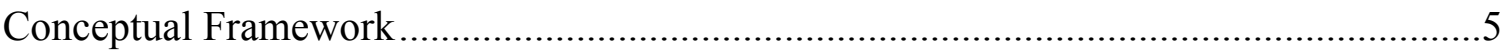

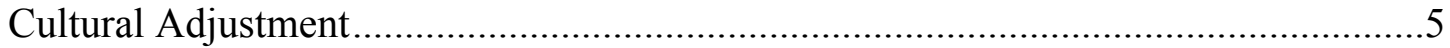

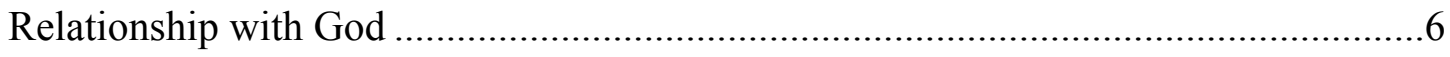

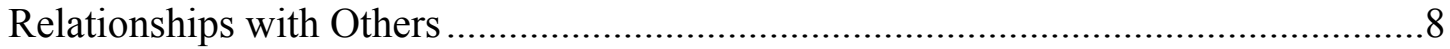

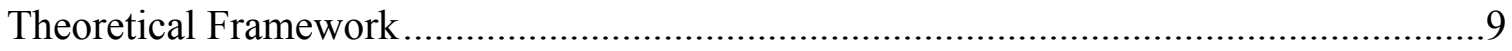

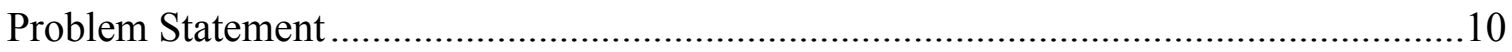

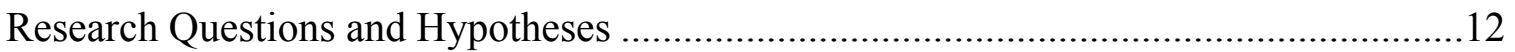

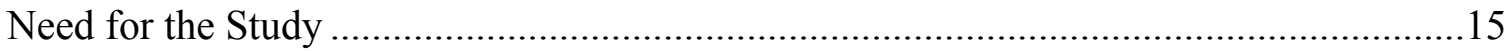

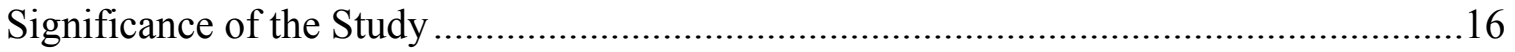

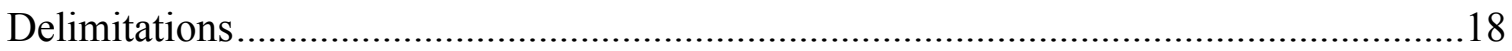

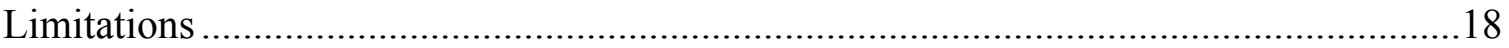

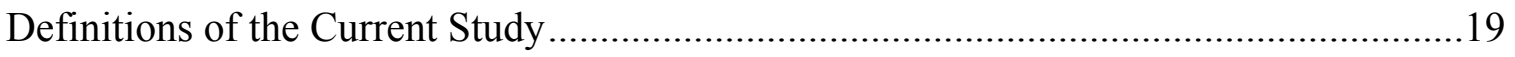

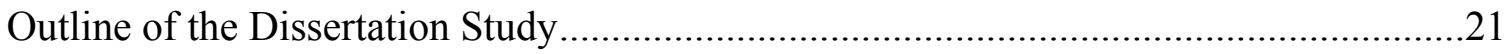

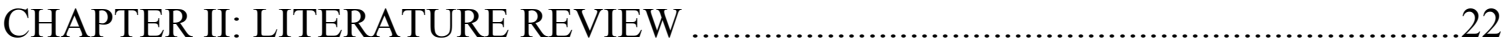


Cultural Adjustment

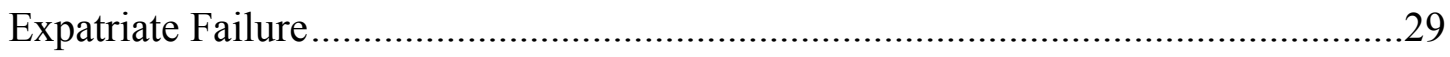

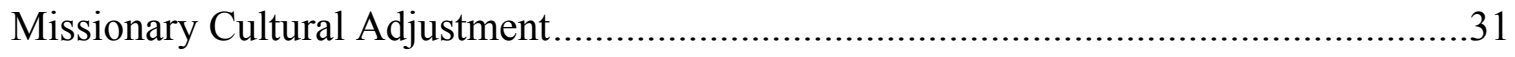

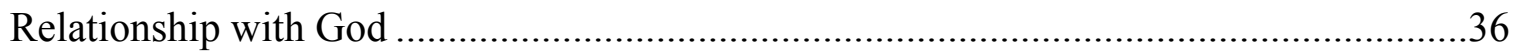

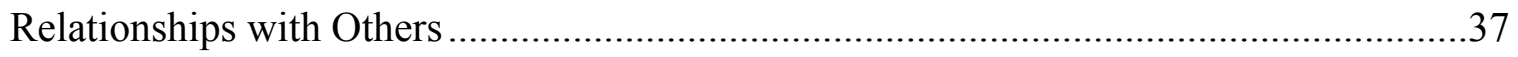

Relationships from Home Culture .....................................................................40

Relationships with Expatriates........................................................................... 41

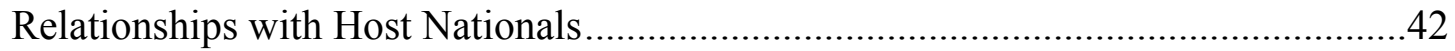

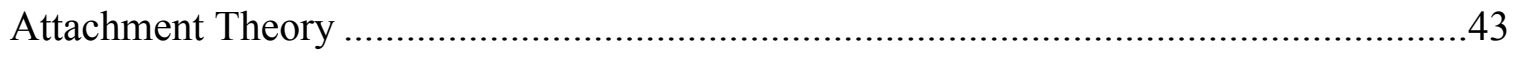

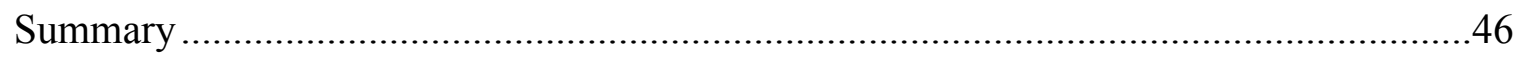

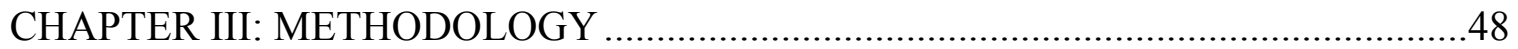

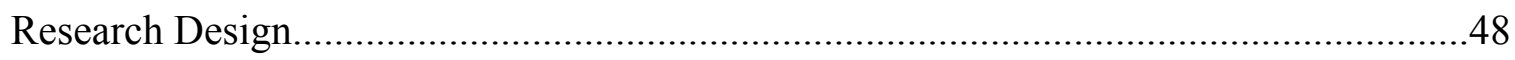

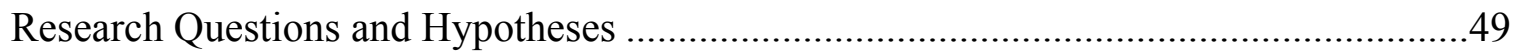

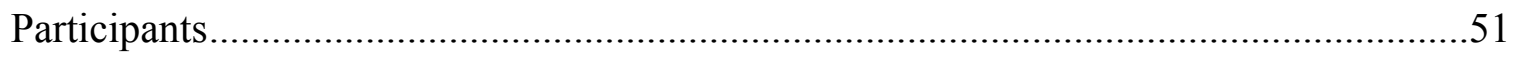

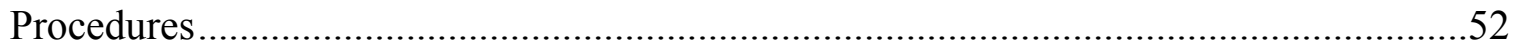

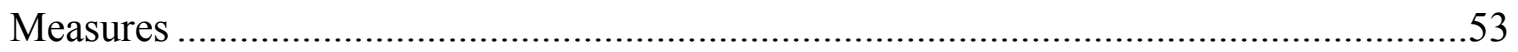

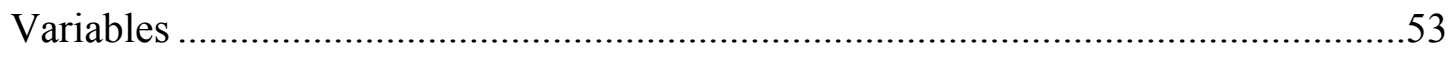

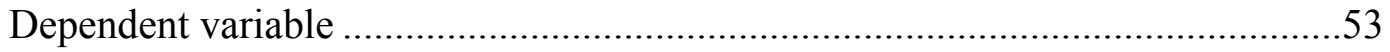

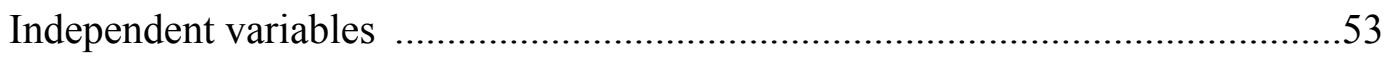

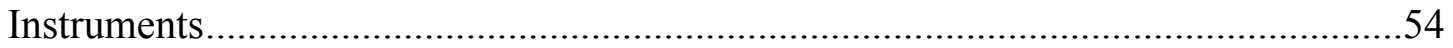

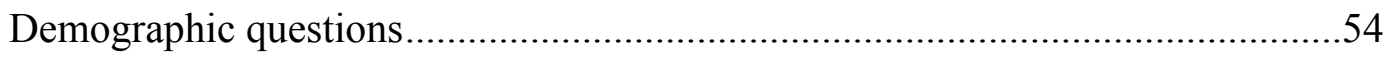

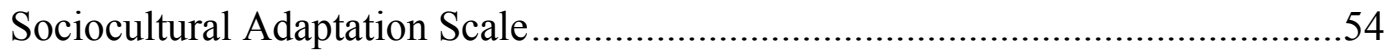

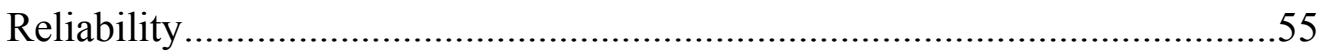




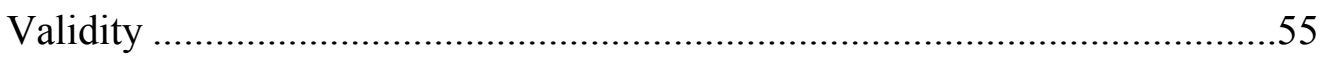

Spiritual Assessment Inventory ………………………………………….......56

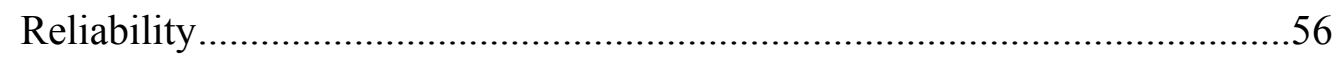

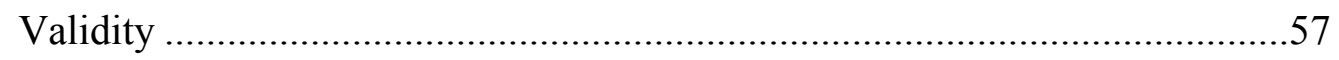

The 2-way Social Support Scale …………………………………..................5

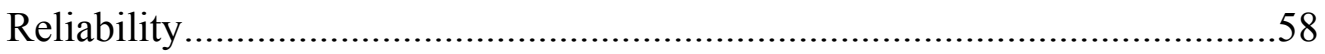

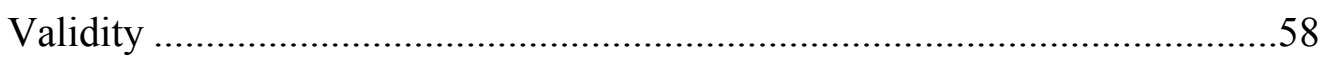

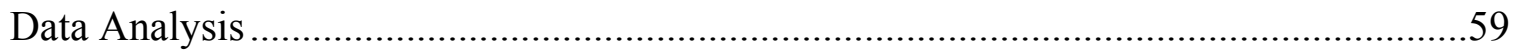

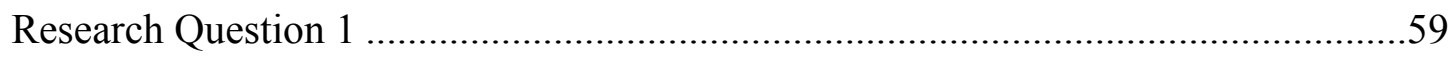

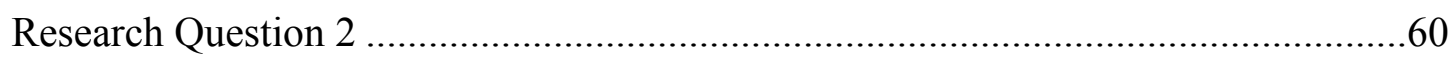

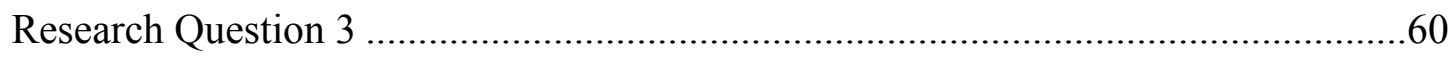

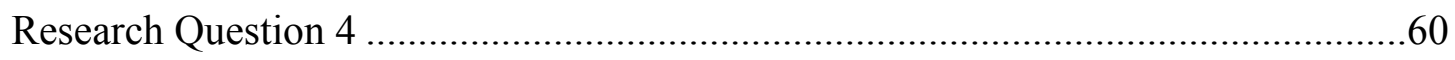

Research Question 5 ...................................................................................61

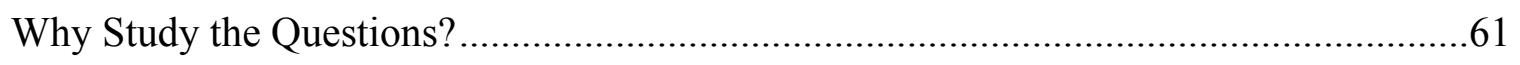

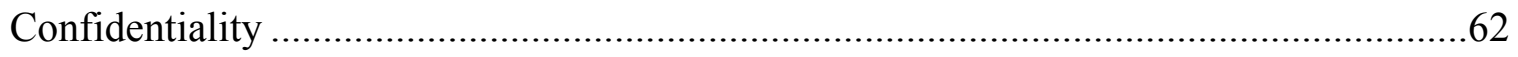

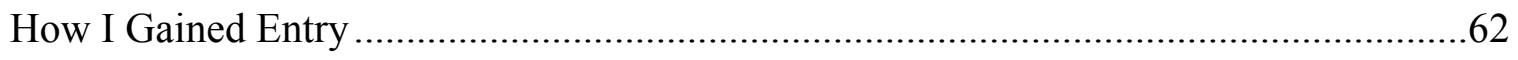

Ethical Considerations of Human Subjects.....................................................................63

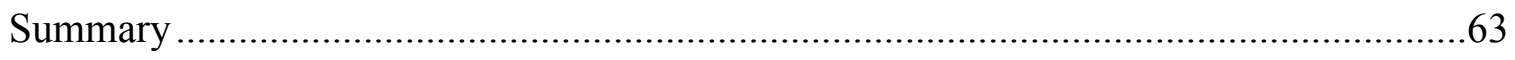

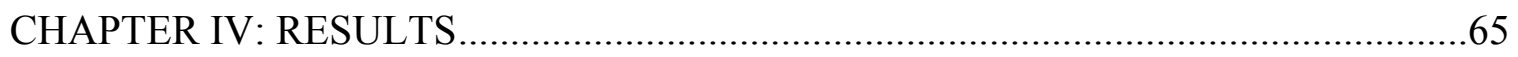

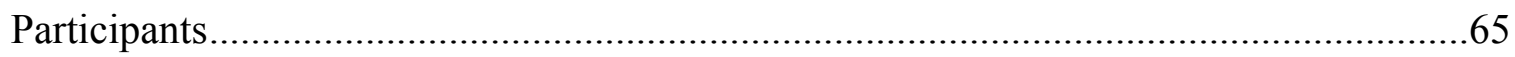

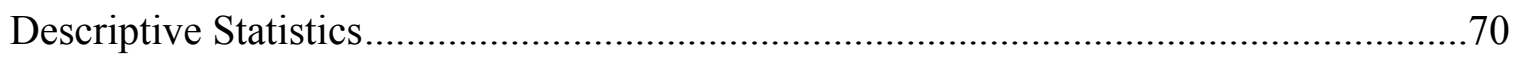

Missionary Cultural Adjustment ...........................................................................

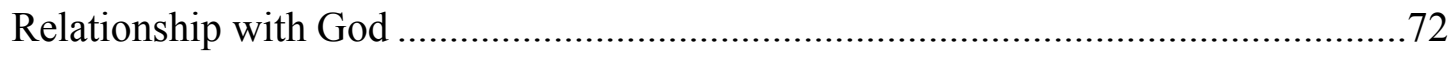




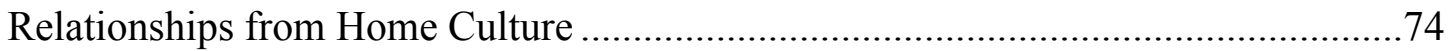

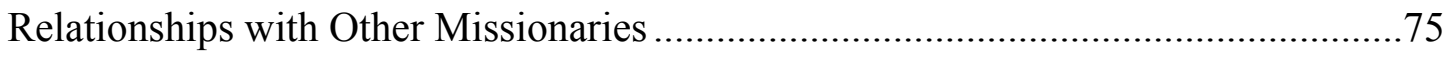

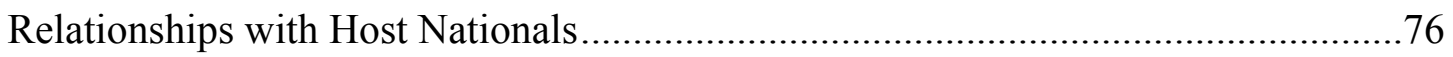

Data Cleaning and Testing of Assumptions.....................................................................77

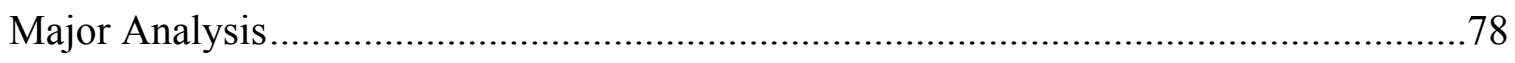

Research Question 1 .........................................................................................78

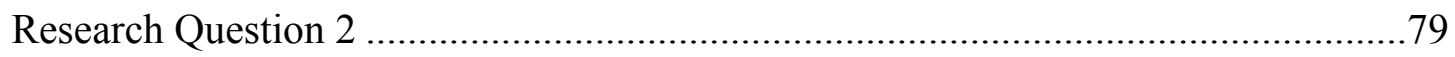

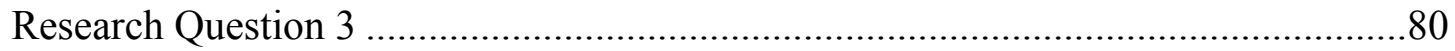

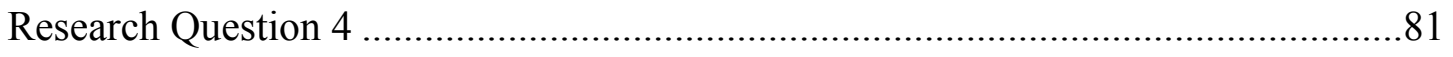

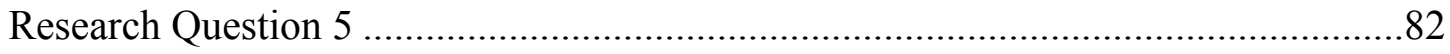

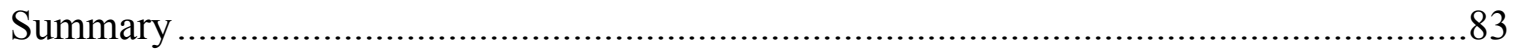

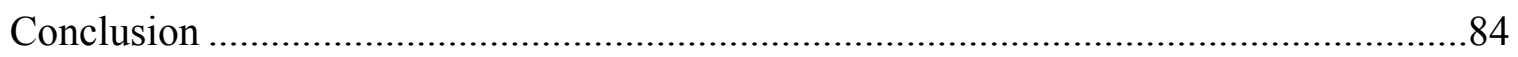

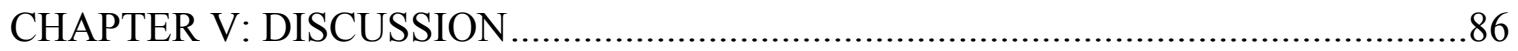

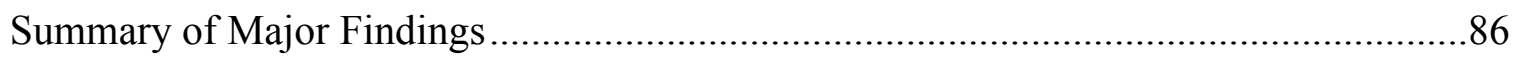

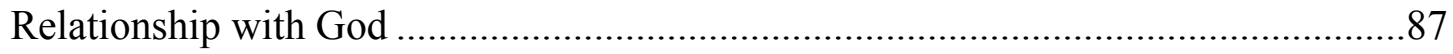

Relationships from Home Culture ……………………........................................90

Relationships with Other Missionaries .................................................................92

Relationships with Host Nationals ...........................................................................94

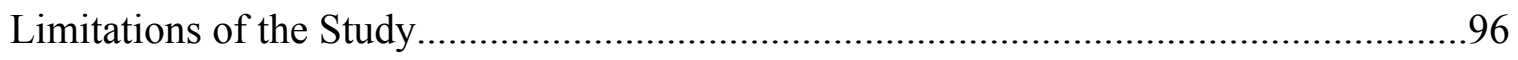

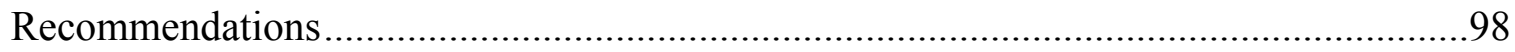

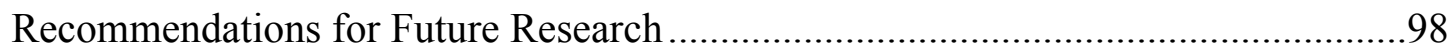

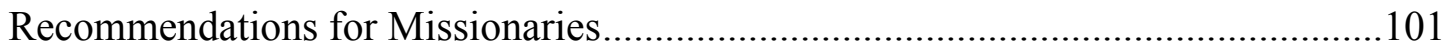

Recommendations for Mission Organizations............................................................103 


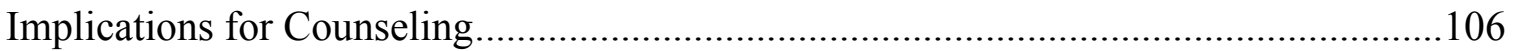

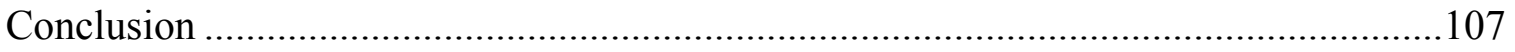

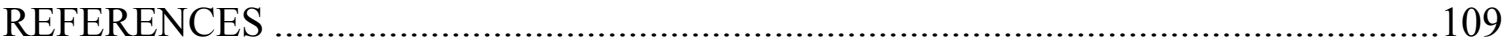

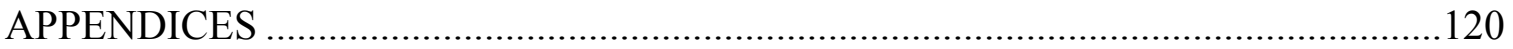

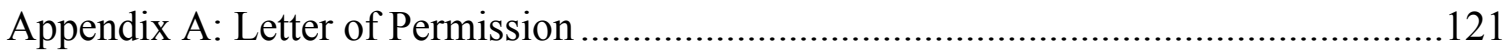

Appendix B: Subject Informed Consent Document ………............................................122

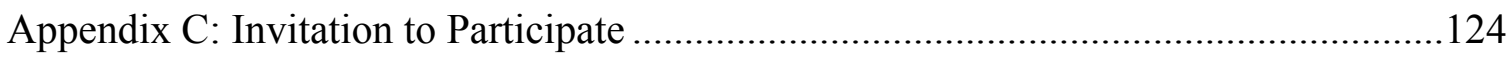

Appendix D: Reminder to Participate .........................................................................125

Appendix E: Demographic Questions ………………….......................................126

Appendix F: Sociocultural Adaptation Scale..............................................................127

Appendix G: Spiritual Assessment Inventory............................................................129

Appendix H: The 2-Way Social Support Scale .........................................................132

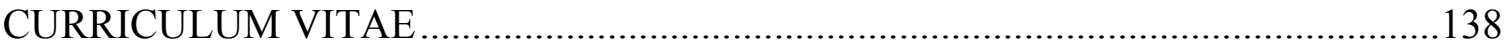




\section{LIST OF TABLES}

$\begin{array}{ll}\text { TABLE } & \text { PAGE }\end{array}$

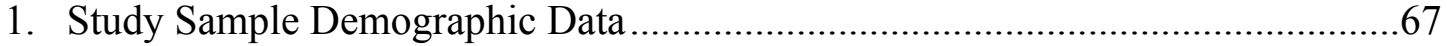

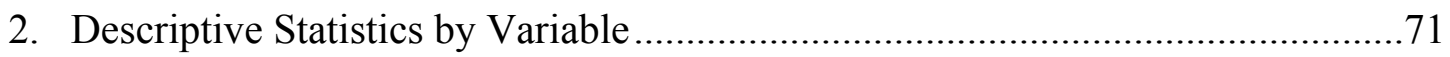

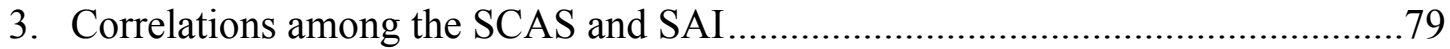

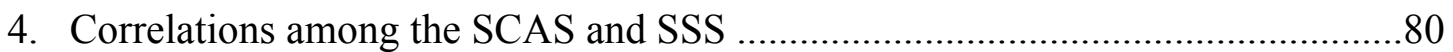

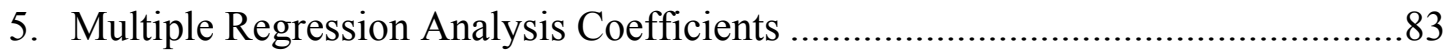




\section{CHAPTER I}

\section{INTRODUCTION}

Research on the cultural adjustment of expatriates has existed for more than four decades and has covered many different aspects and variables related to the cultural adjustment process (Ward \& Kennedy, 1999). However, information related specifically to the cultural adjustment of missionaries, a small but important subcategory of the larger expatriate group, is considerably lacking (Kimber, 2012) and often has been extrapolated from the greater expatriate population, in spite of the fact that missionaries do not always experience cultural adjustment in the same way as other expatriates (Navara \& James, 2002; 2005). The World Christian Database reports that the number of missionaries from all religious denominations is steadily rising, with estimates of approximately 430,000 foreign missionaries serving during the year 2017 (Johnson \& Zurlo, 2016). As the number of missionaries continues to increase, there is an urgent need for empirical investigations that can inform mission organizations on the cultural adjustment process in order to ensure their missionaries have the physical and relational support they need to sustain their ministry on the mission field.

While missionaries typically go through screening and training before moving to the mission field, this training often does not adequately prepare missionaries for the difficulties that can arise when adjusting to a new culture (Whiteman, 2008). Because relatively little research has been conducted exploring the cultural adjustment process of 
missionaries living in foreign placements (Kimber, 2012; Navara \& James, 2005), it is difficult for mission organizations to determine the best information to provide their missionaries in order to assist in the cultural adjustment process. Additionally, mission organizations frequently have problems with assessing a potential missionary's ability to adjust and thrive in a new environment prior to their departure, possibly due to a lack of empirical research on the elements that may be most helpful to missionaries in the cultural adjustment process (Schubert, 1999; Whiteman, 2008).

When missionaries have difficulty with adjusting to their new cultural environment, many problems can arise for both the missionary and their sending organization (Schubert, 1999; White, Absher, \& Huggins, 2011; Whiteman, 2008). Initially, these problems may include difficulties on the job, such as a failure to complete tasks or meet objectives. However, if the problems escalate, they can eventually result in a need for the missionary to return home early, failing to complete their foreign assignment. This type of failure, often referred to as "expatriate failure" (Caligiuri, Hyland, Joshi, \& Bross, 1998), can lead to additional complications for both the missionary and the sending organization.

Complications related to expatriate failure can include a loss of time and effort in mobilizing and training missionaries or a loss of financial security for the missionary who has quit their job and sold their belongings in anticipation of living on the mission field (Caligiuri et al., 1998; Schubert, 1999; White et al., 2011). While data on financial costs (such as relocation, training a replacement, loss of productivity) related specifically to missionaries ending their assignment early is not readily available, the estimation of general costs for expatriates (including missionaries) who prematurely terminate a global 
assignment can range anywhere from $\$ 80,000$ to $\$ 1,000,000$ per employee (Shaffer, Harrison, Gregerson, Black, \& Ferzandi, 2006; Vögel, Van Vuuren, \& Millard 2008; Wu \& Bodigerel-Koehler, 2013). Even if the costs of missionary failures are on the lower end of these estimated amounts, prematurely ending an assignment can still result in a significant financial burden for both the missionary and their sending organization. In order to prevent these costs that arise when missionaries struggle to adjust to a new cultural environment, mission organizations need a greater understanding of the issues (including relationships and other social resources) that may influence a missionary's cultural adjustment. This information can help mission organizations chose the best individuals (i.e., those with a stronger support network) to be sent to the mission field and ensure that those individuals are adequately trained in a way that will increase their likelihood of success during an often-difficult transition process.

Relationships are one way that missionaries may be able to improve the overall process of adjusting to a new cultural environment and avoid some of the potential personal and financial pitfalls that can arise during this transition. The missionaries' relationships with God, family and friends from their home country, other missionaries on the field, and host nationals on the field can all potentially impact how the missionary handles cultural adjustment. Lewis Hall, Edwards, and Hall (2006) argue that spirituality may be related to cultural adjustment, particularly in a population such as missionaries, whose motivation for being in a cross-cultural situation is directly related to their relationship with God.

Additionally, social support from other individuals has been found to be one of the strongest influences on cultural adjustment for missionaries and other expatriates 
(Black, Mendenhall, \& Oddou, 1991; Caligiuri \& Lazarova, 2002; Searle \& Ward, 1990; Ward \& Chang, 1997; Ward \& Kennedy, 1992). Relationships fulfill the basic human need for contact and friendship. In the early stages of global assignments, these emotional connections can off-set the negative psychological effects of isolation and loneliness. Research on the larger population of expatriates has shown that relationships can have a significant correlation with an expatriate's cultural adjustment to a new environment, relieving some of the stress that comes with the cultural adjustment process and allowing the expatriate to adjust to their new culture more quickly and easily (Black et al., 1991; Caligiuri \& Lazarova, 2002; Searle \& Ward, 1990; Ward \& Chang, 1997; Ward \& Kennedy, 1992).

However, while this research on the cultural adjustment of expatriates as a whole can shed some light on the process of missionary cultural adjustment, studies have shown that differences between missionaries and their fellow expatriates do exist, especially related to their relationships and how they interact with host nationals and other expatriates (Navara \& James, 2002; 2005). These findings underscore the critical need for additional studies that specifically examine missionaries and their relationships separately from the general expatriate population. Relationships with God, other expatriates, host nationals, and even family members and friends from the missionary's home culture (especially with technology allowing for more frequent communication with long-distance support systems than was possible in the past), can all influence a missionary's cultural adjustment process. Additional research on missionary relationships with God and others can provide empirical evidence that will assist in understanding how these relationships may be associated with cultural adjustment, 
potentially helping sending organizations and their missionaries in the development of beneficial relationships in order to provide support for missionaries during the transition process. This, in turn, can assist in reducing the potential costs, both financial and personal, that arise when a missionary fails to adjust to their new environment.

The results of this dissertation study will add to the current research base on the topic of missionary cultural adjustment. This study specifically examined missionaries' relationships with God and others and looked at how the strength of these supportive relationships can influence the cultural adjustment process by relieving some of the stress related to cultural adjustment. The findings from this study will help in understanding how relationships can reduce potential obstacles to cultural adjustment so that missionaries are able to adjust to their new culture as quickly and easily as possible and be effective in their ministry on the mission field.

\section{Conceptual Framework}

This study examined how missionary adjustment to a new cultural environment correlates with and predicts a missionary's relationships with others (both on and off the mission field), as well as a missionary's relationship with God. The concepts of missionary relationship and cultural adjustment were informed by specific models that have been developed and studied in the research literature.

\section{Cultural Adjustment}

Cultural adjustment has been studied extensively, and a number of variables have been found to relate to an individual's cultural adjustment to a new environment. Cultural adjustment is generally conceptualized as the degree of discomfort felt by expatriates

(including missionaries) associated with various aspects of the host culture (Black et al., 
1991; Wu \& Bodigerel-Koehler, 2013), with lower levels of discomfort being associated with higher levels of cultural adjustment. Ward and Kennedy (1999) developed a model that conceptualizes cultural adjustment as consisting of two factors: psychological adjustment and sociocultural adjustment. Psychological adjustment, originating from a stress and coping framework, refers to a subjective and internal aspect of psychological well-being, satisfaction, and comfort with the new culture. Sociocultural adjustment refers to an objective and external aspect of cultural adjustment, involving the person's effectiveness in dealing with the challenges of the new environment and the tasks that he or she must complete in that environment. In Ward and Kennedy's model, psychological adjustment is affected by personality factors, life changes, and social support in relationships while sociocultural adjustment is predicted by cultural knowledge, language ability, length of residence in the host culture, and cultural distance (i.e., the difference between the values held by the host culture and the culture of origin; Searle \& Ward, 1990; Ward \& Kennedy, 1992; Ward \& Kennedy, 1999).

\section{Relationship with God}

Although the overwhelming majority of missionaries come to the mission field in large part due to their current relationship with God (Lewis Hall et al., 2006), it cannot be assumed that this is the case for everyone. It is possible that a missionary may be on the field due to other influences, such as the influence of their church, family members, or friends back home. Additionally, while almost all missionaries would profess some level of relationship with God, the strength of that relationship varies from person to person. Therefore, it is impossible to know exactly how strong a person's relationship with God is without asking specific questions to assess that relationship in some way. 
Understanding the strength of one's relationship with God is the first step in understanding how that relationship impacts the issue of cultural adjustment.

In the current study, the concept of a missionary's relationship with God was based on the model put forth by Hall and Edwards $(1996 ; 2002)$ in developing the Spiritual Assessment Inventory (SAI). Spiritual relationship from this perspective involves two primary dimensions: the quality or developmental maturity of one's relationship with God and awareness of God. The first dimension is based on objectrelations theory and what is traditionally understood as a psychological aspect of development. Maturity in one's relationship with God is the ability to maintain a consistent sense of emotional connection with God in the midst of spiritual struggles (Hall \& Edwards, 1996; 2002). Lewis Hall et al. (2006) state that there are two main components of relational maturity. The first component involves experiencing both oneself and the other individual (in this case, God) as increasingly differentiated, meaning that the person recognizes that God is not simply an extension of themselves or someone whose function is to make their life easy. The second component is recognizing that the other individual has both good and bad aspects, or in God's case, has aspects that a person might not like, such as when God does not answer a prayer in the desired way.

The second dimension, awareness of God, refers to a person's capacity to be aware of God's presence and communication in his or her life. Based on this conceptualization, a more mature relationship with God and a more developed capacity for awareness of God should theoretically provide spiritual resources for missionaries as they endeavor to adjust to foreign cultures for the purpose of a spiritually motivated task (Hall \& Edwards, 1996; 2002; Lewis Hall et al., 2006). 


\section{Relationships with Others}

The strength of an individual's relationship with another person is often measured by the amount of social support that can be found within that relationship. James, Hunsley, Navara, and Alles (2004) define social support as the "perceived availability of potential social resources" that can include "appraisal support (advice and discussion), belonging support (identification with a social network), and tangible support (material aid)" (p. 116). Relationships have been found to impact various aspects of both physical and psychological well-being (Brown, Nesse, Vinokur, \& Smith, 2003; Caligiuri \& Lazarova, 2002; Israel-Cohen, Kaplan, Noy, \& Kashy-Rosenbaum, 2016; ShakespeareFinch \& Obst, 2011; Shakespeare-Finch, Rees, \& Armstrong, 2014).

For the purpose of this study, the concept of relationship was structured around Shakespeare-Finch and Obst's (2011) model for the 2-Way Social Support Scale (SSS), which separates social support into emotional support (i.e., encouragement or understanding) and instrumental support (i.e., providing for tangible or physical needs). Within the dimensions of emotional and instrumental social support, Shakespeare-Finch and Obst (2011) found that both giving and receiving social support can be beneficial aspects of a relationship, suggesting that greater psychological benefits can be gained by individuals who both provide and receive support over time. Therefore, they conceptualize social support as being comprised of four separate components: (a) giving emotional support, (b) giving instrumental support, (c) receiving emotional support, and (d) receiving instrumental support. These four components were used to examine the strength of individual missionary's relationships with friends and/or family in their home 
culture, host nationals (residents or citizens) in their country of service, and other missionaries on the field.

\section{Theoretical Framework}

The basic theoretical framework for this study was taken from attachment theory. Bowlby's (1988) theory of attachment states that every person comes into the world determined to form attachments with other people, and that these attachments are what help each person to survive. As part of his attachment theory, Bowlby discusses the concept of a "secure base," claiming that the existence of a secure relationship attachment to another person promotes a greater capacity for exploring one's surrounding environment. Ainsworth, Blehar, Waters, and Wall (1978) found that children with a secure attachment to their caregivers explored a new environment (or "strange situation") more extensively than those with insecure attachments. This idea of a secure base has been extended to adult attachment theory and research, as well as to the field of cultural adjustment (Polek, Wöhrle, \& van Oudenhoven, 2010; Sochos \& Diniz, 2012; Wang \& Mallinckrodt, 2006).

Wang and Mallinckrodt (2006) state that being placed in a new cultural environment is similar to the idea of young children learning to explore new physical surroundings in Ainsworth et al.'s (1978) Strange Situation. Polek et al. (2010) agree, stating that secure attachment is positively related to psychological and sociocultural adjustment. Sochos and Diniz (2012) also found that attachment is connected to cultural adjustment, claiming that attachment-related concepts such as the disruption of interpersonal bonds and the increase of environmental stress are also part of the cultural 
adjustment process and that both secure and dismissive attachment styles are connected to higher levels of sociocultural adjustment in expatriates.

Within the concepts of attachment theory, missionaries and other expatriates with healthy attachments are more likely to have a secure base that will help them to better handle stressful and difficult situations, develop new relationships, and explore unfamiliar cultural environments, increasing the overall likelihood of cultural adjustment (Wang \& Mallinckrodt, 2006). Thus, this study of how relationships correlate with and predict cultural adjustment fits nicely within the theoretical framework of attachment literature.

\section{Problem Statement}

While missionaries often begin their new overseas assignment with a basic idea of the task lying ahead of them on the mission field, not all missionaries fully comprehend the potential problems of adjusting to life in a new cultural environment (Schubert, 1999; Whiteman, 2008). When missionaries are unable to adjust to a new culture, difficulties can arise for both the missionary and their sending organization (Schubert, 1999; White et al., 2011; Whiteman, 2008). If unaddressed, these problems can result in a significant loss of time, effort, and financial resources (Shaffer et al., 2006; Vögel et al., 2008; Wu \& Bodigerel-Koehler, 2013).

Before moving to the field, missionaries often must sell their homes, vehicles, and other belongings and work to raise funds to support their time abroad. Similarly, sending organizations invest time and effort into mobilizing new missionaries and providing them with the needed language and job training to complete their assignment on the mission field (Whiteman, 2008). When missionaries fail to adjust to their new cultural 
environment, they often must return home earlier than planned, which can result in problems with finding a replacement job, a place to live, financial struggles, and other relocation difficulties (Schubert, 1999). The sending organization also experiences difficulties, including unexpected vacancies to fill, a lapse in work being done on the field, and the need to spend additional money finding and training replacement missionaries (Caligiuri et al., 1998; White et al., 2011).

While most mission organizations have experienced these losses that can occur when missionaries return home prematurely, they are not always aware of the best ways to assist their missionaries in handling or preventing the difficulties that arise when living overseas (Whiteman, 2008), and often have problems with assessing a potential missionary's ability to adjust and thrive in a new culture (Schubert, 1999). To assist in this problem, Schubert emphasized the importance of screening missionaries and implementing a strong training process, reiterating that if missionary candidates are not well prepared before being deployed, they often leave the field prematurely, disrupting their families, the missionary team, and the overseas enterprise. However, for a mission organization to be able to screen and assess missionaries before deployment, the organization must first know what issues to address and how those issues may impact the cultural adjustment process.

Therefore, a greater understanding of how a missionary's relationships with God and other people correlate with and predict missionary cultural adjustment can help sending organizations know how best to advise and provide support for their missionaries. Social interaction and support has been found to have a significant influence on the cultural adjustment process for missionaries and other expatriates, often 
by relieving some of the stress that arises in the cultural adjustment process (Black et al., 1991; Caligiuri \& Lazarova, 2002; Searle \& Ward, 1990; Ward \& Chang, 1997; Ward \& Kennedy, 1992). Learning which supportive relationships are most likely to help ease a missionary's transition process can help sending organizations encourage the development of appropriate support systems, providing a "secure base" to help the missionary when dealing with stressful situations and exploring their new cultural environment (Wang \& Mallinckrodt, 2006). Furthermore, empirical investigations that explore cultural adjustment can help with the screening process of missionaries as well as assist in providing adequate training for missionaries prior to their arrival in a new country. This information can assist in making the cultural adjustment process as easy as possible for missionaries, relieving stress and reducing obstacles so that they are able to be the most effective in their ministry.

\section{Research Questions and Hypotheses}

This study examined five research questions to determine the extent to which select factors correlate with and predict cultural adjustment in a sample of missionaries. The specific research questions addressed and the hypotheses that were tested in this study are as follows.

\section{Research Question 1}

To what extent is there an association between a missionary's relationship with God (as measured by the SAI; Hall \& Edwards, 1996; 2002) and their adjustment to a new host culture (as measured by the Sociocultural Adaptation Scale [SCAS]; Ward \& Kennedy, 1999)? 


\section{Hypothesis 1}

There will be a significant positive association between a missionary's relationship with God, as measured by the SAI (Hall \& Edwards, 1996; 2002), and a missionary's adjustment to a new culture, as measured by the SCAS (Ward \& Kennedy, 1999).

\section{Research Question 2}

To what extent is there an association between a missionary's relationships with family and/or friends from their home country (as measured by the SSS; ShakespeareFinch \& Obst, 2011) and their adjustment to a new host culture (as measured by the SCAS; Ward \& Kennedy, 1999)?

\section{Hypothesis 2}

There will be a significant positive association between a missionary's relationships with family and/or friends from their home country, as measured by the SSS (Shakespeare-Finch \& Obst, 2011), and a missionary's adjustment to a new culture, as measured by the SCAS (Ward \& Kennedy, 1999).

\section{Research Question 3}

To what extent is there an association between a missionary's relationships with other missionaries on the mission field (as measured by the SSS; Shakespeare-Finch \& Obst, 2011) and their adjustment to a new host culture (as measured by the SCAS; Ward \& Kennedy, 1999)?

\section{Hypothesis 3}

There will be a significant positive association between a missionary's relationships with other missionaries on the mission field, as measured by the SSS 
(Shakespeare-Finch \& Obst, 2011), and a missionary's adjustment to a new culture, as measured by the SCAS (Ward \& Kennedy, 1999).

\section{Research Question 4}

To what extent is there an association between a missionary's relationships with host nationals (residents or citizens of the host country) on the mission field (as measured by the SSS; Shakespeare-Finch \& Obst, 2011) and their adjustment to a new host culture (as measured by the SCAS; Ward \& Kennedy, 1999)?

\section{Hypothesis 4}

There will be a significant positive association between a missionary's relationships with host nationals (residents or citizens of the host country) on the mission field, as measured by the SSS (Shakespeare-Finch \& Obst, 2011), and a missionary's adjustment to a new culture, as measured by the SCAS (Ward \& Kennedy, 1999).

\section{Research Question 5}

How do a missionary's relationship with God, relationships with family and/or friends from their home country, relationships with other missionaries on the mission field, and relationships with host nationals, separately and taken together, predict a missionary's ability to adjust to a new culture?

\section{Hypothesis 5}

A missionary’s relationship with God, relationships with family and/or friends from their home country, relationships with other missionaries on the mission field, and relationships with host nationals, separately and taken together, will predict a missionary's adjustment to a new culture, as measured by the SCAS (Ward \& Kennedy, 1999). 


\section{Need for the Study}

Research related to cultural adjustment for expatriates has long since been established (Ward \& Kennedy, 1999). However, there is very little research related to the unique cultural adjustment experiences of missionaries. The World Christian Database estimates that the number of foreign missionaries from all religious denominations will reach approximately 430,000 worldwide in the year 2017 (Johnson \& Zurlo, 2016), showing that missionaries represent a large sub-group of the expatriate population. While missionaries have often been placed in the same category as other expatriate groups in the research literature, they have been found to differ from other expatriates in the population at-large in many ways (Navara \& James, 2005). These include the value they put on religion and spirituality, as well as their belief in a call or purpose that has led them to the mission field (Navara \& James, 2005). Studies have shown that there are also differences between the cultural adjustment of missionaries and other expatriates, including differences in coping strategies, satisfaction with their position, and level of social support in relationships (Navara \& James, 2002; 2005). Therefore, it is important to examine missionary cultural adjustment separately from the cultural adjustment of other expatriates in order to determine how missionary needs may differ from those of other expatriate groups.

Additionally, while the importance of relationship and social support has been well documented with other expatriate groups (Caligiuri \& Lazarova, 2002; Ward \& Chang, 1997; Ward \& Kennedy, 1992; Ward \& Rana-Deuba, 2000), studies examining the value of relationship for missionary cultural adjustment are not as common. Furthermore, studies on relationships and cultural adjustment of expatriates as a whole 
often look at support from host nationals and other expatriates in the host culture, but research typically has not included the influence of relationships with family and friends in the expatriate's home culture. With technology allowing many missionaries to remain in regular contact with family and friends back home, it would be valuable to learn more about how the influence of these relationships from a missionary's home culture may correlate with and predict their cultural adjustment to a new cultural environment. Understanding which relational influences have the strongest associations and predictive value with the cultural adjustment process can assist mission organizations in both the selection and training of their missionaries. This can allow organizations to ensure that their missionaries have the necessary resources and information to help them minimize the difficulties of adjusting to a new cultural environment by drawing on support from their relational support systems. The present quantitative study of relationships and missionary cultural adjustment may offer assistance in this area, providing information and guidance to mission organizations hoping to adequately provide support to their missionaries adapting to a new environment.

\section{Significance of the Study}

The current research study adds to the field of cultural adjustment research through its focus on a specific group of expatriates (i.e., missionaries) and examination of relationship variables that influence the cultural adjustment process. As the number of missionaries around the world continues to increase (Johnson \& Zurlo, 2016), the importance of understanding the process of missionary cultural adjustment also increases. When missionaries are unable to adjust in their new cultural environment, problems can arise for both the missionary and their sending organization (Schubert, 1999; White et al., 
2011; Whiteman, 2008). These problems can include difficulties completing tasks or meeting objectives. Problems may even lead to the missionary being sent home earlier than planned, resulting in a significant loss of time, effort, and financial resources for both the missionary and their sending organization (Shaffer et al., 2006; Vögel et al., 2008; Wu \& Bodigerel-Koehler, 2013).

In order to prevent these problems and losses that can arise when missionaries struggle in a new cultural environment, mission organizations need a greater understanding of the issues that may influence a missionary's cultural adjustment. The current study of missionary cultural adjustment may assist mission organizations in this process. Information from the study may be used during the interview and assessment process of missionaries to help sending organizations determine which individuals are best suited to adjust to a new culture based on their current relationships with God and support systems at home. Furthermore, the current study may provide knowledge for missionaries and mission organizations that can be used to provide better missionary training related to the value of continuing to cultivate relationships with God and individuals from a missionary's home culture while developing supportive relationships with missionaries and locals during their time in a new culture. Additional understanding of which relationships provide the most assistance in the cultural adjustment process can encourage missionaries to allocate their time appropriately in order to ensure that they are receiving the support they need to adjust to their new environment as quickly and thoroughly as possible. 


\section{Delimitations}

This study was completed through an online survey distributed to missionaries within the Church of the Nazarene. The sample consisted of 314 English-speaking missionaries serving with the Church of the Nazarene in 162 world areas. Missionaries received an invitation to participate in the survey on September 25, 2017, and had until October 16, 2017 to submit their results. The data collected from the online surveys will contribute to the larger base of knowledge regarding the cultural adjustment and wellbeing of missionaries.

\section{Limitations}

The sample of missionaries participating in this study was limited to individuals associated with the Church of the Nazarene and therefore may not have produced data that can be applied to missionaries working with other denominations or organizations. Similarly, the sample was limited to English-speaking missionaries, and results may not be generalizable to missionaries from non-English-speaking countries.

Furthermore, the self-report design of the study could potentially have subjected the research to bias, as respondents may have held biases in their opinions of themselves or may have embellished their answers to present themselves in a socially desirable manner. However, self-report was the only viable option for obtaining the data related to the research questions, and the anonymity of the responses is assumed to have reduced the potential for self-report bias. 


\section{Definitions of the Current Study}

Acculturation: a process that involves the development of relationships with the new culture, independent from the maintenance of the original culture (Wu \& Mak, 2012).

Acculturative stress: one kind of stress in response to life events that are rooted in the process of acculturation, which usually includes psychosocial difficulties (e.g., loss of social support, rejection by the host culture) when adapting to a new culture (Smart $\&$ Smart, 1995; Wu \& Mak, 2012).

Adaptation: the process of adjusting to a new cultural environment.

Attachment: a lasting psychological connectedness between human beings (Bowlby, 1988).

Country of service: the country a missionary is serving in for ministry purposes.

Cultural adjustment: the degree of psychological or sociocultural discomfort felt by expatriates associated with various aspects of the host culture (Black et al., 1991; Ward \& Searle, 1991; Wu \& Bodigerel-Koehler, 2013).

Culture: the values, beliefs, attitudes, and practices that characterize a racial, religious, or social group.

Expatriate: an individual who relocates to a new host culture with the intent to remain there for an extended period of time, usually not less than a year (Navara \& James, 2002).

Expatriate failure: occurs when individuals either quit or transfer back to their home country prior to the completion of their expected foreign assignments (White et al., 2011). 
Home country: an expatriate's country of origin and citizenship.

Home culture: the values, beliefs, attitudes, and practices that characterize the expatriate's home country.

Host country: the country an expatriate is living and/or working in outside of their home country.

Host culture: the values, beliefs, attitudes, and practices that characterize the expatriate's host country.

Host nationals: residents or citizens of the host country where an expatriate is located.

Mission field: an area, territory, or country where missionaries have been sent to serve.

Missionary: a person sent by a church or mission organization to carry out religious or charitable activities.

Reentry: the process of an expatriate returning to their home country and culture after living abroad.

Relationship: a state of mutual connection, involvement, or association between two parties.

Sending organization: the church or organization sponsoring a missionary's time on the mission field by providing physical, financial, or other types of support.

Social support: perceived availability of potential social resources that can include appraisal support (advice and discussion), belonging support (identification with a social network), and tangible support (material aid; James et al., 2004). 
Spiritual development: the degree to which a person's relationship with God reflects the ability to maintain a consistent sense of emotional connection with God in the midst of spiritual struggles, and the degree to which a person is aware of God's working in his or her life (Lewis Hall et al., 2006).

Support system: a group of people (such as family, friends, or co-workers) who provide social support to an individual.

\section{Outline of the Dissertation Study}

This study is organized into five chapters, with references and appendices. Chapter I has included introductory information related to the research topic and various constructs that will be discussed in the following chapters. Chapter II introduces a review of related literature that examines missionary cultural adjustment as well as the empirical studies that have examined the link between cultural adjustment and relationships with God and others. Chapter III explains the research design and methodology of the study. The sample data and procedures used for analysis are described. Chapter IV describes the statistical analyses that were conducted and the results of those analyses. Finally, Chapter $\mathrm{V}$ discusses the findings of the study, offers recommendations for future research, missionaries, and mission organizations, and discussed the implications for counseling. A list of references and appendices is included at the end of the document. 


\section{CHAPTER II}

\section{LITERATURE REVIEW}

In order to fully examine the concept of missionary cultural adjustment and how it correlates with a missionary's relationships with God and others, it is important to first understand the research that has previously been completed relating to these topics. The following review will examine the existing research literature on cultural adjustment (both in the general expatriate population and within the missionary population), an individual's relationship with God, an individual's relationships with others, and attachment theory in order to provide a foundation for the current research study.

\section{Cultural Adjustment}

Expatriates, often referred to as sojourners in the literature, are individuals who relocate to a new host culture with the intent to remain there for an extended period of time, usually not less than a year (Navara \& James, 2002). This group can include military personnel and their families, aid workers, technical assistants, business managers, embassy staff, professional scholars, and exchange students, as well as the missionary population. Often missionaries and other expatriates require time to adjust to the language, food, social expectations, and other differences that exist between their home culture and the new cultural environment in which they find themselves. Cultural adjustment has been defined as the degree of psychological or sociocultural discomfort felt by these expatriates (including missionaries) associated with various aspects of the 
host culture (Black et al., 1991; Ward \& Searle, 1991). Similarly, Wu and Mak (2012) define acculturation (often used interchangeably with the term cultural adjustment) as a process that involves the development of relationships with the new culture, independent from the maintenance of the original culture. Acculturative stress is a type of stress that occurs in response to life events rooted in the process of acculturation, which usually includes psychosocial difficulties (e.g., loss of social support) when adapting to a new culture (Smart \& Smart, 1995). Acculturative stress and psychological distress can be minimized when individuals acquire appropriate skills to adjust to the host culture (Wu \& Mak, 2012). As this occurs, an intercultural competence develops, which has been defined as "the ability to think and act in inter-culturally appropriate ways" and with sensitivity to relevant cultural differences (Hammer, Bennett, \& Wiseman, 2003, p. 422). Researchers have been studying the issue of cultural adjustment for decades. However, despite significant amounts of theory and research, there is still limited consensus as to what actually constitutes cultural adjustment (Ward \& Kennedy, 1999). Additionally, the majority of empirical studies examining cultural adjustment focus on the expatriate population as a whole instead of on the specific cultural adjustment of the missionary population. This means that researchers are frequently forced to glean their information on missionary cultural adjustment from the larger expatriate population. While the research data provided from the general expatriate population can give some indication of the missionary cultural adjustment process, more research specifically examining missionary cultural adjustment is needed.

In one of the few studies examining the differences between the cultural adjustment of missionaries and the cultural adjustment of other expatriates, Navara and 
James (2002) sent questionnaires to 100 missionaries and 67 other expatriates living in Nepal, measuring coping, cultural adjustment, stress, satisfaction with life, and social support. Navara and James (2002) examined differences between missionaries and other expatriates, and discovered that in general, missionaries reported less satisfaction in their foreign posting than other expatriates. Navara and James (2002) discuss many potential differences between the home and host country that a missionary may face, including: standard of living, accommodations, health and education facilities, food, social relations, climate, economic and political systems, pace of life, values, and beliefs systems (including religion). These perceived cultural differences between the home and host cultures have been seen as an important factor in cultural adjustment (Berry, 1992; Navara \& James, 2002; Searle \& Ward, 1990).

A number of other individual, environmental, and organizational factors have been found to relate to a person's cultural adjustment (Lewis Hall et al., 2006). Individual variables relating to cultural adjustment fall into many different categories. These variables have been examined with the hope of understanding which factors may negatively or positively influence an individual's ability to adapt to a new culture. Wu and Bodigerel-Koehler (2013) determined that self-efficacy, relational skills, emotional stability, open-mindedness, and social initiative all impact cultural adjustment in their study of 182 expatriates from 10 different countries residing in Mongolia. Similarly, Yusoff (2012) examined the relationship between self-efficacy, perceived social support, and psychological adjustment of 185 international students in a Malaysian public university. The study found that self-efficacy, as well as support from friends and significant others, significantly contributed to the level of psychological adjustment. 
Yusoff (2012) argued that high self-efficacy likely helps students approach challenging situations without incapacitating anxiety or confusion. This high self-efficacy likely helps them feel that they have the ability and competency to deal with academic situations and problems. As a result, they experience a better psychological adjustment.

Ward and Kennedy (1992), in their study of 84 New Zealand adults residing in Singapore, found that internal locus of control (referring to the perception of positive and negative events as consequences of one's own behavior and as being under one's personal control), personal relationship satisfaction, and social difficulty predicted psychological adjustment in expatriates. Tanaka, Takai, Kohyama, and Fujihara (1994) found that academic achievement influenced cultural adjustment in their study of 237 international students in Japan. Ward and Rana-Deuba (2000), in their study of 104 expatriates in Nepal, found that relationships with both host-nationals and co-nationals (or fellow expatriates) also influenced cultural adjustment. Additionally, James et al. (2004) examined relational concepts and found that marital and familial variables influenced cultural adjustment among 64 expatriate couples in Nepal.

In a study of 105 expatriates in New Zealand examining the psychological and sociocultural forms of adjustment during the process of cross-cultural transitions, Searle and Ward (1990) identified difficulty of post as an important factor for cultural adjustment. Additionally, Wang and Mallinckrodt (2006), in their study of 104 Chinese international students living in the United States, found that variables related to the host culture, such as foreign language fluency and length of stay in a host country, have been found to influence cultural adjustment because they require "the ability to acquire and 
perform culturally appropriate skills and behavioral competence to fit in the host culture" (p. 423).

Zlobina, Basabe, Paez, and Furnham (2006) conducted a study aimed to replicate the findings of previous investigations regarding the predictors of sociocultural adaptation among different groups of sojourners and to examine which factors best predict successful adjustment of immigrants with 518 expatriates in Spain. Consistent with other literature on sociocultural adaptation, their results showed that length of residence in the new culture, immigration status (having resident permits vs. being “illegal"), and perceived discrimination were the most powerful predictors of sociocultural adjustment of immigrants. Education, relationships with host nationals and perceived cultural distance were other factors significantly associated with difficulty in cultural adjustment.

In a meta-analytic study examining 17 variables analyzed from 68 independent studies with a combined total of 10,672 participants, Wilson, Ward, and Fischer (2013) found that situational factors such as length of residence, cultural knowledge, previous cross-cultural experience, cultural distance, language proficiency, and contact with host nationals were each associated with better sociocultural adjustment. The authors also found that personality variables such as agreeableness, conscientiousness, openness/flexibility, extraversion, cultural empathy, and cross-cultural self-efficacy impacted cultural adjustment. Again, while these studies do not directly examine missionaries, the results give researchers a small indication of how variables such as host culture, language, and time abroad may influence the cultural adjustment of missionaries 
due to the correlation these variables have been found to have with the cultural adjustment of other expatriates.

Ward and Kennedy (1992) examined cross-cultural transitions among 84 expatriates (including missionaries) in Singapore, and discovered that adjustment during cross-cultural transitions can be broadly divided into two categories: a) psychological adjustment, which refers to psychological and emotional well-being and b) sociocultural adjustment, which refers to the ability to "fit in" or negotiate interactive aspects of the host culture. The authors determined that the two adjustive outcomes, though interrelated, are conceptually and empirically distinct.

Psychological adjustment, originating from the stress and coping framework, refers to the more subjective and internal aspect of psychological well-being, satisfaction, and comfort with the new culture. Psychological adjustment is broadly affected by personality, life changes, coping styles, and social support in relationships. Psychological adjustment has been associated with personal flexibility, internal locus of control, relationship satisfaction, approach-oriented coping styles, and the use of humor, while psychological difficulties in expatriates (including missionaries) have been linked to a higher incidence of life changes, loneliness, stress, and avoidant coping styles (Searle \& Ward, 1990; Ward \& Kennedy 1992; 1999; Ward \& Rana-Deuba, 1999). Yang, Noels, and Saumure (2006) examined how both self-construals and communicative competence in the language of the host society contribute to the cross-cultural adaptation of international students. Their study examined a group of 81 international students and 135 Canadian-born students registered at a Canadian university. Results showed that more independent international students experienced higher self-esteem and fewer 
sociocultural difficulties. Language self-confidence was also found to play a role in psychological adjustment and sociocultural difficulty. Yang et al. stated that psychological adjustment is believed to be broadly affected by personality, life changes, coping styles, satisfaction/identification with co-nationals, and social support from co/host nationals.

Sociocultural adjustment, by contrast, refers to a more objective and external aspect of cross-cultural adjustment. Sociocultural adjustment is defined in terms of behavioral competence, and is more strongly influenced by factors underpinning cultural learning and social skills acquisition (Ward \& Kennedy, 1999). Sociocultural adjustment has been defined as the acquisition of appropriate knowledge, social skills and behavioral competence that influence individuals' ability to negotiate effectively in a new cultural milieu (Wu \& Mak, 2012). These include length of residence in the new culture, cultural knowledge, amount of interaction and identification with host nationals, cultural distance, language fluency, and acculturation strategies (Searle \& Ward, 1990; Ward \& Chang, 1997; Ward \& Kennedy, 1999). Wu and Mak (2012) examined the effects of acculturation on psychological distress by asking 180 international students to complete questionnaires every 2 months for a period of 6 months. Their results emphasized the importance of sociocultural adjustment in the process of acculturation and highlighted a lack of acculturation as an identifier of risk rather than a direct predictor of psychological distress. Wu and Mak argued that because many acculturative stressors are psychological stressors resulting from unfamiliarity with new customs and social norms, the amount of acculturative stress will be reduced when individuals experience fewer sociocultural difficulties and, in turn, a reduction in psychological distress. 
Ward and Searle (1991) examined 155 expatriates in New Zealand, assessing psychological and sociocultural adjustment in relationship to cultural knowledge, crosscultural experience and training, attitudes toward host culture, personality, cultural distance, loneliness, amount of contact with host and co-nationals, cultural identity, and values. The authors claimed that a great deal of confusion has arisen in the literature because the separate aspects of psychological and sociocultural adjustment are often collapsed as one construct. Additional research on the aspects of psychological and sociocultural adjustment has been completed by Ward and colleagues (Ward \& Chang, 1997; Ward \& Kennedy, 1992; 1999; Ward, Okura, Kennedy, \& Kojima, 1998; Ward \& Rana-Deuba, 1999) showing that these two dimensions of cultural adjustment, although interrelated, are differentially linked to a variety of factors and exhibit different patterns over time. As a result of the research in these studies, Ward and Kennedy (1999) developed the SCAS based off of the Ward and Kennedy model of cultural adjustment. This scale assesses both psychological and sociocultural adjustment of the individual in order to determine one's level of sociocultural difficulty and overall cultural adaptation.

\section{Expatriate Failure}

Cultural adjustment is important to understand, not only to assist missionaries and other expatriates with adjusting in the most effective way possible, but also to prevent the numerous problems that arise when individuals fail and are forced to return home prematurely. Expatriate failure has been defined as occurring when individuals (including missionaries) either quit or transfer back to their home country prior to the completion of their expected foreign assignments (White et al., 2011). 
White et al. (2011) conducted a study based on 544 responses from expatriate sales managers originating from 62 countries and serving in 77 different countries around the world. Using hierarchical regression, the authors tested main effects of both cultural distance and psychological hardiness on the expatriate's ability to adapt to a new cultural environment. The authors found that for multinational organizations employing expatriates, an individual's inability to adjust to the host culture can lead to lower than expected performance, poor management, low productivity, and failure to meet objectives. Caligiuri et al. (1998) collected longitudinal data from 110 families that had been relocated for global assignments, assessing family characteristics before the assignment and cultural adjustment approximately 6 months into the assignment. The study found that poor cultural adjustment was a common reason given for prematurely terminating global assignments, and that family characteristics such as support, communication, and family adaptability were related to expatriates' cultural adjustment to working in the host country.

Caligiuri et al. (1998) argued that premature termination of a global assignment is especially problematic given the high cost of relocating employees overseas. Due to these high costs, along with high expatriate failure rates and turnover, researchers have become progressively more interested in understanding why some expatriates have succeeded while others have failed in the new environment (Wu \& Bodigerel-Koehler, 2013). The direct costs associated with expatriate cultural adjustment failure have been estimated at $\$ 150,000$ per employee, while the costs associated with training, relocation, and compensation have been estimated at about $\$ 80,000$ per employee (Shaffer et al., 2006; Wu \& Bodigerel-Koehler, 2013). Other estimates are even higher, placing the cost 
of failed expatriate assignments between $\$ 250,000$ and \$1,000,000 (Vögel et al., 2008). And these calculations do not include things such as damaged relationships with the host country, diminished reputation of the company, impact on morale of other employees, or cost of replacement if they leave the organization. Taken as a whole, it is evident that the cost of expatriate failure is significant. The better an organization is able to predict the potential roadblocks to cultural adjustment of expatriates, the more likely it is that they will be able to promote healthy cultural adjustment among their employees, assist expatriates in completing their overseas assignments, and prevent potential problems (White et al., 2011).

\section{Missionary Cultural Adjustment}

Missionaries have been traveling to new cultural environments for centuries, and Navara and James (2005) state that missionaries have historically gone to the mission field for various reasons. These reasons often involve ways of expressing their faith, possibly through acts of humanitarianism or by leading others into their particular religious belief. However, historically, some missionaries have gone to the mission field with the goal of not simply teaching others about their religion, but also pressuring them to change their cultural behaviors so that they matched those of the missionary's home culture. This resulted in the missionaries forcing nationals to adjust to a new culture instead of the missionary learning about the local culture and finding ways to connect that culture with religious beliefs. At times, this viewpoint required nationals to deny their own culture and change so that their lifestyle completely aligned with the missionary's lifestyle. Historically this requirement caused problems, and Navara and James (2005) argue that while missionaries have been credited with many acts of kindness and faith 
over the centuries, the belief that nationals needed to change everything about their lifestyle in order to fit into the missionary's "ideal" resulted in many terrible acts being committed against the individuals missionaries supposedly wanted to serve.

Over time, however, missionaries and mission organizations learned that this method seldom worked, and instead attempted to improve the training, understanding, and cultural sensitivity of missionaries related to the cultural adjustment process (Schubert, 1999; Whiteman, 2008). As a result, missionaries are better equipped to adjust and work within their new cultural environment in a way that honors both religious and cultural beliefs, instead of working against the local culture and expecting the host nationals to adjust to the missionary's way of living.

In spite of this long history of missionary adjustment to cultural differences, and regardless of the fact that missionaries make up an important sub-section of expatriates as a whole, they have not been studied as extensively as other expatriate groups. Most research on expatriate cultural adjustment has focused on groups such as military personnel, humanitarian aid workers, technical assistants, business managers, embassy staff, professional scholars, or exchange students. When studies have been conducted involving missionaries, the focus has often been on missionary reentry into their home country instead of cultural adjustment to a host country. Relatively little research has been conducted exploring the cultural adjustment process of missionaries living in foreign placements (Kimber, 2012; Navara \& James, 2005), in spite of the fact that research from the World Christian Database estimates that the number of foreign missionaries from all religious denominations will reach approximately 430,000 worldwide for the year 2017 (Johnson \& Zurlo, 2016). Missionaries make up a 
significant number of people dealing with cultural adjustment in ways that are mostly unknown to scholars, missionary organizations, or others working to support them, which is unfortunate considering the fact that missionaries are a unique group of people with different needs than many of the other expatriate groups (Lewis Hall et al., 2006).

However, Lewis Hall et al. (2006) argue that this is slowly changing, and some research studies involving missionaries have been completed with the purpose of understanding the unique characteristics of missionary life and developing relevant interventions for this population (Navara \& James 2002; 2005). Research has shown that missionaries in new cultural environments are not always in situations that are similar or equal to other expatriates. Because of this, missionaries may not adjust to or cope with the stressors of life in a new culture in the same way. For example, Navara and James (2002) distributed questionnaires to 167 expatriates (100 missionaries, 67 other expatriates) living in Nepal in order to compare the levels of coping and cultural adjustment of missionaries to those of other expatriates. Along with coping and cultural adjustment measures, questionnaires included measures of stress, satisfaction with life, and social support.

Navara and James (2002) discovered that in general, missionaries reported less satisfaction in their foreign posting than other expatriates. They discussed reasons for this difference, including the idea that various groups of expatriates perceive their host culture differently due to distinctive lifestyle situations. Navara and James (2002) pointed out that expatriates working as embassy staff might be more insulated from the host culture than those working as Red Cross staff, or business executives might have more financial resources than missionaries, which could impact their perception of the host 
culture. Navara and James (2002) also stated that missionaries often have more direct contact with host nationals, sometimes living in small villages as the only person of their own nationality while other expatriates might be more socially buffered from direct contact with host nationals, with a stronger network of expatriate support. Additionally, missionaries may have a lower average income, standard of living and status than some other expatriates (such as embassy staff or business managers) which would presumably affect their satisfaction with their general living conditions and possibly their perception of the host culture. Therefore, differences in the work and lifestyle of missionaries, including increased direct contact with host nationals, along with lower social status and feelings of not being 'connected' to other, culturally similar, expatriate support, may impact host country satisfaction and overall cultural adjustment to a new environment.

Navara and James (2002) also showed that missionaries living in Nepal utilized different paths of coping when compared with non-missionary, humanitarian aid workers. They argued that the use of different coping skills could imply that missionaries adjust to new cultures in a completely different manner than other expatriates, especially if religious belief is taken into account. When missionaries perceive higher levels of stress, they are more inclined to engage in activities such as praying, seeking pastoral support, or trusting God to relieve that stress (Andrews, 1999; Kimber, 2012; Navara \& James, 2005).

Lewis Hall et al. (2006) distributed a questionnaire to 181 missionaries living in 46 countries examining the relationship between spiritual development and both psychological development and cultural adjustment. It was hypothesized that spiritual development would be positively related to psychological development as viewed from a 
relational psychodynamic perspective. It was also hypothesized that spiritual development would be positively related to psychological and sociocultural cultural adjustment, and that it would contribute to the variance of cultural adjustment above and beyond the contributions made by psychological development. Results of Lewis Hall et al.'s study revealed a significant interaction between psychological development and spiritual development in predicting sociocultural adjustment. More specifically, participants who reported lower levels of psychological development and fewer psychological resources appeared to be affected more when their spiritual relationship with God suffered from ambivalence, resulting in a poorer level of sociocultural adjustment. Lewis Hall et al. suggested that special care should be taken in the assessment of missionaries with lower levels of psychological resources, because these individuals may be at significant risk for poorer adjustment "when their relationship to God suffers from ambivalence and a lack of acceptance of the difficult aspects of the relationship" (p. 207).

Kimber (2012) found similar results in his study examining the spiritual development and reentry adjustment of 102 missionaries, stating that missionaries with lower levels of psychological development may be more vulnerable to the effects of spiritual difficulties during cultural adjustment. These differences in coping strategies could impact a missionary's overall ability to handle the stress of adjusting to a new culture, making their process of cultural adjustment very different from other expatriates, especially those who are non-religious. 


\section{Relationship with God}

Significant amounts of research have demonstrated that spirituality and one's relationship with God can impact overall health and well-being (Baumsteiger \& Chenneville, 2015; Hall \& Edwards, 2002; Hill \& Pargament, 2008; Koenig, 2012; Paine \& Sandage, 2017). However, there is not a great deal of research that examines the link between relationship with God and cultural adjustment (Kimber, 2012). In spite of this, Lewis Hall et al. (2006) argue that it seems theoretically reasonable that spirituality would be related to cultural adjustment. Lewis Hall et al. state that the established link between support and cultural adjustment can be translated to the spiritual dimension, and that it seems likely that a good relationship with God would also contribute to good cultural adjustment, particularly in a population such as missionaries, whose motivation for being in a cross-cultural situation is directly related to their relationship with God.

Hill and Pargament (2008) argue that similarities can be made between God and other attachment figures, stating that in the same way children often look to their parents for protection, people may look to God as a safe haven who offers protection during times of stress. Additionally, this attachment would suggest that people who experience a secure relationship with God should also experience comfort and confidence in stressful situations. Lewis Hall et al. (2006) indicated that spiritual development, which they define as being “the degree to which a person's relationship with God reflects the ability to maintain a consistent sense of emotional connection with God in the midst of spiritual struggles, and the degree to which a person is aware of God's working in his or her life" (p. 195) is positively related to both the psychological and the sociocultural aspects of cultural adjustment. 
Andrews (1999) examined the interrelationships of a missionary's spiritual life satisfaction, family life satisfaction, and vocational ministry satisfaction in 245 adult missionaries, 127 missionary adolescents, and 140 missionary children. Andrews found that a vital spiritual life among missionaries was nurtured through the regular practice of spiritual disciplines and the awareness of their calling from God. Along similar lines, Kimber (2012) studied the relationship between spiritual development and cultural reentry adjustment in a group of 102 missionaries, exploring the relationship between reentry distress and calling, regularly practicing spiritual disciplines, and returning home to a supportive community. Kimber states that the consistent practice of spiritual disciplines, including prayer, Bible reading, fasting, worship, retreat, solitude, and silence, may enhance one's awareness of God's presence throughout the reentry transition, thereby providing much-needed stability during a potentially turbulent time. Kimber's study focused on the influence of relationship with God on missionary reentry to their home country after a time abroad, indicating that relationship with God is a significant factor in the reentry adjustment of missionaries. Additionally, these missionaries reported that they regularly practiced spiritual disciplines during their cross-cultural transition. While the influence of relationship with God on a missionary's cultural adjustment to a new country was not specifically explored in either the Kimber (2012) or Andrews (1999) study, these findings do lay the groundwork, and could help in understanding the role of relationship with God during cultural transitions.

\section{Relationships with Others}

The social support received from strong relationships with other individuals has long been recognized as a valuable asset for those dealing with stressful life or work 
situations. According to James et al. (2004), social support is defined as "perceived availability of potential social resources" and can include "appraisal support (advice and discussion), belonging support (identification with a social network), and tangible support (material aid)" (p. 11). The value of supportive relationships has been examined in various groups of people, including emergency response professionals (ShakespeareFinch et al., 2014), police officers (Stephens, Long, \& Miller, 1997), and military personnel (Israel-Cohen et al., 2016). Similarly, relationships have been examined as part of the cultural transition process. Social interaction and social support for missionaries and other expatriates has been found to be one of the biggest influences on cross-cultural adjustment (Black et al., 1991; Caligiuri \& Lazarova, 2002; Hendrickson, Rosen, \& Aune, 2010; Searle \& Ward, 1990; Ward \& Chang, 1997; Ward \& Kennedy, 1992; Yusoff, 2012). The initial stages of most foreign assignments are often associated with stress, disorientation and loneliness. Social interactions from all sources can provide the emotional support that helps with overcoming the negative feelings and experiences that are a natural part of the cross-cultural transition. Caligiuri and Lazarova (2002) argue that "social support (e.g. from family, host national colleagues, or expatriates from other countries) helps in mobilizing psychological resources and serves to provide feelings of reinforcement, recognition, and affirmation that can greatly enhance expatriates' crosscultural adjustment” (p. 762). Relationships fulfill the basic human need for contact, companionship and friendship. In the early stages of global assignments, these emotional connections can off-set the negative psychological effects of isolation and loneliness.

Expatriate (i.e., missionary) relationships are often divided into two separate categories - relationships with host nationals and relationships with other expatriates. 
Both categories have been found to impact acculturation to a new environment (Ward \& Rana-Deuba, 2000). However, the most effective source of relational support remains a controversial issue (Cemalcilar, Falbo, \& Stapleton, 2005; Ward \& Kennedy, 1993; Ward \& Rana-Deuba, 2000). Ward and Kennedy (1993), for example, found that relationships with other expatriates were a strong predictor of psychological adjustment of Malaysian and Singaporean students in New Zealand, but that relationships with host nationals were unrelated to decreases in depression. However, Ward and Rana-Deuba (2000) state it is likely that both home and host national relationships affect the psychological adjustment of expatriates, since social support from either group can diminish feelings of loneliness and isolation. Loneliness has been commonly mentioned as a negative consequence of cross-cultural transition. Ward and Searle (1991), for example, reported that loneliness was a powerful predictor of mood disturbance in a multi-national sample of foreign students in New Zealand.

Research has also emphasized that the quality, rather than the quantity, of social interactions is crucial for expatriate cultural adjustment. This may be because the quality of social relations is often what addresses the issue of loneliness. Ward and Rana-Deuba (2000) studied a multi-national sample of 104 expatriates residing in Nepal by asking participants to complete questionnaires examining locus of control, loneliness, host and co-national identification, frequency of contact with host and co-nationals, discrepancy between actual and desired contact with host and co-nationals, and satisfaction with host and co-national relations as predictors of psychological adjustment. The authors found that the quality of both host and co-national's interactions was associated with decreased feelings of loneliness while actual frequency of social interaction bore no relationship to 
the loneliness measure. Additionally, perceived loneliness was a significant predictor of psychological distress for expatriates.

\section{Relationships from Home Culture}

One aspect of relationships that has not been researched extensively in connection to cultural adjustment is the idea of relationships with individuals from an expatriate's home culture. Caligiuri et al. (1998) did find that family characteristics (family support, family communication, and family adaptability) were related to expatriates' cultural adjustment to working in the host country. However, this study (along with other research) focused mainly on family members who accompanied the expatriate to the host country. Little research has been done examining the impact that family and friends in the home country can have on the cultural adjustment of an expatriate. Ward and RanaDeuba (2000) did suggest that both home and host culture influences differentially affect the psychological adjustment of expatriates during cross-cultural transitions, and strong identification with culture of origin was associated with greater psychological well-being, but differences between fellow expatriates and influence from family or friends in one's home country were not discussed.

While there is not a significant amount of additional research examining the support from family or friends in the home culture, technology has been shown to have some influence on the cultural adjustment process. Cemalcilar et al. (2005) examined the influence of technology on expatriates in their study of 280 international students at the University of Texas, stating that internet-related technologies are used frequently by expatriates as communication tools to correspond with people and keep up with the daily life at home. Their results showed that technological communication results in the 
maintenance of home cultural values and preservation of national identity as well as the continuation of existing social networks as support mechanisms even when these support sources are not present face-to-face. Their results further suggested that this perceived social support influences expatriates' psychological adjustment.

Cemalcilar et al. (2005) argued that technological communication provides a special opportunity for missionaries and other expatriates to be in continuous contact with family and friends from their home culture, which can contribute to the maintenance of relationships. Their study suggests that this continuous contact has a positive effect on the expatriate's maintenance of home identity and perceptions of available social support, which combine to affect adaptation to the new culture. As the use of technology continues to grow and missionaries and other expatriates are able to communicate with people from home on a more frequent basis, it is possible that these influences will have a growing impact an expatriate's cultural adjustment.

\section{Relationships with Expatriates}

While studies focusing on relationships between expatriates are also lacking in the research literature, there is some research that shows these relationships can assist with the cross-cultural adjustment process as well (Ward \& Kennedy, 1993; Ward \& RanaDeuba, 2000). For example, Ward and Kennedy (1993) examined psychological and sociocultural adjustment during cross-cultural transitions of 145 Malaysian and Singaporean students in New Zealand and 156 Malaysian students in Singapore. Their results found that interaction with both host nationals and co-nationals predicted sociocultural adaptation, showing that each type of relationship (those with host nationals and those with other expatriates) can be beneficial in the cultural adjustment process. 
In their paper presenting a model to describe how female expatriates develop and utilize relationships to become cross-culturally adjusted, Caligiuri and Lazarova (2002) claim that other expatriates can be a useful resource for learning about the culture, norms and behavior of the host country. These expatriates are in a unique position to help with the cultural adaptation of newcomers, especially if they have already established relationships with host nationals. They can also provide information about the local community regarding schools, shopping, or leisure activities, reducing many of the hassles associated with adapting in a new environment (Caligiuri \& Lazarova, 2002). Hendrickson et al. (2010), in their study of 84 international students at a university in Hawaii, argue that co-national friendships can give expatriates an opportunity to enhance their understanding of the new culture through discussions, social interaction, and intellectual exchange with other expatriates who are experiencing the same emotions. Additionally, Caligiuri and Lazarova (2002) argue that social interaction with co-workers makes expatriates feel that they are valued, resulting in acceptance, belonging, and satisfaction which can help to facilitate cultural adjustment.

\section{Relationships with Host Nationals}

Some researchers have argued that it is interaction with host nationals that has the greatest impact on cultural adjustment. Caligiuri et al. (1998) claim that from a social learning perspective, the more contact missionaries and other expatriates have with host nationals and the host culture, the greater the cultural adjustment and the more successful the assignment will likely become. Ward and Rana-Deuba (2000) agree that relationships with host nationals can be beneficial, stating that while friendships with members of the host culture may be more difficult to develop, they also can potentially be more 
rewarding, and have additional advantages in terms of facilitating long term adaptation in the new culture.

Hechanova-Alampay, Beehr, Christiansen, and van Horn (2002) completed a longitudinal study surveying 294 student expatriates to examine their cultural adjustment process during the first six months of entry into a medium-sized university in the Midwestern United States. Their results showed that international students who interacted more with individuals from the host culture experienced greater cultural adjustment and less strains during the cultural adjustment process. Similarly, in their study of 84 international students studying in Hawaii, Hendrickson et al. (2010) found a relationship between having more host country friends and satisfaction, contentment, decreased homesickness, and social connectedness.

Additionally, Li and Gasser (2005), examined predictors of Asian international students' sociocultural adjustment by questioning 117 students from 17 Asian countries about their sociocultural adjustment, contact with hosts nationals, ethnic identity, and cross-cultural self-efficacy. The authors found that increased contact with the hosts had positive effects on international students' cultural adjustment because "the increased amount of contact with the hosts may have enabled them to develop local networks, understand the local culture, and acquire social skills necessary for the effective adjustment to the new culture" (p. 571).

\section{Attachment Theory}

Bowlby's (1988) theory of attachment stated that people come into the world determined to form attachments with others because these attachments will help them to survive. Bowlby discussed the concept of a "secure base" in attachment theory, claiming 
that a secure relationship attachment promotes a greater capacity for exploring one's environment. In children, research found that those with a secure attachment to their caregivers explored a new environment (or "strange situation") more extensively than those with insecure attachments (Ainsworth et al., 1978). This concept of a secure base for exploration has been extended to adult attachment theory and research, and to the concept of cultural adjustment (Polek et al., 2010; Sochos \& Diniz, 2012; Wang \& Mallinckrodt, 2006).

Bowlby (1988) believed that individuals who experience consistent responsiveness and care within their relationships with attachment figures develop an internalized sense of security that enhances their ability to explore new environments. As a result, Wang and Mallinckrodt (2006) argue that securely attached adults are able to access comforting mental representations of attachment figures and the concept of "home," even when they are in unfamiliar surroundings and away from their attachment relationships. In contrast, individuals who lack a sense of secure attachment tend to remain limited in their ability to regulate affect and explore unfamiliar social surroundings. Along with the secure attachment style, Sochos and Diniz (2012) identified three insecure attachment styles in adults: the dismissive style, characterized by the avoidance of emotional intimacy and a focus on solitary; the preoccupied or anxious style characterized by over-dependency, demandingness, aggressiveness, and restricted capacity for mastery and coping; and the fearful style, characterized by intense conflict between approaching and distancing, high interpersonal aggression, and chaotic engagement with the environment. 
Wang and Mallinckrodt (2006) claim that cultural adjustment and the idea of being placed in a new and unfamiliar cultural environment has some similarity with the young children learning to explore new physical surroundings in Ainsworth et al.'s (1978) Strange Situation protocol, making it likely that the new cultural environment will activate adult attachment systems. Polek et al. (2010) agreed, and found that attachment styles play an important role in the process of adjusting to a new social surrounding and culture. In their study of 792 expatriates in the Netherlands, Poland, Germany, Hungary, and Russia, Polek et al. found that secure attachment is positively related to psychological and sociocultural adjustment.

Sochos and Diniz (2012) also linked attachment to cultural adjustment, stating that concepts such as the disruption of interpersonal bonds and the increase of environmental stress are part of both the attachment and cultural adjustment process. Sochos and Diniz conducted a research study involving 172 Brazilian nationals living in the United Kingdom, in which they found that both secure and dismissive attachment styles are linked to higher levels of sociocultural adjustment. Sochos and Diniz found that attachment style moderates the effect of acculturation variables on psychological distress, so that a secure or a dismissing attachment style would protect immigrants from psychological distress, whereas a preoccupied or a fearful style would not. Sochos and Diniz argued that moving to a new cultural environment usually involves the disruption of important interpersonal relationships in the country of origin. Although such relationships may not necessarily be dissolved, moving to another country implies that supportive and familiar people are no longer directly accessible in times of need. It also 
implies that the individual would need to substitute, at least partly, those relationships with new ones.

From an adult attachment perspective, missionaries and other expatriates with healthy relationships (both with God and with other people) are more likely to have developed an internalized secure base that may equip them to better cope with encountered stress and difficulties, explore their new cultural environment more extensively, and develop additional relationships in their host culture, therefore increasing the likelihood of cultural adjustment (Wang \& Mallinckrodt, 2006). For missionaries with high attachment anxiety, however, the lack of a strong attachment to God, physical separation from significant others in the home culture, and elevated feelings of loneliness and distress are likely to prevent them from engaging in a full range of exploration in the new cultural environment, just as the anxiously attached infants discussed in Ainsworth et al. (1978) did not fully explore their new environment.

\section{Summary}

In summary, while there has been much research completed that examines the cultural adjustment of expatriates as a whole, there are still many questions left unanswered regarding how that information relates to the specific cultural adjustment of missionaries. Missionaries have been shown to differ from other expatriate groups, yet their process of cultural adjustment has been left mostly unexamined in research literature up to this point. Moreover, while past research has focused on both home and host culture influences (Caligiuri et al., 1998; Ward \& Rana-Deuba, 2000) it is unclear which support group has the greatest impact on cultural adjustment. The results of this study shine some additional light on the cultural adjustment process of missionaries and how 
relationships with individuals from the home-culture, fellow missionaries, host-nationals, and God correlate with and predict the missionary's ability to adjust to a new cultural environment. 


\section{CHAPTER III METHODOLOGY}

The purpose of this study was to examine the extent to which specific relationships (relationship with God, relationships with individuals from one's home culture, relationships with other missionaries, and relationships with individuals from one's host culture) correlate with and predict cultural adjustment among missionaries. This chapter describes the research design, participants, measures that were used, data collection procedures, and analysis procedure for examining missionary cultural adjustment experiences. The type of study, research questions, and methodology that were used will also be explained.

As described later in this chapter, all participants in this study were missionaries serving with the Global Mission Department of the Church of the Nazarene. The data source for this dissertation study consisted of completed online surveys (see appendices) consisting of demographic questions, the SCAS (Ward \& Kennedy, 1999), the SAI (Hall \& Edwards, 1996; 2002), and the SSS (Shakespeare-Finch \& Obst, 2011). Data derived from these measures was used in the dissertation study to explore the research questions.

\section{Research Design}

The current study utilized a quantitative, correlational research design. A crosssectional convenience sample of missionaries serving with the Church of the Nazarene's 
Global Mission Department were examined. Missionaries meeting the inclusion criteria were invited to participate in the study by completing an online survey.

\section{Research Questions and Hypotheses}

This study examined five research questions to determine the extent to which select factors correlate with and predict cultural adjustment in a sample of missionaries. The specific research questions that were addressed and the hypotheses that were tested in this study are as follows.

\section{Research Question 1}

To what extent is there an association between a missionary's relationship with God (as measured by the SAI; Hall \& Edwards, 1996; 2002) and their adjustment to a new host culture (as measured by the SCAS; Ward \& Kennedy, 1999)?

\section{Hypothesis 1}

There will be a significant positive association between a missionary's relationship with God, as measured by the SAI (Hall \& Edwards, 1996; 2002), and a missionary's adjustment to a new culture, as measured by the SCAS (Ward \& Kennedy, 1999).

\section{Research Question 2}

To what extent is there an association between a missionary's relationships with family and/or friends from their home country (as measured by the SSS; ShakespeareFinch \& Obst, 2011) and their adjustment to a new host culture (as measured by the SCAS; Ward \& Kennedy, 1999)? 


\section{Hypothesis 2}

There will be a significant positive association between a missionary's relationships with family and/or friends from their home country, as measured by the SSS (Shakespeare-Finch \& Obst, 2011), and a missionary's adjustment to a new culture, as measured by the SCAS (Ward \& Kennedy, 1999).

\section{Research Question 3}

To what extent is there an association between a missionary's relationships with other missionaries on the mission field (as measured by the SSS; Shakespeare-Finch \& Obst, 2011) and their adjustment to a new host culture (as measured by the SCAS; Ward \& Kennedy, 1999)?

\section{Hypothesis 3}

There will be a significant positive association between a missionary's relationships with other missionaries on the mission field, as measured by the SSS (Shakespeare-Finch \& Obst, 2011), and a missionary's adjustment to a new culture, as measured by the SCAS (Ward \& Kennedy, 1999).

\section{Research Question 4}

To what extent is there an association between a missionary's relationships with host nationals (residents or citizens of the host country) on the mission field (as measured by the SSS; Shakespeare-Finch \& Obst, 2011) and their adjustment to a new host culture (as measured by the SCAS; Ward \& Kennedy, 1999)?

\section{Hypothesis 4}

There will be a significant positive association between a missionary's relationships with host nationals (residents or citizens of the host country) on the mission 
field, as measured by the SSS (Shakespeare-Finch \& Obst, 2011), and a missionary’s adjustment to a new culture, as measured by the SCAS (Ward \& Kennedy, 1999).

\section{Research Question 5}

How do a missionary's relationship with God, relationships with family and/or friends from their home country, relationships with other missionaries on the mission field, and relationships with host nationals, separately and taken together, predict a missionary's ability to adjust to a new culture?

\section{Hypothesis 5}

A missionary's relationship with God, relationships with family and/or friends from their home country, relationships with other missionaries on the mission field, and relationships with host nationals, separately and taken together, will predict a missionary's adjustment to a new culture, as measured by the SCAS (Ward \& Kennedy, 1999).

\section{Participants}

Participants in this study were missionaries serving with the Global Mission Department of the Church of the Nazarene. The Church of the Nazarene currently has approximately 700 missionaries serving in 162 areas around the world. Missionaries within the Church of the Nazarene may serve on short-term mission trips for as little as 10 days, or as full-time career missionaries for many years. Additionally, while the majority of missionaries within the Church of the Nazarene originate from the United States, some missionaries originate from other countries and speak a variety of languages. The participants in this study were delimited from the general population of missionaries within the Church of the Nazarene to only include those who are age 18 or older, 
English-speaking, and have served with the Global Mission Department for at least three months. These inclusion criteria limited the number of individuals receiving an invitation e-mail to participate in the study to 314 missionaries.

According to Cohen (1992), a bivariate analysis examining the individual correlations between missionary cultural adjustment and each of the independent variables (relationship with God, relationships with family and/or friends from the missionary's home culture, relationships with other missionaries, and relationships with host nationals) would ideally have a significance criterion $(\alpha)$ of .05 , a power of .80 ( $(\beta=$ $.20)$, and a medium effect size $(r)$ of .30 . This would result in a target sample size of 85 participants. A multiple regression analysis examining how the four independent variables, separately and taken together, predict missionary cultural adjustment would have values of $\alpha=.05, \beta=.20$, and $r=.15$, resulting in a target sample size of 84 . Therefore, the overall target sample size of this study was the higher of these two numbers, or 85 participants.

\section{Procedures}

Permission was secured from the Church of the Nazarene's Global Mission Department to distribute an online survey to all missionaries who have been serving with the Global Mission Department for at least three months, are English-speaking, and are age 18 or older (see Appendix A for permission letter). Once approval for the study was granted by the university institutional review board (IRB), data collection began.

Missionaries' information was derived from a pre-existing database by an assistant in the Global Mission Department office, and those who met the inclusion criteria were sent an e-mail (see Appendix C) from the Global Mission Department. This e-mail explained the 
study, requested the individual's participation in an online survey, and provided a link to the online informed consent form (see Appendix B) and survey document. Participation in the survey was voluntary and anonymous. Missionaries were informed in the initial email that they had three weeks to complete the survey. A reminder e-mail (see Appendix D) was sent every seven days until the survey was closed.

\section{Measures}

The measures for this study consisted of a series of non-identifying demographic questions (see Appendix E) along with the SCAS (Ward \& Kennedy, 1999; see Appendix F), the SAI (Hall \& Edwards, 1996; 2002; see Appendix G), and the SSS (ShakespeareFinch \& Obst, 2011; see Appendix H). The SSS was completed three separate times with participants first focusing on relationships with family and friends in their home country, then other missionaries on the field, and finally citizens or residents of their country of service.

\section{Variables}

Dependent variable. Missionary cultural adjustment was measured by the individual's scores on the SCAS (Ward \& Kennedy, 1999). The SCAS is a self-report measurement used to assess a person's level of adjustment to a different culture.

Independent variables. Relationship with God was measured using the SAI (Hall \& Edwards, 1996; 2002). Relationships with family and friends in the missionaries' home country were measured using the SSS (Shakespeare-Finch \& Obst, 2011), relationships with other missionaries on the field were measured using the SSS, and relationships with citizens or residents of the missionaries' country of service were 
measured using the SSS. Therefore, participants were asked to complete the SSS three separate times to examine each of the independent variables.

\section{Instruments}

Demographic questions. Participants were asked to respond to nine basic demographic questions (see Appendix E). The information received from these questions assisted in understanding and describing the sample population. These questions included: gender (male; female), age (18-24; 25-44; 45-64; 65 years or older), race/ethnicity (American Indian/Alaska Native; Asian; Black/African; Hispanic/Latino; Pacific Islander; White; Other), marital status (divorced; married; never married; separated widowed), country of origin, current country of service, length of time in missionary service (years: $0-2 ; 3-5 ; 6-10 ; 11-15 ; 16-20 ; 21$ years or more), and length of time in their current country of service (years: $0-2 ; 3-5 ; 6-10 ; 11-15 ; 16-20 ; 21$ years or more). Participants were also asked to rate their socioeconomic status compared with others in their country of service on a 5-point Likert scale ranging from 1 (very below average) to 5 (very above average).

Sociocultural Adaptation Scale. The SCAS (Ward \& Kennedy, 1999) is designed to assess the psychological and sociocultural skills needed to manage the everyday aspects of living in a new culture (see Appendix F). The SCAS is a self-report inventory consisting of 29 items. Each item is rated on a 5-point Likert scale ranging from 1 (no difficulty) to 5 (extreme difficulty). Items require respondents to indicate the amount of sociocultural difficulty experienced in a number of areas, such as "Making friends," and "Making yourself understood." Scores range from 29 to 145, with lower 
scores indicating a lower level of sociocultural difficulty in social activities and therefore a higher level of overall cultural adjustment.

Reliability. The SCAS (Ward \& Kennedy, 1999) is a "reliable and valid measurement of cultural competence or behavioral adaptability in cross-cultural sojourners" (p. 659). The assessment has been used with samples from North America, China, Japan, Great Britain, New Zealand, Singapore, Hong Kong, Nepal, and Pakistan (Ward \& Kennedy, 1999; Tonsing, 2014). White et al. (2011) reported internal reliability scores of 0.94 in their study of expatriate sales managers serving in 77 different countries. Wu and Mak (2011) reported a similar Cronbach's alpha score of 0.91 when using the SCAS with Chinese university students studying abroad. Additionally, Kimber (2012) reported an alpha score of 0.91 in a study of the cross-cultural reentry process for missionaries. Tonsing (2014) examined the experiences of psychological and sociocultural adaptation among immigrants and reported Cronbach's alphas of 0.90 and 0.89 when the SCAS was used with Pakistani and Nepalese samples, respectively. Ward and Kennedy (1999) report evidence of reliability in 16 cross-sectional sample populations, with the alpha scores ranging from 0.75 to $0.91(M=0.85)$.

Validity. Ward and Kennedy (1999) evaluated the validity of the SCAS using the Zung Self-Rating Depression Scale (ZSDS; Zung, 1965). The ZSDS was used because of it's well-documented cross-cultural reliability and validity, and its ability to examine the construct validity between sociocultural and psychological adjustment. Ward and Kennedy found significant correlations between the scores derived from the SCAS and the scores derived from the ZSDS in their examination of 16 cross-sectional sample populations, with scores ranging from 0.20 to $0.62(M=0.38)$. 
Spiritual Assessment Inventory. The SAI (Hall \& Edwards, 1996; 2002) is designed to assess spiritual maturity from a Judeo-Christian perspective that integrates object relations theory, and awareness of and communication with God. The SAI is a self-report inventory consisting of 54 items (see Appendix G). Items are divided to examine two dimensions of one's relationship with God. The first dimension, awareness of God, includes 19 items and specifically relates to a person's ability to be aware of God's presence in his or her life. The second dimension, quality of relationship, includes 35 items divided into five subscales: Disappointment with God (7 items), Grandiosity (7 items), Impression Management (5 items), Instability (9 items), and Realistic Acceptance (7 items). These subscales assess the developmental maturity of one's patterns of relationship with respect to God (Hall \& Edwards, 1996; 2002; Kimber, 2012; Lewis Hall et al., 2006). Each item is rated on a 5-point Likert scale ranging from 1 (not at all true) to 5 (very true). Items require respondents to describe relational patterns with and spiritual awareness of God in specific areas by responding to statements such as: "My experiences of God's presence impact me greatly" and "When I sin, I still have a sense that God cares about what happens to me." The score for each scale is the average of answered items, with higher scores indicating a higher level of awareness and communication with God.

Reliability. The SAI has been found to be a reliable measure of spiritual maturity and relationship with God (Hall \& Edwards, 1996; 2002). Hall and Edwards examined the reliability of each of the six subscales using Cronbach's coefficient alpha measure of internal consistency. The values for the scales were: Awareness, 0.95; Disappointment with God, 0.90; Grandiosity, 0.73; Impression Management, 0.77; Instability, 0.84; and 
Realistic Acceptance, 0.83. All values indicate good lower-bound estimates of scale reliability.

Validity. To evaluate construct and convergent validity of the SAI, each of the subscales were correlated with several other measures in a study by Hall and Edwards (2002). These scales include the Bell Object Relations Inventory (BORI; Bell, Billington, \& Becker, 1986), used because of its conceptual convergence with the SAI. Additionally, the SAI subscales were correlated with the Spiritual Well-Being Scale (SWBS; Ellison, 1983), the Intrinsic/Extrinsic-Revised (Gorsuch \& McPherson, 1989), the Defense Styles Questionnaire (Andrews, Singh, \& Bond, 1993), and the Narcissistic Personality Inventory (Raskin \& Terry, 1988). Correlations between the scores derived from the SAI and the scores derived from each of these scales supported the construct validity of the SAI. Some of the highest correlations found between the Grandiosity subscale of the SAI and the Egocentricity subscale BORI $(r=0.47)$, as well as between the Awareness subscale of the SAI and the Religious well-being subscale of the SWBS ( $r$ $=0.68$; Hall \& Edwards, 2002).

The 2-way Social Support Scale. The SSS (Shakespeare-Finch \& Obst, 2011) is designed to assess four factors of social support, including receiving emotional support, receiving instrumental support, giving emotional support, and giving instrumental support. The SSS is a self-report inventory consisting of 21 items (see Appendix H), divided into four subscales. The giving emotional support subscale includes 5 items while the receiving emotional support subscale includes 7 items. The giving instrumental support subscale includes another 5 items, while the receiving instrumental support subscale includes 4 items. Each item is rated on a 6-point Likert scale ranging from 0 
(not at all) to 5 (always). Items require respondents to indicate the extent to which they give and receive support in specific areas by responding to statements such as: "There is someone in my life that makes me feel worthwhile," and "People confide in me when they have problems." Overall scores range from 0 to 105 , with higher scores indicating a greater extent of giving or receiving emotional or instrumental support.

Reliability. The SSS has been found to be a reliable measure of social support, with scores remaining consistent across populations (Shakespeare-Finch et al., 2014). Scores from the four subscales have been found to have moderate to high internal reliability in a study by Shakespeare-Finch and Obst (2011), with Cronbach's alpha scores ranging from 0.81 to 0.92 . In a separate study by Hermanto and Zuroff (2016) examining the effects of care-seeking and caregiving, the Cronbach's alpha scores for the SSS were 0.91 for the subscale of receiving emotional support, 0.74 for receiving instrumental support, 0.86 for giving emotional support, and 0.78 for giving instrumental support.

Validity. Shakespeare-Finch and Obst (2011) examined the convergent validity of the four subscales of the SSS using the Sarason Social Support Scale (SSQ; Sarason, Levine, Basham, \& Sarason, 1983) and the Berlin Social Support Scale (BSSS; Schulz \& Schwarzer, 2003). The scores derived from the SSQ were correlated with the scores from the receiving emotional support subscale at $r=0.55$, the receiving instrumental support subscale at $r=0.42$, the giving emotional support subscale at $r=0.32$, and the giving instrumental support subscale at $r=0.28$. The BSSS was correlated with the receiving emotional support subscale at $r=0.66$, receiving instrumental support at $r=0.62$, giving emotional support at $r=0.43$, and giving instrumental support at $r=0.46$. 
Shakespeare-Finch and Obst (2011) also examined the predictive validity of the 2-Way SSS using four separate scales: the Perceived Stress Scale (PSS; Cohen, Kamarck, \& Mermelstein, 1983), an indicator of stress; the K10 (Kessler \& Mroczek, 1992), an indicator of depression; the Satisfaction With Life Scale (SWLS; Diener, Emmons, Larsen, \& Griffin, 1985), an indicator of life satisfaction; and the General Health Questionnaire 12 (GHQ-12; Goldberg et al., 1997), an indicator of general health. The models of prediction for the outcome variables measured were all significant: the PSS, $r$ $=.23$, the K10, $r=.31$, the SWLS, $r=.50$, and the GHQ-12, $r=.22$ (Shakespeare-Finch \& Obst, 2011).

\section{Data Analysis}

Data analyses were performed using the IBM program SPSS (version 24). Appropriate tests were used to obtain descriptive statistics on demographic information and each of the research variables. Prior to conducting the main data analyses, preliminary tests were completed to examine the assumptions of normality, linearity, homoscedasticity and outliers (Stevens, 2009). In order to test normality of all variables, skewness and kurtosis of the variables were examined, and linearity was assessed using scatterplots. Residuals were examined to check the assumption of homoscedasticity and look for outliers that may have influenced the data.

\section{Research Question 1}

Correlation analysis were used to determine if there was a statistically significant correlation between the dependent variable of missionary cultural adjustment to a new host culture (as measured by the SCAS; Ward \& Kennedy, 1999) and the independent 
variable of a missionary's relationship with God (as measured by the SAI; Hall \& Edwards, 1996; 2002).

\section{Research Question 2}

Correlation analysis were used to determine if there was a statistically significant correlation between the dependent variable of missionary cultural adjustment to a new host culture (as measured by the SCAS; Ward \& Kennedy, 1999) and the independent variable of a missionary's relationships with family and/or friends from their home country (as measured by the SSS; Shakespeare-Finch \& Obst, 2011).

\section{Research Question 3}

Correlation analysis were used to determine if there was a statistically significant correlation between the dependent variable of missionary cultural adjustment to a new host culture (as measured by the SCAS; Ward \& Kennedy, 1999) and the independent variable of a missionary's relationships with other missionaries on the mission field (as measured by the SSS; Shakespeare-Finch \& Obst, 2011).

\section{Research Question 4}

Correlation analysis were used to determine if there was a statistically significant correlation between the dependent variable of missionary's relationships with host nationals (residents or citizens of the host country) on the mission field (as measured by the SSS; Shakespeare-Finch \& Obst, 2011) and the independent variable of a missionary's relationships with other missionaries on the mission field (as measured by the SSS; Shakespeare-Finch \& Obst, 2011). 


\section{Research Question 5}

A multiple regression analysis was conducted to examine how missionary's relationship with God (as measured by the SAI; Hall \& Edwards, 1996; 2002), relationships with family and/or friends from their home country, relationships with other missionaries on the mission field, and relationships with host nationals (each measured by the SSS; Shakespeare-Finch \& Obst, 2011), separately and taken together, predict missionary cultural adjustment to a new host culture (as measured by the SCAS; Ward \& Kennedy, 1999). Due to the exploratory nature of the study, each of these variables was entered in to the multiple regression analysis simultaneously.

\section{Why Study the Questions?}

Missionaries often leave their homes, family, and friends to travel to other parts of the world and serve people in a different cultural environment. However, for many of these missionaries, problems with adjusting to this new culture can cause problems in job performance or result in the missionary returning home earlier than planned (Caligiuri et al., 1998).

Supportive relationships have been shown to help individuals dealing with stressful or difficult situations (Caligiuri \& Lazarova, 2002; Israel-Cohen et al., 2016; Shakespeare-Finch et al., 2014). Understanding more about how a missionary's supportive relationships with God and other people can impact missionary adjustment to a new culture may help with the often-stressful adjustment process. Learning which specific relationships may make a missionary's cultural adjustment easier can help missionaries and sending organizations by encouraging the development of appropriate relationships and support systems. 
To care for missionaries serving on the mission field, sending organizations need a greater understanding of issues related to a missionary's cultural adjustment in a new environment. Gaining additional knowledge about how relationships influence this process can help with the screening process of missionaries, as well as assist in providing training for missionaries on developing and maintaining beneficial relationships prior to their arrival in a new country. This information can help with making the transition and cultural adjustment process as easy as possible for missionaries in order to relieve stress and reduce obstacles so that they are able to be the most effective in their ministry.

\section{Confidentiality}

Confidentiality and anonymity were maintained throughout the study. The researcher did not have access to the names or any identifiers of the individual missionaries who received the e-mail and access to the online survey. The demographic questions included in the survey did not request any identifying information, and no individual data were communicated to the Church of the Nazarene's Global Mission office at any time.

\section{How I Gained Entry}

I currently serve as the Well-Being Manager with Extreme Nazarene Missions, a mission organization that is associated with the Church of the Nazarene. This is a fulltime, volunteer missionary position in Quito, Ecuador where I work to provide help and support to missionaries throughout South America. Through Extreme Nazarene Missions, I was put in contact with Marty Hoskins, the Global Mission Personnel Director for the Church of the Nazarene. I requested permission to complete the study from Mr. Hoskins, as well as from Vern Ward, the Global Mission Director. I received 
permission from the Global Mission Office to complete my research through their organization (see Appendix A) by submitting an online survey that was distributed by the Global Mission Office to all missionaries within the Church of the Nazarene who met the inclusion criteria of the study.

\section{Ethical Considerations of Human Subjects}

Research using data from missionaries who completed an online survey was approved by the University of Louisville's Human Subject Protection Program (HSPP) and Institutional Review Board (IRB). Each participant was asked to read and agree to an Informed Consent form (see Appendix B) which explained the purpose, procedures, potential risks, and benefits of participation in the research study. The consent form stated that confidentiality or total privacy cannot be guaranteed; however, the missionaries' privacy was protected to the extent permitted by law and published results will not use any missionary names or personal identifiers.

\section{Summary}

In conclusion, this study utilized an online survey consisting of demographic questions, the SCAS (Ward \& Kennedy, 1999), SAI (Hall \& Edwards, 1996; 2002), and SSS (Shakespeare-Finch \& Obst, 2011) to examine how relationship with God, home culture relationships, relationships with other missionaries, and host culture relationships correlate with and predict the cultural adjustment of missionaries. The online survey was distributed to 314 missionaries within the Global Mission Department of the Church of the Nazarene who were given approximately three weeks to participate in the study. Once responses were gathered, bivariate and multiple regression analyses were used to 
determine the extent to which select study factors correlate with and predict missionary cultural adjustment. 


\section{CHAPTER IV}

\section{RESULTS}

The purpose of this study was to examine the extent to which specific relationships (relationship with God, relationships with individuals from one's home culture, relationships with other missionaries, and relationships with individuals from one's host culture) correlate with and predict cultural adjustment among missionaries. This chapter will present descriptive statistics, organized in terms of demographic data and the study's variables of interest. This information will be followed by the results of the study organized by the five research questions presented in Chapters I and III.

\section{Participants}

A total of 314 individuals from the Global Mission Department of the Church of the Nazarene were invited to participate in this study. Of those 314 individuals, 129 chose to participate in the study, resulting in an $41 \%$ response rate. Of the 129 participants, 28 responses were excluded from the study due to missing information. Thus, the final sample size was $N=101$.

The demographic data show that $66.3 \%(n=67)$ of participants identified as female, while $33.7 \%(n=34)$ of the sample identified as male. With respect to age, the majority of participants identified as being within the two middle age brackets, with 43.6\% $(n=44)$ of participants listing their age as between 25 and 44, and $46.5 \%(n=47)$ between 45 and 64 . The majority of participants identified their country of origin as the 
United States $(n=92,91.1 \%)$, and the racial makeup of the sample indicated that $91.1 \%$ $(n=92)$ identified as White. A small percentage $(2.0 \%, n=2)$ reported their race/ethnicity as "other," with one participant identifying as "coloured" and another listing their race/ethnicity as "European descent." A total of 4 participants (3.9\%) indicated identification with multiple groups by marking more than one race/ethnicity option.

Participants listed a wide range of current countries of service. The largest number of missionaries $(n=16,15.8 \%)$ listed Ecuador as their place of service. The next largest was the Philippines $(n=7,6.9 \%)$, followed by Argentina and Kenya, each with $5.0 \%(n=5)$. In response to the item regarding length of time in missionary service, $27.7 \%(n=28)$ of participants reported that they have been in missionary service for $0-2$ years, with an additional $20.8 \%(n=21)$ stating they have been in missionary service for 3-5 years. Responses to missionary's length of time in the current country of service showed that $39.6 \%(n=40)$ of participants have been in their current country of service for $0-2$ years and an additional $28.7 \%(n=29)$ have been in their country of service for 35 years.

When participants were asked to rate their socioeconomic status compared with others in their country of service, the majority identified as average $(30.7 \%, n=31)$ or somewhat above average $(37.6 \%, n=38)$, with a mean score of 3.57 . The study's complete sample demographic data are presented in Table 1. 
Table 1

Study Sample Demographic Data

\begin{tabular}{|c|c|c|c|}
\hline Characteristic & $N$ & $n$ & $\%$ \\
\hline Gender & 101 & & \\
\hline Female & & 67 & 66.3 \\
\hline Male & & 34 & 33.7 \\
\hline Age & 101 & & \\
\hline $18-24$ & & 9 & 8.9 \\
\hline $25-44$ & & 44 & 43.6 \\
\hline $45-64$ & & 47 & 46.5 \\
\hline 65 years or more & & 1 & 1.0 \\
\hline Race/Ethnicity & 101 & & \\
\hline American Indiana/Alaska Native & & 2 & 2.0 \\
\hline Asian & & 2 & 2.0 \\
\hline Black/African & & 1 & 1.0 \\
\hline Hispanic/Latino & & 6 & 5.9 \\
\hline Pacific Islander & & 0 & 0 \\
\hline White & & 92 & 91.1 \\
\hline Other & & 2 & 2.0 \\
\hline
\end{tabular}

Marital Status

101

Divorced

$2 \quad 2.0$

Married

$75 \quad 74.3$

Never married

$24 \quad 23.8$

Country of Origin

101

Brazil

$1 \quad 1.0$

Canada

$2 \quad 2.0$

Mexico

$1 \quad 1.0$

South Africa

$1 \quad 1.0$

South Korea

$1 \quad 1.0$ 
Trinidad and Tobago

1

1.0

Table 1 Continued

\begin{tabular}{|c|c|c|c|}
\hline Characteristic & $N$ & $n$ & $\%$ \\
\hline United Kingdom & & 1 & 1.0 \\
\hline United States & & 92 & 91.1 \\
\hline United States and Guatemala & & 1 & 1 \\
\hline Country of Service & 101 & & \\
\hline Africa & & 1 & 1.0 \\
\hline Argentina & & 5 & 5.0 \\
\hline Asia Pacific & & 1 & 1.0 \\
\hline Bulgaria & & 2 & 2.0 \\
\hline Chile & & 3 & 3.0 \\
\hline Costa Rica & & 3 & 3.0 \\
\hline Croatia & & 1 & 1.0 \\
\hline Dominican Republic & & 3 & 3.0 \\
\hline Ecuador & & 16 & 15.8 \\
\hline Ethiopia & & 2 & 2.0 \\
\hline Germany & & 3 & 3.0 \\
\hline Grenada & & 1 & 1.0 \\
\hline Guam & & 1 & 1.0 \\
\hline Hungary & & 2 & 2.0 \\
\hline Indonesia & & 1 & 1.0 \\
\hline Japan & & 1 & 1.0 \\
\hline Kenya & & 5 & 5.0 \\
\hline Kosovo & & 1 & 1.0 \\
\hline Micronesia & & 1 & 1.0 \\
\hline New Zealand & & 2 & 2.0 \\
\hline Papua New Guinea & & 3 & 3.0 \\
\hline Peru, Ecuador, Paraguay, Argentina, Chile, USA & & 1 & 1.0 \\
\hline Philippines & & 7 & 6.9 \\
\hline
\end{tabular}


Table 1 Continued

\begin{tabular}{|c|c|c|c|}
\hline Characteristic & $N$ & $n$ & $\%$ \\
\hline Portugal & & 4 & 4.0 \\
\hline Republic of Ireland & & 1 & 1.0 \\
\hline Romania & & 2 & 2.0 \\
\hline Russia & & 1 & 1.0 \\
\hline Saipan & & 1 & 1.0 \\
\hline Senegal & & 1 & 1.0 \\
\hline Singapore & & 1 & 1.0 \\
\hline South Africa & & 4 & 4.0 \\
\hline South Africa, Madagascar, Kenya, USA & & 1 & 1.0 \\
\hline South Asia Field: Sri Lanka, Bangladesh, Nepal, Pakistan & & 1 & 1.0 \\
\hline Switzerland & & 1 & 1.0 \\
\hline Thailand & & 3 & 3.0 \\
\hline Trinidad & & 1 & 1.0 \\
\hline Uganda & & 1 & 1.0 \\
\hline United Kingdom & & 1 & 1.0 \\
\hline Ukraine & & 3 & 3.0 \\
\hline United States & & 4 & 4.0 \\
\hline Vanuatu & & 2 & 2.0 \\
\hline Time as Missionary & 101 & & \\
\hline $0-2$ & & 28 & 27.7 \\
\hline $3-5$ & & 21 & 20.8 \\
\hline $6-10$ & & 16 & 15.8 \\
\hline $11-15$ & & 11 & 10.9 \\
\hline $16-20$ & & 9 & 8.9 \\
\hline 21 years or more & & 16 & 15.8 \\
\hline
\end{tabular}


Table 1 Continued

\begin{tabular}{lccc}
\hline Characteristic & $N$ & $n$ & $\%$ \\
\hline Time in Current Country & 101 & & \\
$0-2$ & & 40 & 39.6 \\
$3-5$ & 29 & 28.7 \\
$6-10$ & 13 & 12.9 \\
$11-15$ & 4 & 4.0 \\
$16-20$ & 8 & 7.9 \\
21 years or more & 7 & 6.9 \\
Socioeconomic Status & & & \\
Very Below Average & 5 & 5.0 \\
Somewhat Below Average & 8 & 7.9 \\
Average & & 31 & 30.7 \\
Somewhat Above Average & & 38 & 37.6 \\
Very Above Average & & 19 & 18.8 \\
\hline
\end{tabular}

\section{Descriptive Statistics}

This section will describe the descriptive statistics for each of the current study's constructs of interest, a) missionary cultural adjustment as measured by the SCAS (Ward \& Kennedy, 1999); b) relationship with God as measured by the SAI (Hall \& Edwards, 1996; 2002); c) relationships with family and/or friends from one's home country as measured by the SSS (Shakespeare-Finch \& Obst, 2011); d) relationships with other missionaries on the mission field as measured by the SSS; and e) relationships with host nationals as measured by the SSS. This discussion will focus on the demographic data related to each construct. The descriptive statistics for each of the variables are presented in Table 2. 
Table 2

Descriptive Statistics by Variable

\begin{tabular}{lcccccccc}
\hline \multicolumn{1}{c}{ Study Variable } & $N$ & $M$ & $S D$ & $\alpha$ & Range & Median & Skewness & Kurtosis \\
\hline SCAS & 101 & 63.81 & 16.83 & .93 & $30-105$ & 64.00 & .090 & -.368 \\
SAI & 101 & 16.45 & 2.17 & .80 & $10.81-22.10$ & 16.42 & .169 & .522 \\
SSS Home & 101 & 83.53 & 15.95 & .93 & $7-105$ & 85.00 & -.624 & -.091 \\
SSS Missionary & 101 & 74.81 & 20.46 & .95 & $24-105$ & 78.00 & -.714 & -.206 \\
SSS Nationals & 101 & 71.93 & 19.68 & .94 & $21-105$ & 73.00 & -.381 & -.112 \\
\hline
\end{tabular}

Note. SCAS = Sociocultural Adaptation Scale; SAI = Spiritual Assessment Inventory; SSS Home = 2-Way Social Support Scale, related to relationships with family and/or friends from the home country; SSS Missionary $=2$-Way Social Support Scale, related to relationships with other missionaries on the mission field; SSS Nationals = 2-Way Social Support Scale, related to relationships with host nationals in the country of service.

\section{Missionary Cultural Adjustment}

Missionary cultural adjustment was assessed using the SCAS (Ward \& Kennedy, 1999). Scores on the SCAS range from 29 to 145, with lower scores indicating a lower level of sociocultural difficulty and therefore a higher level of overall cultural adjustment. The overall mean score for the SCAS in the current study was $M=63.81(S D=16.83)$, with scores ranging from 30 to 105 . The SCAS yielded a strong internal consistency value at $\alpha=.93$, which is consistent with the internal consistency values found in previous studies (Kimber, 2012; White et al., 2011; Wu \& Mak, 2011).

When examining age, the highest level of sociocultural difficulty was found among the one participant in the 65 years or more age bracket $(M=79)$, with participants in the 18-24 age bracket having the next highest levels of sociocultural difficulty $(M=$ 74.77, $S D=20.38$ ), indicating a lower level of overall cultural adjustment. Participants 
in the 45-64 age group had the lowest levels of sociocultural difficulty on the SCAS ( $M=$ $58.93, S D=15.78)$, indicating a higher level of cultural adjustment.

With regard to length of time in missionary service, scores of those serving $0-2$ years had the highest levels of sociocultural difficulty $(M=69.82, S D=13.77)$, indicating lower levels of cultural adjustment. Those serving 3-5 years were not far behind $(M=69.76, S D=19.82)$. Participants serving 21 years or more had the lowest levels of sociocultural difficulty among participants, indicating higher levels of cultural adjustment $(M=53.56, S D=14.22)$. Additionally, when examining length of time in current country of service, scores of those serving 0-2 years received the highest scores of sociocultural difficulty $(M=68.32, S D=15.07)$. The lowest levels of sociocultural difficulty related to current country of service, indicating the highest levels of cultural adjustment, were found among participants serving 21 years or more $(M=44.42, S D=$ 13.17).

Finally, when examining socioeconomic status, it was found that those rating their socioeconomic status as "Somewhat Below Average" had the highest levels of sociocultural difficulty $(M=68.75 ; S D=14.21)$, indicating lower levels of cultural adjustment. Those who rated themselves as being "Very Below Average" had the lowest levels of sociocultural difficulty $(M=51.00 ; S D=17.42)$, indicating a higher level of overall cultural adjustment.

\section{Relationship with God}

The SAI (Hall \& Edwards, 1996; 2002) was used to assess participants' relationship with God. The SAI is divided into six subscales: Awareness of God, Disappointment with God, Grandiosity, Impression Management, Instability, and 
Realistic Acceptance. Scores for each subscale are determined by finding the mean of the raw scores and can range from 1 to 5, with higher scores indicating a higher level of awareness and communication with God. The total score is found by adding the six subscale scores together, and can range from 6 to 30 .

The mean total score for the SAI in the current study was $M=18.90(S D=2.38)$, which is higher than the mean score found in Hall, Reise, and Haviland's (2007) analysis of the SAI $(M=15.17)$. Overall scores in the current study ranged from 12.24 to 25.85 . The SAI had an internal consistency value of $\alpha=.80$, which is consistent with internal consistency values in previous studies (Hall \& Edwards, 1996; 2002). Participants in the 18-24 age group had the lowest total mean scores on the SAI $(M=18.29, S D=3.50)$. The highest total score was attributed to the one individual in the 65 years or more age group $(M=20.89)$, with those aged 45-64 years having the second highest total scores ( $M$ $=19.49, S D=2.09$ ).

With regard to length of time in missionary service, scores of those serving 11-15 years indicated the lowest overall levels on the SAI $(M=18.58, S D=3.13)$, with the highest total scores among participants serving 21 years or more $(M=19.85, S D=1.48)$. When examining length of time in current country of service, scores of those serving 3-5 years had the lowest total scores $(M=18.58, S D=2.18)$, with the highest scores among participants serving $11-15$ years $(M=21.15, S D=1.70)$.

Finally, with regard to socioeconomic status, it was found that those rating their socioeconomic status as "Very Below Average" had the lowest total mean scores $(M=$ $18.11, S D=2.39$ ). Those who rated themselves as being "Somewhat Below Average" were found to have the highest mean scores $(M=19.42, S D=1.56)$. 


\section{Relationships from Home Culture}

The SSS (Shakespeare-Finch \& Obst, 2011) was used to assess participants' relationships with others, including relationships with individuals from the home culture, relationships with other missionaries, and relationships with host nationals. Overall scores on the SSS can range from 0 to 105 , with higher scores indicating a greater extent of giving or receiving emotional or instrumental support. The overall mean score for the SSS when examining social support with individuals from one's home culture was $M=$ $83.53(S D=15.95)$, which is similar to the mean score found in Shakespeare-Finch and Obst's original study $(M=83.34)$. Overall scores in the current study ranged from 7 to 105. When examining relationships with individuals in the missionary's home culture, the SSS had an internal consistency value of $\alpha=.93$, which is consistent with previous studies (Shakespeare-Finch \& Obst, 2011). The lowest scores were given by the one individual in the 65 years or more age bracket $(M=80)$, with those aged 25-44 having the second lowest mean scores $(M=82.79 ; S D=18.70)$. Participants in the 18-24 age group had the highest mean scores $(M=88.22, S D=15.17)$.

With regard to length of time in missionary service, scores of those serving 3-5 years indicated the lowest levels social support from the home culture $(M=79.85, S D=$ 22.69), with the highest scores among participants serving 0 -2 years $(M=88.60, S D=$ 11.77). When examining length of time in current country of service, scores of those serving 6-10 years indicated the lowest levels of social support $(M=79.00, S D=12.05)$, with the highest scores among participants serving $0-2$ years $(M=87.85, S D=12.12)$. 
Finally, with regard to socioeconomic status, it was found that those rating their socioeconomic status as "Somewhat Above Average" had the lowest mean scores related to social support received from the home culture $(M=81.39, S D=14.43)$. Those who rated themselves as being "Somewhat Below Average" were found to have the highest mean scores $(M=91.25, S D=12.47)$.

\section{Relationships with Other Missionaries}

The SSS (Shakespeare-Finch \& Obst, 2011) was also used to assess participants' relationships with other missionaries. The overall mean score for the SSS when examining social support with other missionaries on the field was $M=74.81(S D=$ 20.46), which is lower than the mean score in Shakespeare-Finch and Obst's original study $(M=83.34)$. Scores in the current study related to relationships with other missionaries ranged from 24 to 105 . Additionally, when examining missionary relationships, the SSS had an internal consistency value of $\alpha=.95$. This is slightly higher than the internal consistency values found in the authors' previous studies (ShakespeareFinch $\&$ Obst, 2011), which ranged from $\alpha=.81$ to $\alpha=.92$. Participants in the 25-54 age group had the lowest mean scores $(M=73.06, S D=24.60)$, while the highest mean scores were found among those 45-64 years $(M=76.31, S D=16.62)$.

With regard to length of time in missionary service, scores of those serving 3-5 years indicated the lowest levels of social support from other missionaries on the field ( $M$ $=69.38, S D=22.58$ ), with the highest scores coming from participants serving 21 years or more $(M=81.87, S D=16.94)$. When examining length of time in current country of service, scores of those serving 21 years or more indicated the lowest levels of social 
support from other missionaries $(M=70.42, S D=22.51)$, with the highest scores among participants serving 16-20 years $(M=84.62, S D=12.54)$.

Finally, with regard to socioeconomic status, it was found that those rating their socioeconomic status as "Somewhat Below Average" had the lowest mean scores related to social support received from other missionaries $(M=71.00, S D=30.48)$. Those who rated themselves as being "Somewhat Above Average" were found to have the highest mean scores $(M=76.36, S D=18.28)$.

\section{Relationships with Host Nationals}

Finally, the SSS (Shakespeare-Finch \& Obst, 2011) was used to assess participants' relationships with host nationals in their country of service. The overall mean score for the SSS when examining social support with host nationals was $M=$ $71.93(S D=19.68)$, which is considerably lower than the mean score in ShakespeareFinch and Obst's previous study $(M=83.34)$. Scores on the SSS related to relationships with host nationals ranged from 21 to 105 . The SSS had an internal consistency value of $\alpha=.94$ related to host national relationships, which is again slightly higher than the internal consistency values found in previous studies $(\alpha=.81$ to $\alpha=.92$; ShakespeareFinch \& Obst, 2011). Participants in the 18-24 age group had the lowest mean scores $(M$ $=62.77, S D=20.11)$. The highest mean scores were found among those $25-44$ years $(M$ $=74.22, S D=21.60)$.

When examining length of time in missionary service, scores of those serving 0-2 years indicated the lowest levels of social support from host nationals $(M=66.00, S D=$ $20.49)$, with the highest scores among participants serving 3-5 years $(M=76.28, S D=$ 20.23). With regard to length of time in current country of service, scores of those 
serving $0-2$ years indicated the lowest levels of social support from host nationals $(M=$ $68.12, S D=19.55)$, with the highest scores among participants serving $11-15$ years $(M=$ $84.25, S D=18.99)$.

With regard to socioeconomic status, it was found that those rating their socioeconomic status as "Average" had the lowest mean scores related to social support received from other missionaries $(M=68.32, S D=21.84)$. Those who rated themselves as being "Somewhat Below Average" were found to have the highest mean scores ( $M=$ $78.62, S D=10.14)$.

\section{Data Cleaning and Testing of Assumptions}

The data were cleaned to ensure that all participants included within the final study sample had complete data for each variable. A total of 129 individuals from the Global Mission Department of the Church of the Nazarene chose to participate in the research study. Of the 129 participants, 28 responses were excluded from the study due to missing information. Thus, the final sample size was $N=101$.

Preliminary tests were completed to examine the assumptions of normality, linearity, homoscedasticity, and outliers for each of the study variables used in the analyses. Variables were normally distributed, as indicated by levels of skewness and kurtosis. Linear relationships were confirmed by examining scatterplots. The assumption of reliability of measurement was met with Cronbach's alphas of measures ranging between .80 and .95 . Finally, the assumption of homoscedasticity was tested and met by examining plots of the standardized errors by the regression standardized predicted value. 


\section{Major Analysis}

\section{Research Question 1}

The study's first research question asked, To what extent is there an association between a missionary's relationship with God (as measured by the SAI; Hall \& Edwards, 1996; 2002) and their adjustment to a new host culture (as measured by the SCAS; Ward \& Kennedy, 1999)? In order to answer this research question, a correlation analysis was used to determine the presence of a statistically significant correlation between the study variables. While correlation analyses cannot give conclusions regarding causal relationships between variables, they can provide information related to the variables and possible direction for further study (Cohen, 2008).

The scores associated with each variable were entered in a correlation analysis using SPSS (Version 24). The variables for Research Question 1 included: a) missionary relationship with God, as measured by the SAI (Hall \& Edwards, 1996; 2002) and b) missionary adjustment to a new host culture, as measured by the SCAS (Ward \& Kennedy, 1999). The correlations were examined between the SCAS and the SAI, as well as between the SCAS and each of the SAI's six subscales (Awareness of God, Disappointment with God, Grandiosity, Impression Management, Instability, and Realistic Acceptance). The correlations of the variables for each scale are presented in Table 3.

Overall, the correlation variables related to Research Question 1 ranged from $r=$ -.242 to $r=.167$. The correlation analysis indicated that there was not a significant correlation between the SCAS and the SAI total score, or the SCAS and five of the six 
subscales of the SAI. However, examination of the correlations between variables indicated that there was a statistically significant negative correlation between the SCAS and the Instability subscale of the SAI at the $\mathrm{p}<.05$ level $(r=-.242)$, with a small effect size (Cohen, 1992). This correlation indicates that as participants' level of sociocultural difficulty decreased (indicating an increase in their overall level of cultural adjustment), their level of stability in their relationship with God increased.

Table 3

Correlations among the SCAS and SAI

\begin{tabular}{lcc}
\hline \multicolumn{1}{c}{ SAI Scale } & $N$ & SCAS \\
\hline SAI Awareness & 101 & -.133 \\
SAI Disappointment & 101 & -.169 \\
SAI Grandiosity & 101 & .078 \\
SAI Impression Management & 101 & -.137 \\
SAI Instability & 101 & $-.242 *$ \\
SAI Realistic Acceptance & 101 & .167 \\
SAI Total & 101 & -.052 \\
\hline $\begin{array}{l}\text { Note. SCAS = Sociocultural Adaptation Scale; SAI = Spiritual Assessment Inventory } \\
* p<.05\end{array}$ & &
\end{tabular}

\section{Research Question 2}

The study's second research question asked, To what extent is there an association between a missionary's relationships with family and/or friends from their home country (as measured by the SSS; Shakespeare-Finch \& Obst, 2011) and their adjustment to a new host culture (as measured by the SCAS; Ward \& Kennedy, 1999)? In order to answer this research question, a correlation analysis was once again used to determine the presence of a statistically significant correlation between the study variables. 
The variables for Research Question 2 included: a) missionary relationships with family and/or friends from their home country, measured by the SSS (Shakespeare-Finch \& Obst, 2011) and b) missionary adjustment to a new host culture, measured by the SCAS (Ward \& Kennedy, 1999). The correlations of the variables for each scale are presented in Table 4.

Overall, the variables related to Research Question 2 were negatively correlated at $r=-.006$. Examination of this data did not indicate a statistically significant correlation between cultural adjustment and a missionary's relationships with family and friends from their home country.

Table 4

Correlations among the SCAS and SSS

\begin{tabular}{lcccc}
\hline & $N$ & SSS Home & SSS Missionary & SSS Nationals \\
\hline SCAS & 101 & -.006 & .055 & $-.358^{* *}$ \\
\hline
\end{tabular}

Note. SCAS = Sociocultural Adaptation Scale; SSS Home = 2-Way Social Support Scale, related to relationships with family and/or friends from the home country; SSS Missionary = 2-Way Social Support Scale, related to relationships with other missionaries on the mission field; SSS Nationals $=2$-Way Social Support Scale, related to relationships with host nationals in the country of service.

$* * p<.01$

\section{Research Question 3}

The study's third research question asked, To what extent is there an association between a missionary's relationships with other missionaries on the mission field (as measured by the SSS; Shakespeare-Finch \& Obst, 2011) and their adjustment to a new host culture (as measured by the SCAS; Ward \& Kennedy, 1999)? A correlation analysis determined the presence of a statistically significant correlation between the study variables.

The variables for Research Question 3 included: a) missionary relationships with other missionaries on the mission field, measured by the SSS (Shakespeare-Finch \& 
Obst, 2011) and b) missionary adjustment to a new host culture, measured by the SCAS (Ward \& Kennedy, 1999). The correlation variables were positively correlated at $r=$ .055. Examination of this data did not indicate a statistically significant correlation between cultural adjustment and a missionary's relationships with other missionaries on the mission field. The correlations of the variables are presented in Table 4.

\section{Research Question 4}

The study's fourth research question asked, To what extent is there an association between a missionary's relationships with host nationals (residents or citizens of the host country) on the mission field (as measured by the SSS; Shakespeare-Finch \& Obst, 2011) and their adjustment to a new host culture (as measured by the SCAS; Ward \& Kennedy, 1999)? Once again, a correlation analysis determined the presence of a statistically significant correlation between the variables. The correlations of the variables are presented in Table 4.

The variables for Research Question 4 included: a) missionary relationships with host nationals on the mission field, measured by the SSS (Shakespeare-Finch \& Obst, 2011) and b) missionary adjustment to a new host culture, measured by the SCAS (Ward \& Kennedy, 1999). Overall, the correlation variables related to Research Question 4 were significantly negatively correlated at the $p<.01$ level $(r=-.358)$, indicating a medium effect size (Cohen, 1992).

The analysis indicated that cultural adjustment, as measured by level of sociocultural difficulty on the SCAS, and social support scales examining missionary relationships with host nationals, as measured by the SSS, were significantly negatively correlated. This association shows that as levels of sociocultural difficulty on the SCAS 
decreased (indicating higher levels of cultural adjustment), the scores on the SSS examining relationships with host nationals increased.

\section{Research Question 5}

The final question of this study asked How do a missionary's relationship with God, relationships with family and/or friends from their home country, relationships with other missionaries on the mission field, and relationships with host nationals, separately and taken together, predict a missionary's ability to adjust to a new culture? A multiple regression analysis was conducted to examine the variables.

The variables for Research Question 5 included: a) missionary relationship with God, measured by the SAI (Hall \& Edwards, 1996; 2002); b) missionary relationships with family and/or friends from their home country, measured by the SSS (ShakespeareFinch \& Obst, 2011); c) missionary relationships with other missionaries on the mission field, measured by the SSS; d) missionary relationships with host nationals on the mission field, measured by the SSS; and e) missionary adjustment to a new host culture, measured by the SCAS (Ward \& Kennedy, 1999). Due to the exploratory nature of the study, each of these variables was entered into the multiple regression analysis simultaneously. The results of the multiple regression analysis are displayed in Table 5.

The overall model indicated that there was a significant positive relationship between the dependent variable (cultural adjustment) and the independent variables (relationship with God, relationships with family and/or friends from the home country, relationships with other missionaries, and relationships with host nationals), $F(4,96)=$ $5.314, p=.001$. The $\mathrm{R}$ value $(r=.426)$ indicated a medium effect size (Cohen, 1992), and the adjusted $R^{2}$ value indicated that $14.7 \%$ of the variance in missionary cultural 
adjustment scores was explained by missionary relationships with God, family and/or friends in the home culture, other missionaries, and host nationals in the country of service. The beta weights showed that missionary relationships with host nationals made a significant contribution $(\beta=-.388, p=.000)$, but that no other variables made a significant impact on the dependent variable of cultural adjustment.

Table 5

Multiple Regression Summary for Study Variables Predicting Cultural Adjustment

\begin{tabular}{lccccc}
\hline & $B$ & $S E B$ & $\beta$ & $\mathrm{t}$ & $p$ \\
\hline SAI Total & .625 & .720 & .081 & .868 & .388 \\
SSS Home & .066 & .107 & .062 & .615 & .540 \\
SSS Missionary & .167 & .085 & .203 & 1.968 & .052 \\
SSS Nationals & -.388 & .088 & -.454 & -4.432 & $.000^{* *}$ \\
\hline
\end{tabular}

Note: $R^{2}=.181(N=101, \mathrm{p}<.01)$.

Dependent Variable: SCAS Total. Independent Variables: SCAS = Sociocultural Adaptation Scale; SAI = Spiritual Assessment Inventory; SSS Home = 2-Way Social Support Scale, related to relationships with family and/or friends from the home country; SSS Missionary = 2-Way Social Support Scale, related to relationships with other missionaries on the mission field; SSS Nationals =2-Way Social Support Scale, related to relationships with host nationals in the country of service.

$* * p<.01$

\section{Summary}

Correlation analysis was used to examine the association among the study's primary variables of cultural adjustment, missionary relationship with God, missionary relationships with family and/or friends from one's home country, missionary relationships with other missionaries on the mission field, and missionary relationships with host nationals. A multiple regression analysis was used to examine how missionary relationship with God, missionary relationships with family and/or friends from one's home country, missionary relationships with other missionaries on the mission field, and 
missionary relationships with host nationals, separately and taken together, predict cultural adjustment.

Results indicated that missionary level of sociocultural difficulty, which indicates cultural adjustment, was not significantly correlated with missionary relationships with family and/or friends from one's home country or relationships with other missionaries on the mission field. While overall scores of relationship with God, as measured by the SAI, were not correlated with missionary cultural adjustment, one of the six subscales of the SAI, the Instability subscale, was negatively correlated with level of sociocultural difficulty, indicating a positive correlation with cultural adjustment. Additionally, results showed that a missionary's relationships with host nationals were significantly negatively correlated with level of sociocultural difficulty, indicating a positive correlation with missionary cultural adjustment.

A multiple regression analyses indicated a significant relationship between the dependent variable (cultural adjustment) and the independent variables (relationship with God, relationships with family and/or friends from the home country, relationships with other missionaries, and relationships with host nationals). However, results showed that this difference was mainly due to the impact of missionary's relationships with host nationals in their country of service, which was the only variable that resulted in a significant coefficient score.

\section{Conclusion}

This chapter reviewed the purpose of the study, discussed the instruments used, and presented descriptive statistics regarding the study participants. Additionally, the analyses used to examine each research question were described, as were the results of 
those analyses. The following chapter will discuss these results within the context of the literature on cultural adjustment, relationship with God, and relationships with others. Recommendations will be made for future research, as well as for missionaries and mission organizations. 


\section{CHAPTER V \\ DISCUSSION}

The purpose of this study was to examine the extent to which specific relationships (relationship with God, relationships with individuals from one's home culture, relationships with other missionaries, and relationships with individuals from one's host culture) correlate with and predict cultural adjustment among missionaries.

Participants were recruited from within the Church of the Nazarene's Global Mission Department. The final study sample included 101 participants, all of whom were English-speaking missionaries who had been serving with the Church of the Nazarene for at least 3 months. Findings from the current study will be discussed within the context of the research in the following sections of this chapter, and implications for future research and practice will be offered.

\section{Summary of Major Findings}

The current study examined the extent to which relationships with God and others correlate with and predict missionary cultural adjustment in a new environment. While some of the relationship variables were not significantly correlated with cultural adjustment as hypothesized, other variables did display significant associations. The data gathered in this research study showed that a missionary's relationships with host nationals, as well as stability in a missionary's relationship with God, both correlate with missionary adjustment to a new cultural environment. 


\section{Relationship with God}

This study initially examined missionary cultural adjustment as it relates to the missionary's relationship with God. Based on the data from the current study, there was not a significant correlation found between missionary cultural adjustment and overall relationship with God. However, there was a significant correlation found between missionary cultural adjustment and the Instability subscale of the SAI (Hall \& Edwards, 1996; 2002). Therefore, the idea that missionary cultural adjustment and a missionary's relationship with God would be positively correlated was partially supported.

Items from the Instability subscale of the SAI (Hall \& Edwards, 1996; 2002) examined the degree to which individuals experience emotional instability, insecurity, or fear of abandonment in their relationship with God. Items included questions such as "I am afraid that God will give up on me," "My emotional connection with God is unstable," and "I feel I have to please God or he might reject me." The negative correlation between the Instability subscale and the SCAS (Ward \& Kennedy, 1999) indicates that as missionaries' level of stability in their relationship with God increased, their level of sociocultural difficulty decreased, demonstrating a higher level of cultural adjustment.

While other areas of the SAI (i.e., the Awareness of God, Disappointment with God, Grandiosity, Impression Management, and Realistic Acceptance subscales; Hall \& Edwards, 1996; 2002), were not significantly correlated with the SCAS (Ward \& Kennedy, 1999), the fact that the Instability subscale correlated with cultural adjustment does support the theoretical framework of the study. Stability in one's relationship with God has been tied to the concept of a secure attachment in Bowlby's (1988) attachment 
theory. Hill and Pargament (2008) argue that similarities can be made between God and other attachment figures, stating that in the same way that children look to their parents for protection, people look to God as a safe haven during times of difficulty. This would suggest that people who experience a secure, or stable, relationship with God should also experience comfort and confidence in new or stressful situations. Additionally, this confidence can help them in their willingness to explore unfamiliar situations similar to the way that securely attached children were more likely to explore and adapt to a strange environment in Ainsworth et al.'s (1978) Strange Situation. Lewis Hall et al. (2006) stated that spiritual development, or “the degree to which a person's relationship with God reflects the ability to maintain a consistent sense of emotional connection with God in the midst of spiritual struggles" (p. 195), is positively related to cultural adjustment. The current research supported the results of Lewis Hall et al.'s empirical study, indicating that when missionaries have a secure, stable relationship with God, it is more likely that they will achieve a higher level of cultural adjustment in new cultural environments.

Other aspects of one's relationship with God that were examined by the SAI (Hall \& Edwards, 1996; 2002), such as an awareness of God working in one's life, disappointment with God, and an attitude of grandiosity in one's relationship with God, did not correlate with cultural adjustment. There are various reasons why these subscales, and therefore the overall SAI scores, may not have significantly correlated with cultural adjustment. First, it is possible that some of the SAI subscales did not measure the specific aspects of one's relationship with God that would be expected to impact cultural adjustment based on the framework of Bowlby's (1988) attachment 
theory. For example, the Grandiosity subscale is included in the SAI for internal consistency, and includes items such as "God recognizes that I am more spiritual than most people" and "I find my prayers to God are more effective than other people's." While these questions can be beneficial in understanding other aspects of one's relationship with God, they are not necessarily concepts that would impact one's ability to adjust to a new cultural environment based on the tenets of attachment theory or other research literature.

For other subscales of the SAI (Hall \& Edwards, 1996; 2002), such as the Awareness subscale, it is possible that participants' scores did not significantly correlate with cultural adjustment due to similarities within the sample missionary population, which would make statistically significant differences in the assessment scores more difficult to detect. The SAI was originally validated using predominantly single, Caucasian undergraduate students between the ages of 18 and 22 (Hall \& Edwards, 1996; 2002). This population is very different from the missionary population in the current study. It can be assumed that the majority of missionaries serving on the mission field are there because they believe they have been led by God to leave their home culture and move to a new cultural environment (Lewis Hall et al., 2006). Therefore, it could be argued that there is an underlying expectation that missionaries have a stronger awareness of God than the average individual. If this is the case, it would make sense that some of the scores on the SAI would exhibit a smaller amount of variance, making it more difficult to establish a significant correlation between the various aspects of one's relationship with God and cultural adjustment. Participants in this study had a mean score of 4.14 on the Awareness subscale (on a scale of 1 to 5), with a low level of 
standard deviation $(S D=.52)$. This is higher than the mean score of the Awareness subscale found in Hall et al.'s (2007) analysis of the SAI $(M=3.83)$, and may support the theory that within the sample missionary population, there is a larger amount of similarity related to participants' level of awareness of God. This similarity could make it difficult to detect enough of a variance in scores to establish a significant correlation with other variables.

\section{Relationships from Home Culture}

This study also examined missionary cultural adjustment as it relates to relationships with family and/or friends from the home culture. The proposition that missionary cultural adjustment and a missionary's relationships with family and/or friends from their home culture would be positively correlated was not supported in the current research.

The concept for this research question was again based on Bowlby's (1988) attachment theory, and the idea that the existence of a secure relationship attachment to another person (such as a family or friend in the home culture) promotes a greater capacity for exploring a new cultural environment (Ainsworth et al., 1978; Polek et al., 2010; Sochos \& Diniz, 2012; Wang \& Mallinckrodt, 2006). Therefore, it was suggested that the stronger a missionary's relationships were with family and friends from their home country, the more likely that individual would be to explore their new cultural environment and become better culturally adjusted. The results of Cemalcilar et al.'s (2005) study supported this concept, indicating that social support from one's family and friends back home, even through technological forms of long-distance communication, can influence the psychological aspect of an expatriate's adjustment. However, 
Cemalcilar et al. and other researchers who have examined the influence of relationships from an expatriate's home culture have not included the missionary population in their samples, which may partially explain the differences that exist between the previous research literature and the current study (Caligiuri et al., 1998; Cemalcilar et al., 2005; Ward \& Rana-Deuba, 2000).

While Shakespeare-Finch and Obst's (2011) model of 2-Way Social Support examines the giving and receiving of both emotional and instrumental support, it is possible that these concepts would look different within relationships that are supportive from a distance as opposed to those that are providing tangible, in-person support. While Cemalcilar et al. (2005) found that communication can impact the continuation of social support even when support systems were far away, the measurements used for social support in their study focused on the amount of time participants spent connecting with individuals from their home culture and on the emotional support received from individuals back home. Since the SSS also focuses on the giving and receiving of instrumental support (which could look different and could arguably be more difficult over long distances), it is possible that this disparity in the measurement tools impacted the incongruence between Cemalcilar et al.'s research findings and the findings of the current study.

Furthermore, while the idea of a correlation between missionary cultural adjustment and relationships with friends and/or family from the home culture was not supported, previous research and additional information gleaned from the study may indicate that these variables warrant additional examination. First, it is possible that the data did not support the concept of relationships from the home culture correlating with 
cultural adjustment in part due to the limited influence of younger missionaries

participating in the study. The youngest group of participants, those in the 18-24-yearold age bracket, only represented $8.9 \%$ of the overall sample $(n=9)$. This group of young missionaries would arguably be the most likely to remain in frequent contact with home influences due to increases in technological communication within younger populations (Cemalcilar et al., 2005). When examining the scores for relationships with family and/or friends from one's home culture, participants in the 18-24 age group had the highest mean scores $(M=88.22, S D=15.17)$ of any age bracket. It is possible that as more individuals from this this younger population begin to participate in full-time mission work, their connections to technology, social media, and other home influences will change how missionaries maintain relationships in the future, as well as how these relationships impact overall cultural adjustment in missionaries.

\section{Relationships with Other Missionaries}

This research study also examined missionary relationships with other missionaries on the mission field. The data from the current study did not show a significant relationship between missionary cultural adjustment and relationships with other missionaries. Therefore, the idea that missionary cultural adjustment and a missionary's relationships with other missionaries on the mission field would be positively correlated was not supported. While studies focusing on relationships between expatriates are lacking in the research literature, there is research showing that these relationships influence the cross-cultural adjustment process (Caligiuri \& Lazarova, 2002; Ward \& Kennedy, 1993; Ward \& Rana-Deuba, 2000). However, the results of the 
current study did not support the research literature, instead suggesting that missionary cultural adjustment is not linked to the level of support received from other missionaries.

The idea for the research question investigating the association between missionary cultural adjustment and missionary relationships was developed from previous research examining expatriate relationships with other expatriates (Caligiuri \& Lazarova, 2002; Hendrickson et al., 2010; Ward \& Kennedy, 1993; Ward \& Rana-Deuba, 2000). Caligiuri and Lazarova (2002) claim that other expatriates can be a useful resource for learning about the culture, norms, and behavior of the host country. Similarly, Hendrickson et al. (2010), argue that co-national friendships can give expatriates an opportunity to enhance their understanding of the new culture through discussions, social interaction, and intellectual exchange with other expatriates who are experiencing the same emotions. However, it is possible that these opportunities for connection with fellow expatriates are less likely in the lives of missionaries as compared to other expatriate groups. One participant of this study sent an e-mail to the researcher after completing the survey assessment. This participant explained that he and his family are currently located in a very remote area, 1,500 miles from other missionary support systems (personal communication, September 26, 2017). As a result, they are only able to meet with fellow missionaries once or twice a year. If missionaries are located long distances away from one another with limited opportunities to connect and share information, it could impact their ability to experience this aspect of social support. This is especially true if these missionary support systems are in different countries, and therefore are unable to share information or experiences related to a specific culture. While sharing about general experiences (such as being away from family and friends) 
may be helpful, the additional information that Caligiuri and Lazarova (2002) and Hendrickson et al. (2010) found valuable between expatriates, such as assisting with the understanding of the new culture, may not apply in these types of situations. Therefore, it is possible that a better understanding of the participant's opportunity for relationships with other missionaries would be helpful in interpreting the data from this study. Examining the number and type of relationships that individuals have with their fellow missionaries, as well as the frequency of interactions that occur based on a person's location and distance from other missionaries could also be beneficial for future research studies.

\section{Relationships with Host Nationals}

Finally, this research study examined missionary relationships with host nationals (residents or citizens of the host country) on the mission field. Based on the data from the current study, there was a significant negative relationship found between a missionary's level of sociocultural difficulty and relationships with host nationals in the missionary's country of service. These results indicate that as levels of sociocultural difficulty decreased (demonstrating an increase in level of cultural adjustment), the scores examining relationships with host nationals increased. Therefore, the concept that missionary cultural adjustment and a missionary's relationships with host nationals would be correlated was supported at the $p<.01$ level $(r=-.358)$. Additionally, the multiple regression analysis indicated that there was a significant positive relationship between the dependent variable of cultural adjustment and the independent variables of relationship with God, relationships with family and/or friends from the home country, relationships with other missionaries, and relationships with host nationals. This relationship was 
significant at the $p=.001$ level, with the $\mathrm{R}$ value $(r=.426)$ indicating a medium effect size (Cohen, 1992). However, the beta weights showed that of the independent variables, only missionary relationships with host nationals significantly impacted missionary cultural adjustment $(\beta=-.388, p=.000)$. Additionally, the data indicated that only $14.7 \%$ of the variance in missionary cultural adjustment scores was explained by the independent variables in the current research. Therefore, a large portion of the variance in this study $(85.3 \%)$ remains unexplained.

Researchers have argued that it is interaction with host nationals that has the greatest impact on cultural adjustment (Caligiuri et al., 1998; Li \& Gasser, 2005; Ward \& Rana-Deuba, 2000). Caligiuri et al. (1998) claim that from a social learning perspective, the more contact missionaries and other expatriates have with host nationals and the host culture, the greater the cultural adjustment and the more successful the assignment will likely become. While these relationships can potentially be more difficult to develop due to cultural and language barriers (Ward \& Rana-Deuba, 2000), they can also be rewarding, and can enable missionaries to develop networks, understand the local culture, and acquire the social skills necessary for effective cultural adjustment (Li \& Gasser, 2005). The current research study supports the previous literature, showing that as relationships with host nationals grow stronger, so does the missionary's level of cultural adjustment in their host country. From the perspective of Bowlby's (1988) attachment theory, these results make sense. First, it can be argued that relationships with host nationals can serve as the "secure base" that Bowlby discusses, making it easier for the missionary to explore unfamiliar cultural environments with assistance and an added sense of security. Furthermore, the more culturally adjusted a missionary becomes, the 
more likely it is that he or she will continue to develop additional relationships in their host culture (Wang \& Mallinckrodt, 2006), therefore increasing the strength of relationships with host nationals. While causation cannot be established in the current study (i.e., we cannot say with certainty whether stronger relationships cause increased cultural adjustment or better cultural adjustment causes an increase in host national relationships) it is easy to see how these two variables correlate with one another to increase both the strength of a missionary's relationships with host nationals and the missionary's overall cultural adjustment.

\section{Limitations of the Study}

It is necessary to discuss the possible limitations of the current study. First, the sample of missionaries participating in this study was limited to individuals associated with the Church of the Nazarene's Global Mission Department. Therefore, it is possible that the study did not produce data that could be applied to missionaries working with other denominations or organizations. Similarly, the sample was limited to Englishspeaking missionaries, and may not be generalizable to missionaries from non-Englishspeaking countries.

The measurements used within this research study could also be seen as a potential limitation. While the measurements were chosen due to their use in previous studies and the strength of past research supporting their reliability and validity, it is possible that other measurements would be able to more accurately examine the study's specific constructs. For example, while the Instability subscale of the SAI (Hall \& Edwards, 1996; 2002) was useful within the current research study, it is possible that other subscales of the SAI did not assist in accurately measuring the aspects of one's 
relationship with God that would impact cultural adjustment. Additionally, while the SSS (Shakespeare-Fist \& Obst, 2011) is known to be effective in assessing social support within face-to-face relationships, the measurements of giving and receiving instrumental support may not apply in the same way to long-distance relationships such as those with family and friends in one's home culture. While the measurements that were used appeared to be the best options available, it is possible that newer or more specific measurements would more accurately assess the constructs used in this research study.

Furthermore, it is possible that the self-report design of the study subjected the research data to bias, as respondents may have held biases in their opinions of themselves or provided an embellished response in order to present themselves in a more desirable manner. However, self-report was the only viable option for obtaining the data related to the research questions, and the anonymity of the responses is assumed to have reduced this potential for self-report bias.

In addition to limitations related to the research design, data limitations were also present. The study sample was overwhelmingly identified as female $(n=67,66.3 \%)$, White $(n=92,91.1 \%)$, and from the United States $(n=92,91.1 \%)$. In contrast, only $64 \%$ of the overall missionary population within the Church of the Nazarene identifies their country of citizenship as the United States. While attempts were made to increase the diversity of the sample by recruiting participants from various world areas, the strength of the Church of the Nazarene's presence in the United States, along with the need for English-speaking participants, likely limited the diversity of the sample. As a result, the study may not be generalizable to more diverse populations. 
Finally, while the results of the multiple regression analysis indicated a significant positive relationship between the dependent variable (cultural adjustment) and the independent variables (relationship with God, relationships with family and/or friends from the home country, relationships with other missionaries, and relationships with host nationals), the results indicated that only $14.7 \%$ of the variance in missionary cultural adjustment scores was explained by the independent variables in the current research. Therefore, a large portion of the variance in this study $(85.3 \%)$ remains unexplained. Additional research needs to be completed to examine alternative variables (such as previous cross-cultural experience, language acquisition, or personality traits) and determine how they may influence the construct of missionary cultural adjustment.

\section{Recommendations}

In spite of the limitations present in this study, there is still useful information that can be derived from the findings. Significant correlations that were found between cultural adjustment and stability in a missionary's relationship with God, as well as between cultural adjustment and relationships with host nationals in the missionary's country of service can potentially impact future research, missionaries, and mission organizations. The following paragraphs will examine recommendations for utilizing the information obtained in this research study in each of these areas.

\section{Recommendations for Future Research}

Research on the cultural adjustment of missionaries remains limited (Kimber, 2012). The research literature which does exist has often been taken from the greater expatriate population, and cannot always be applied to the missionary cultural adjustment experience (Kimber, 2012; Navara \& James, 2002; 2005). While aspects of this study 
supported the previous literature on cultural adjustment (Caligiuri et al., 1998; Li \& Glasser, 2005; Ward \& Rana-Deuba, 2000), additional research is still needed to understand the various aspects of missionary cultural adjustment and develop a stronger and more accurate understanding of cultural adjustment. The findings from this research study can inform future research by encouraging more studies that investigate missionaries, their relationships, and the cultural adjustment process.

This study was limited by the fact that it included only English-speaking participants who overwhelmingly identified their race as White and their country of origin as the United States. Additionally, all participants were part of the Church of the Nazarene, one denomination and mission organization out of countless sending organizations around the world. Additional research that includes a wider variety of missionaries from various language and people groups would give a more accurate view of missionary cultural adjustment and could potentially examine any struggles with the cultural adjustment process that may be unique to specific populations. Since different cultures place a varied emphasis on the importance of relationships with family, friends, or other support systems, it is possible that the addition of missionaries from various cultural backgrounds would provide added insight into the variables examined in this study and other factors related to missionary cultural adjustment.

Furthermore, the results of this study showed that stability in a missionary's relationship with God is correlated with cultural adjustment. Hall and Edwards (1996; 2002) designed the Instability subscale of the SAI to measure the degree to which individuals experience emotional instability, insecurity, or fear of abandonment in their relationship with God. However, additional research is needed to understand exactly how 
stability is developed and maintained. Additional information related to the concept of stability could assist missionaries and mission organizations in utilizing the information from this research study to encourage higher levels of stability in one's relationship with God, impacting missionaries' levels of overall cultural adjustment. The results of this study could then be used in the assessment of potential missionaries, training of new missionaries, and support for current missionaries on the field (Schubert, 1999;

Whiteman, 2008). However, additional research providing a deeper understanding of the development of stability in one's relationship with God is needed before this information can be applied in an effective manner.

Additionally, while this study found no direct relationship between cultural adjustment and relationships with family and/or friends back home, this concept was partially based on the research of Cemalcilar et al. (2005), which showed that the social support received through technological forms of communication with individuals in one's home culture can impact cultural adjustment. Cemalcilar et al. also indicated that age can influence an individual's use of technology for communication purposes. Therefore, it could be argued that younger missionaries would be more likely to connect with family and friends through the use of technology and social media than individuals from older generations. However, the limited number of study participants in the lowest age bracket, 18-24 year olds $(n=9,8.9 \%)$, might not have included a large enough population to influence the scores of the overall sample concerning relationships with one's home culture. Additional research examining the amount of time participants spend connecting with their home culture, as well as their level of comfort with various types of technology, could be beneficial. As more individuals from this younger population begin 
to participate in full-time mission work, additional research could determine if their connections to technology, social media, and home influences will change how missionaries maintain relationships, and if the maintenance of those relationships will impact cultural adjustment.

Finally, it could also be beneficial for future research to include a qualitative component examining the missionary experience. First, a greater understanding of how missionaries define relationships could provide relevant information for researchers. A discussion of which relationships missionaries feel are most beneficial to them on the field and the reasoning behind their choices could provide additional knowledge related to the impact of relationships on cultural adjustment. Additionally, a qualitative discussion examining why missionaries are on the mission field could be productive. Navara and James (2005) state that missionaries have historically gone to the mission field for various reasons. While many of these reasons are likely connected to their religious beliefs and relationship with God, it is also possible that some missionaries are on the field due to other causes, such as pressures from their family or church. Understanding missionaries' motivations for coming to the field could provide some additional insight into their attitude on to the field, and therefore their overall process of cultural adjustment.

\section{Recommendations for Missionaries}

The results of this research study have a few implications for missionaries who are currently serving on the mission field and for those preparing to move to the mission field in the near future. Research has shown that when missionaries have difficulty with adjusting to their new cultural environment, many problems can arise for both the 
missionary and their sending organization (Schubert, 1999; White et al., 2011;

Whiteman, 2008). The findings of this study can assist missionaries in understanding their own cultural adjustment process in hopes of preventing potential problems that may occur during this transition.

First, this study found that relationships with host nationals from the missionary's country of service are correlated with missionary cultural adjustment. These results confirm the results of previous research studies claiming that interaction with host nationals can be highly beneficial in the cultural adjustment process (Caligiuri et al., 1998; Hechanova-Alampay et al., 2002; Hendrickson et al., 2010; Li \& Gasser, 2005; Ward \& Rana-Deuba, 2000). This knowledge can encourage missionaries to be intentional about building relationships with host nationals in their country of service whenever possible. The stronger a missionary's relationships and support systems are with residents of their new cultural environment, the more likely it is that the missionary will have a higher level of cultural adjustment. Missionaries should utilize this information and work towards building strong interpersonal relationships as early as possible in the transition process. This could potentially be done by spending time learning about the social expectations of the new environment before moving, by joining social groups or community organizations that may already exist in the missionary's new environment in order to connect with local people, by connecting to a church or religious organization, or by intentionally finding ways to get to know one's neighbors.

Additionally, it could be possible to connect missionaries with individuals from their host culture before deployment, either through a brief trip to visit the new culture before the missionary officially moves, or through regular correspondence with individuals from the 
host culture via e-mail or other forms of communication. What is important is that the missionary is intentionally forming relationships and putting themselves into their environment with the purpose of spending time with residents of their new culture.

Additionally, the results of this study showed the importance of stability in the missionary's relationship with God. These results fit well within the framework of Bowlby's (1988) attachment theory which focused on the importance of secure, stable relationships with attachment figures. Hill and Pargament (2008) argue that similarities can be made between God and other attachment figures, stating that in the same way children look to their parents for protection, people may look to God as a safe haven who offers protection during times of stress. While additional research is needed to fully understand this concept of stability and how it impacts cultural adjustment, it is hoped that missionaries will be able to use this information to help develop and maintain more stability in their relationship with God. The knowledge gleaned from this study can help missionaries understand the importance of making their relationship with God a priority in order to ensure that they have a strong, stable relationship to help them during difficult or stressful situations, including their transition to a new cultural environment.

\section{Recommendations for Mission Organizations}

Finally, the results of this study have several implications for organizations hoping to prepare their missionaries for the mission field and provide adequate support for missionaries after they have arrived in their new cultural environment. As previously stated, this study found a significant correlation between a missionary's relationships with host nationals from their country of service and a missionary's cultural adjustment. The information provided in this research study can add to mission organization's 
understanding of missionary cultural adjustment and the potential impact that relationships with host nationals can have. Mission organizations often have difficulty assessing a potential missionary's ability to adjust and thrive in a new environment, possibly due to a lack of existing research on the elements that are most helpful to the cultural adjustment process (Schubert, 1999; Whiteman, 2008). Mission organizations can utilize the results of this study in their training and introductory information provided to new missionary's, encouraging them to be intentional about connecting with residents from their host country and building strong relationships whenever possible. Teaching missionaries how to appropriately interact with individuals in their country of service could be beneficial for facilitating the development of these relationships as quickly as possible and preventing the potential problems that can arise when missionaries fail to adjust to their new environment (Caligiuri et al., 1998; Schubert, 1999; White et al., 2011; Whiteman, 2008). Also, since relationships with host nationals have been found to be important to the cultural adjustment of missionaries, it is possible that mission organizations could work to provide these relationships as early in the transition process as possible. This could happen by connecting new missionaries with a host family or resident mentor who is willing to dedicate time toward building a strong relationship with the new missionary in order to help them adjust to their new environment. Mission organizations could also provide connections between new missionaries and experienced missionaries who have returned from the field in order to facilitate discussions and ideas about developing effective and supportive relationships with host nationals.

Mission organizations may also find it beneficial to assess a missionary's level of cultural awareness before they head to the mission field. This assessment could 
specifically examine the missionary's understanding of their potential area of service in order to ensure that the missionary has a strong foundation of cultural knowledge and awareness that can be used to build relationships and connections once they are in their new cultural environment. An assessment could also examine the missionary's own level of personal cultural awareness, to ensure that the missionary possesses a basic understanding of their personal biases, beliefs, and cultural idiosyncrasies. These examinations could potentially help mission organizations ensure that their missionaries have a strong understanding of culture before heading to the mission field, in order to facilitate the process of cultural adjustment.

Additionally, the results of this study showed the importance of stability in the missionary's relationship with God. Additional research is needed to understand the various aspects of this concept of stability, including how it is developed and maintained. However, mission organizations could use this information in multiple ways. First, assessing a potential missionary's stability in their relationship with God could be used with other assessment tools to help mission organizations determine which missionary candidates would be the best fit for the mission field. Schubert (1999) emphasized the importance of screening missionaries and implementing a strong training process, reiterating that if missionary candidates are not well prepared before being deployed, they often leave the field prematurely. While stability in one's relationship with God may only be one small aspect of an individual's ability to serve on the mission field, an understanding of this level of stability can help mission organizations determine how well this individual may be able to adjust to the new culture. This, in turn, could influence the location where a missionary is placed, the additional support they may or may not need to 
assist with cultural adjustment, or even the individual's overall ability to serve on the mission field.

Furthermore, mission organizations can use the information taken from this study to emphasize to their missionaries the importance of developing strong, stable relationships with God. With the knowledge that stability in one's relationship with God does impact cultural adjustment, mission organizations can work to develop trainings, workshops, or other helpful tools that will assist missionaries in cultivating and maintaining a more stable relationship with God in order to help with the cultural adjustment process and prevent problems in the future.

\section{Implications for Counseling}

Along with adding to the field of cultural adjustment, the results of this study also have implications for the field of counseling, specifically related to the counseling of missionaries. First, this information can be used to assist in the prevention of mental health problems for those on the mission field. Research has shown that emotional connections can off-set the negative psychological effects of isolation and loneliness (Caligiuri \& Lazarova, 2002). Encouraging missionaries to develop supportive relationships, especially within their relationship with God and relationships with host nationals in their country of service, can work to prevent the negative psychological effects (such as depression or anxiety) that can come about from loneliness or expatriate failure.

Additionally, the information from this study can be used by counselors to assist in developing techniques to inform counseling sessions with missionaries. For example, missionaries may come to counseling because they are struggling with the feelings of 
loneliness or depression that can stem from isolation in a new cultural environment. The knowledge that host-national relationships can assist with the cultural adjustment process can lead counselors to examine potential blocks in this relationship-building process. In this way, counselors can encourage their missionary clients to focus on the development of relationships in order to off-set the problems that can arise when missionaries do not have high levels of social support. This understanding of the relationships that can impact adjustment can be used by counselors to assist in facilitating the cultural adjustment process.

\section{Conclusion}

This research study examined the extent to which specific relationships (relationship with God, relationships with individuals from one's home culture, relationships with other missionaries, and relationships with individuals from one's host culture) correlate with and predict cultural adjustment among missionaries. A review of the research literature and an explanation of Bowlby's (1988) attachment theory as the theoretical framework for the study provided a foundation for the study's research questions and the investigation of a correlation between relationships and missionary cultural adjustment.

While the study's findings indicated a lack of significant correlation between cultural adjustment and a missionary's relationships with family and/or friends from their home culture, the research study did show a significant correlation between cultural adjustment and a missionary's relationships with host nationals in the missionary's country of service. Additionally, while there was not a correlation found between cultural adjustment and overall scores of relationship with God on the SAI (Hall \& 
Edwards, 1996; 2002), a correlation was found between cultural adjustment and the Instability subscale of the SAI, indicating that stability in one's relationship with God is positively correlated with cultural adjustment. These findings align with the basic concepts of Bowlby's (1988) attachment theory by indicating that missionaries who experience a secure, or stable, relationship with God should also experience comfort and confidence in stressful situations such as adjusting to a new cultural environment.

The results of this research study will assist missionaries and mission organizations in understanding the cultural adjustment process. It is hoped that this information will be used to inform the interview and training processes in order to prevent the problems and losses that can arise when missionaries struggle in a new cultural environment (Schubert, 1999). As the number of missionaries continues to increase (Johnson \& Zurlo, 2016), there is a need for empirical investigations such as this one that can provide information on the missionary cultural adjustment process in order to ensure missionaries have the physical and relational support they need to sustain their ministry on the mission field (Kimber, 2012; Navara \& James, 2005). It is hoped that the information provided in this research study, together with additional research in the area of missionary cultural adjustment, will assist in choosing the best individuals for the mission field and ensuring that those individuals are adequately trained and supported in ways that will increase their likelihood of success during the often-difficult process of transitioning to a new culture. 


\section{REFERENCES}

Ainsworth, M. S., Blehar, M., Waters, E., \& Wall, S. (1978). Patterns of attachment. Hillsdale, NJ: Erlbaum.

Andrews, G., Singh, M., \& Bond, M. (1993). The defense style questionnaire. Journal of Nervous and Mental Disease, 181, 246-256.

Andrews, L. A. (1999). Spiritual, family and ministry satisfaction among missionaries. Journal of Psychology and Theology, 27, 107-118.

Baumsteiger, R., \& Chenneville, T. (2015). Challenges to the conceptualization and measurement of religiosity and spirituality in mental health research. Journal of Religion and Health, 54, 2344-2354. doi:10.1007/s10943-015-0008-7

Bell, M., Billington, R., \& Becker, B. (1986). A scale for the assessment of object relations: Reliability, validity, and factorial invariance. Journal of Clinical Psychology, 42, 733-741.

Berry, J. W. (1992). Acculturation and adaptation in a new society. International Migration Quarterly Review, 30, 69-85. doi:10.1111/j.1468-2435.1992.tb00776.x

Black, J. S., Mendenhall, M., \& Oddou, G. (1991). Toward a comprehensive model of international adjustment: An integration of multiple theoretical perspectives. Academy of Management Review, 16, 291-317. doi:10.2307/258863

Bowlby, J. (1988). A secure base: Parent-child attachment and healthy human development. New York, NY: Basic Books. 
Brown, S. L., Nesse, R. M., Vinokur, A. D., \& Smith, D. M. (2003). Providing social support may be more beneficial than receiving it: Results from a prospective study of martality. Psychological Science, 14, 320-327. doi:10.1111/14679280.14461

Caligiuri, P., \& Lazarova, M. (2002). A model for the influence of social interaction and social support on female expatriates' cross-cultural adjustment. The International Journal of Human Resource Management, 13, 761-772.

doi:10.1080/09585190210125903

Caligiuri, P. M., Hyland, M. M., Joshi, A., \& Bross, A. S. (1998). Testing a theoretical model for examining the relationship between family adjustment and expatriates' work adjustment. Journal of Applied Psychology, 83, 598-614.

Cemalcilar, Z., Falbo, T., \& Stapleton, L. M. (2005). Cyber communication: A new opportunity for international students' adaptation?. International Journal of Intercultural Relations, 29, 91-110. https://doi.org/10.1016/j.ijintrel.2005.04.002

Cohen, B. (2008). Explaining psychological statistics. Hoboken, NJ: John Wiley \& Sons.

Cohen, J. (1992). A power primer. Psychological Bulletin, 112, 155-159.

Cohen, S., Kamarck, T., \& Mermelstein, R. (1983). A global measure of perceived stress. Journal of Health and Social Behaviour, 24, 385-396.

Diener, E., Emmons, R. A., Larsen, R. J., \& Griffin, S. (1985). The satisfaction with life scale. Journal of Personality Assessment, 49, 71-75. doi:10.1207/s15327752jpa4901_13 
Ellison, C. W. (1983). Spiritual well-being: Conceptualization and measurement. Journal of Psychology and Theology, 11, 330-340.

Goldberg, D. P., Gater, R., Sartorius, N., Ustun, T. B., Piccinelli, M., Gureje, O., \& Rutter, C. (1997). The validity of two versions of the GHQ in the WHO study of mental illness in general health care. Psychological Medicine, 27, 191-197. doi:10.1017/S0033291796004242

Gorsuch, R. L., \& McPherson, S. E. (1989). Intrinsic/extrinsic measurement: I/E-revised and single-item scales. Journal for the Scientific Study of Religion, 28, 348-354. doi:10.2307/1386745

Hall, T. W., \& Edwards, K. J. (1996). The initial development and factor analysis of the Spiritual Assessment Inventory. Journal of Psychology and Theology, 24, 233246. doi:10.1037/t06791-000

Hall, T. W., \& Edwards, K. J. (2002). The spiritual assessment inventory: A theistic model and measure for assessing spiritual development. Journal for the Scientific Study of Religion, 41, 341-357. doi:10.1111/1468-5906.00121

Hall, T. W., Reise, S. P., \& Haviland, M. G. (2007). An item response theory analysis of the Spiritual Assessment Inventory. The International Journal for the Psychology of Religion, 17, 157-178. doi:10.1080/10508610701244197

Hammer, M. R., Bennett, M. J., \& Wiseman, R. (2003). Measuring intercultural sensitivity: The intercultural development inventory. International Journal of Intercultural Relations, 27, 421-443. doi:0.1016/S0147-1767(03)00032-4 
Hechanova-Alampay, R., Beehr, T. A., Christiansen, N. D., \& van Horn, R. K. (2002). Adjustment and strain among domestic and international student sojourners: A longitudinal study. School Psychology International, 23, 458-474.

Hendrickson, B., Rosen, D., \& Aune, R. K. (2010). An analysis of friendship networks, social connectedness, homesickness, and satisfaction levels of international students. International Journal of Intercultural Relations, 35, 281-295. https://doi.org/10.1016/j.ijintrel.2010.08.001

Hermanto, N., \& Zuroff, D. C. (2016). The social mentality theory of self-compassion and self-reassurance: The interactive effect of care-seeking and caregiving. Journal of Social Psychology, 156, 523-535.

doi:10.1080/00224545.2015.1135779

Hill, P. C., \& Pargament, K. I. (2008). Advances in the conceptualization and measurement of religion and spirituality: Implications for physical and mental health research. Psychology of Religion and Spirituality, S, 3-17. doi:10.1037/1941-1022.s.1.3

Israel-Cohen, Y., Kaplan, O., Noy, S., \& Kashy-Rosenbaum, G. (2016). Religiosity as a moderator of self-efficacy and social support in predicting traumatic stress among combat soldiers. Journal of Religion and Health, 55, 1160-1171. doi:10.1007/s10943-016-0187-X

James, S., Hunsley, J., Navara, G. S., \& Alles, M. (2004). Marital, psychological, and sociocultural aspects of sojourner adjustment: Expanding the field of enquiry. International Journal of Intercultural Relations, 28, 111-126. doi:10.1016/j.ijintrel.2004.03.003 
Johnson, T. M. \& Zurlo, G. A. (Eds.). (2016). Status of global christianity, 2017, in the context of 1900-2050. Center for the Study of Global Christianity. Retrieved from http://www.gordonconwell.edu/ockenga/research/documents/StatusofGlobalChris tianity2017.pdf

Kessler, R. E., \& Mroczek, D. (1992). An update of the development of mental health screening scales for the US National Health Interview Study. American Journal of Psychiatry, 149, 443-454.

Kimber, T. (2012). The role of spiritual development in the cross-cultural reentry adjustment of missionaries. Journal of Psychology and Theology, 40, 211-219.

Koenig, H. G. (2012). Religion, spirituality, and health: The research and clinical implications. International Scholarly Research Network: Psychiatry, 2012, 1-33. doi: $10.5402 / 2012 / 278730$

Lewis Hall, M. E., Edwards, K. J., \& Hall, T. W. (2006). The role of spiritual and psychological development in the cross-cultural adjustment of missionaries. Mental Health, Religion \& Culture, 9, 193-208. doi:10.1080/13694670500355262

Li, A., \& Gasser, M. B. (2005). Predicting Asian international students' sociocultural adjustment: A test of two mediation models. International Journal of Intercultural Relations, 29, 561-576. doi:10.1016/j.ijintrel.2005.06.003

Navara, G. S., \& James, S. (2002). Sojourner adjustment: Does missionary status affect acculturation?. International Journal of Intercultural Relations, 26, 695-709. https://doi.org/10.1016/S0147-1767(02)00042-1 
Navara, G. S. \& James, S. (2005). Acculturative stress of missionaries: Does religious orientation affect religious coping and adjustment?. International Journal of Intercultural Relations, 29, 39-58. doi:10.1016/j.ijintrel.2005.04.004

Paine, D. R., \& Sandage, S. J. (2017). Religious involvement and depression: The mediating effect of relational spirituality. Journal of Religion and Health, 56, 269-283. doi:10.1007/s10943-016-0282-Z

Polek, E., Wöhrle, J., \& van Oudenhoven, J. P. (2010). The role of attachment styles, perceived discrimination, and cultural distance in adjustment of German and Eastern European immigrants in the Netherlands. Cross-Cultural Research, 44, 60-88.

Raskin, R., \& Terry, H. (1988). A principal-components analysis of the Narcissistic Personality Inventory and further evidence of its construct validity. Journal of Personality and Social Psychology, 54, 890-902. doi:10.1037/00223514.54.5.890

Sarason, I. G., Levine, H. M., Basham, R. B., \& Sarason, B. R. (1983). Assessing social support: The Social Support Questionnaire. Journal of Personality and Social Psychology, 44, 127-139. http://dx.doi.org/10.1037/0022-3514.44.1.127

Schubert, E. (1999). A suggested prefield process for missionary candidates. Journal of Psychology and Theology, 27, 87-97.

Schulz, U., \& Schwarzer, R. (2003). Soziale Unterstützung bei der Krankheitsbewältigung. Die Berliner Social Support Skalen (BSSS) [Social support in coping with illness: The Berlin Social Support Scales (BSSS)]. Diagnostica, 49, 73-82. 
Searle, W., \& Ward, C. (1990). The prediction of psychological and sociocultural adjustment during cross-cultural transitions. International Journal of Intercultural Relations, 14, 449-464. doi:10.1016/0147-1767(90)90030-Z

Shaffer, M. A., Harrison, D. A., Gregersen, H., Black, J. S., \& Ferzandi, L. A. (2006). You can take it with you: Individual differences and expatriate effectiveness. Journal of Applied Psychology, 91(1), 109-125. doi:10.1037/0021-9010.91.1.109

Shakespeare-Finch, J., \& Obst, P. L. (2011). The development of the 2-Way Social Support Scale: A measure of giving and receiving emotional and instrumental support. Journal of Personality Assessment, 93, 483-490.

doi:10.1080/00223891.2011.594124

Shakespeare-Finch, J., Rees, A., \& Armstrong, D. (2014). Social support, self-efficacy, trauma and well-being in emergency medical dispatchers. Social Indicators Research, 123, 549-565. doi:10.1007/s11205-014-0749-9

Smart, J. F., \& Smart, D. W. (1995). Acculturative stress of Hispanics: Loss and challenge. Journal of Counseling and Development, 73, 390-396. doi:10.1002/j.1556-6676.1995.tb01770.x

Sochos, A., \& Diniz, M. (2012). The role of attachment in immigrant sociocultural adaptation and psychological distress. Journal of Community \& Applied Social Psychology, 22, 75-91. doi:10.1002/casp.1102

SPSS Statistics for Macintosh (Version 24) [Computer software]. (2016). IBM Corp. Stephens, C., Long, N., \& Miller, I. (1997). The impact of trauma and social support on posttraumatic stress disorder: A study of New Zealand police officers. Journal of Criminal Justice, 25, 303-314. https://doi.org/10.1016/S0047-2352(97)00015-9 
Stevens, J. (2009). Applied multivariate statistics for the social sciences (5th ed.). New York, NY: Routledge.

Tanaka, T., Takai, J., Kohyama, T., \& Fujihara, T. (1994). Adjustment patterns of international students in Japan. International Journal of Intercultural Relations, 18, 55-75. https://doi.org/10.1016/0147-1767(94)90004-3

Tonsing, K. N. (2014). Acculturation and adaptation of first- and second-generation South Asians in Hong Kong. International Journal of Social Welfare, 23, 410420. doi:10.1111/ijsw.12079

Vögel, A. J., van Vuuren, J. J., \& Millard, S. M. (2008). Preparation, support and training requirements of South African expatriates. South African Journal of Business Management, 39, 33-40.

Wang, C. -C. D. C., \& Mallinckrodt, B. (2006). Acculturation, attachment, and psychosocial adjustment of Chinese/Taiwanese international students. Journal of Counseling Psychology, 53, 422-433. doi:10.1037/0022-0167.53.4.422

Ward, C., \& Chang, W. C. (1997). "Cultural fit": A new perspective on personality and sojourner adjustment. International Journal of Intercultural Relations, 21, 525 533. https://doi.org/10.1016/S0147-1767(97)00023-0

Ward, C., \& Kennedy, A. (1992). Locus of control, mood disturbance, and social difficulty during cross-cultural transitions. International Journal of Intercultural Relations, 16, 175-194. doi:10.1016/0147-1767(92)90017-o

Ward, C., \& Kennedy, A. (1993). Where's the "culture" in cross-cultural transition?: Comparative studies of sojourner adjustment. Journal of Cross-Cultural Psychology, 24, 221-249. http://dx.doi.org/10.1177/0022022193242006 
Ward, C., \& Kennedy, A. (1999). The measurement of sociocultural adaptation. International Journal of Intercultural Relations, 23, 659-677. https://doi.org/10.1016/S0147-1767(99)00014-0

Ward, C., Okura, Y., Kennedy, A., \& Kojima, T. (1998). The U-curve on trial: A longitudinal study of psychological and sociocultural adjustment during crosscultural transition. International Journal of Intercultural Relations, 22, 277-291. https://doi.org/10.1016/S0147-1767(98)00008-X

Ward, C., \& Rana-Deuba, A. (1999). Acculturation and adaptation revisited. Journal of Cross-Cultural Psychology, 30, 422-442. doi:10.1177/0022022199030004003

Ward, C., \& Rana-Deuba, A. (2000). Home and host culture infleunces on sojourner adjustment. International Journal of Intercultural Relations, 24, 291-306. https://doi.org/10.1016/S0147-1767(00)00002-X

Ward, C., \& Searle, W. (1991). The impact of value discrepancies and cultural identity on psychological and sociocultural adjustment of sojourners. International Journal of Intercultural Relations, 25, 209-224. https://doi.org/10.1016/01471767(91)90030-K

White, D. W., Absher, R. K., \& Huggins, K. A. (2011). The effects of hardiness and cultural distance on sociocultural adaptation in an expatriate sales manager population. Journal of Personal Selling and Sales Management, 31, 325-337. doi:10.2753/pss0885-3134310309

Whiteman, D. L. (2008). Integral training today for cross-cultural mission. Missiology: An International Review, 36, 5-16. 
Wilson, J., Ward, C., \& Fischer, R. (2013). Beyond culture learning theory: What can personality tell us about cultural competence?. Journal of Cross-Cultural Psychology, 44, 900-927. doi:10.1177/0022022113492889

Wu, E. K. Y., \& Mak, W. W. S. (2012). Acculturation process and distress: Mediating roles of sociocultural adaptation and acculturative stress. The Counseling Psychologist, 40, 66-92. doi:10.1177/0011000011410893

Wu, W. -Y., \& Bodigerel-Koehler, M. (2013). The mediating effects of cross-cultural dynamic competencies on the relationship between multicultural personality and cross-cultural adjustment. The International Journal of Human Resource Management, 24, 4026-4045. doi:10.1080/09585192.2013.781518

Yang, R. P. -J., Noels, K. A., \& Saumure, K. D. (2006). Multiple routes to cross-cultural adaptation for international students: Mapping the paths between self-construals, English language confidence, and adjustment. International Journal of Intercultural Relations, 30, 487-506. doi:10.1016/j.ijintrel.2005.11.010

Yusoff, Y. M. (2012). Self-efficacy, perceived social support, and psychological adjustment in international undergraduate students in a public higher education institution in Malaysia. Journal of Studies in International Education, 16, 353371. doi:10.1177/1028315311408914

Zlobina, A., Basabe, N., Paez, D., \& Furnham, A. (2006). Sociocultural adjustment of immigrants: Universal and group-specific predictors. International Journal of Intercultural Relations, 30, 195-211.

https://doi.org/10.1016/j.ijintrel.2005.07.005 
Zung, W. W. K. (1965). A self-rating depression scale. Archives of General Psychiatry, 12, 63-70. doi:10.1001/archpsyc.1965.01720310065008 
APPENDICES 


\title{
Appendix A
}

\author{
Letter of Permission
}

\section{CHURCH ов \\ Global Mission}

January 31, 2017

To Whom It May Concern:

This letter is to inform you that Sarah Warren has received permission from the Global Mission Department of the Church of the Nazarene to conduct a research study titled The Impact of Relationship on Missionary Adjustment as part of the requirements for completing her doctoral dissertation with the University of Louisville.

It is our understanding that Ms. Warren's study will work to identify the impact of various relationships on a missionary's ability to adjust to the mission field. For this purpose, Ms. Warren has been granted permission to approach English-speaking missionaries through our organization and request their participation in an electronic survey. Once the research is complete, the Global Mission Department will have access to the outcomes of the study in order to utilize the information within our organization.

Sincerely,

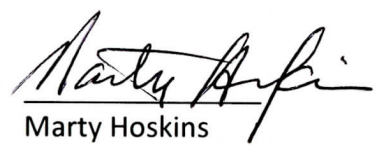

Global Mission Personnel Director 913-577-0500 
Appendix B

Subject Informed Consent Document

Dear Participant:

You are being invited to participate in a research study by answering questions in the attached survey about the extent to which specific relationships (relationship with God, relationships with individuals from one's home culture, relationships with other missionaries, and relationships with individuals from one's host culture) correlate with and predict cultural adjustment among missionaries.

This study is being conducted by Sarah Warren and Dr. Lisa Hooper of the University of Louisville. There are no known risks for your participation in this research study. The information collected may not benefit you directly. The information learned in this study may be helpful to others. The information you provide will contribute to the learning, knowledge, and understanding of missionary cultural adjustment. It may help mission organizations to evaluate, improve and revise the training procedures for future missionaries.

Your completed survey will be stored at maintained on a password protected computer. The survey will take approximately 30 minutes time to complete.

Individuals from the Department of Counseling and Human Development, the Institutional Review Board (IRB), the Human Subjects Protection Program Office (HSPPO), and other regulatory agencies may inspect these records. In all other respects, however, the data will be held in confidence to the extent permitted by law. Should the data be published, your identity will not be disclosed.

Taking part in this study is voluntary. By answering survey questions, you agree to take part in this research study. You do not have to answer any questions that make you uncomfortable. You may choose not to take part at all. If you decide to be in this study you may stop taking part at any time. If you decide not to be in this study or if you stop taking part at any time, you will not lose any benefits for which you may qualify.

If you have any questions, concerns, or complaints about the research study, please contact Sarah Warren at the following e-mail address: swarren@extremenazarene.org or phone number (812) 821-7495.

If you have any questions about your rights as a research subject, you may call the Human Subjects Protection Program Office at (502) 852-5188. You can discuss any questions about your rights as a research subject, in private, with a member of the Institutional Review Board (IRB). You may also call this number if you have other questions about the research, and you cannot reach the research staff, or want to talk to someone else. The IRB is an independent committee made up of people from the University community, staff of the institutions, as well as people from the community not connected with these institutions. The IRB has reviewed this research study. 
If you have concerns or complaints about the research or research staff and you do not wish to give your name, you may call 1-877-852-1167. This is a 24-hour hot line answered by people who do not work at the University of Louisville.

Sincerely,

Sarah Warren

Lisa M. Hooper 


\section{Appendix C \\ Invitation to Participate}

Dear (missionary),

As a missionary with the Church of the Nazarene, you are invited to participate in a research study examining the correlation between relationships and missionary cultural adjustment. This study is being conducted as part of the completion requirements for a doctoral dissertation through the University of Louisville, in conjunction with the Global Mission Department of the Church of the Nazarene. Our hope is that the data collected in this study will increase our understanding of how a missionary's relationships with God and others (both on and off the mission field) help with adapting to a new cultural environment, providing a greater understanding of how the Church of the Nazarene and other mission organizations can best support missionaries on the field. As a current missionary, you are in an ideal position to give valuable, first-hand information from your personal experiences.

This study is being completed through an online survey, which will take approximately 1 hour to complete. The survey is set up in a way that will allow you the option of completing it in sections if your schedule does not allow for finishing your responses in one sitting. All responses to the questions will be kept confidential, and your personal information will not be given out at any time.

While your participation in this research study would be greatly appreciated, you are under no obligation from the Global Mission Department or the Church of the Nazarene to complete the online survey. Participation is completely voluntary, and the Global Mission Department will not receive any individual information related to missionaries who do or do not chose to complete the survey. If you do chose to participate in the study, you can go to http://louisville.az1.qualtrics.com/jfe/form/SV 54Hvhzd5PWT3ccB to begin the survey. The deadline for completion of the survey will be October 16, 2017.

If you have any questions please do not hesitate to contact me at swarren@extremenazarene.org.

Thank you for your help,

Sarah Warren, MA, LMFT, LCAC 


\author{
Appendix D \\ Reminder to Participate
}

Dear (missionary),

You previously received an e-mail with an invitation to participate in a research study examining the correlation between relationships and missionary cultural adjustment. This study is being conducted as part of the completion requirements for a doctoral dissertation through the University of Louisville, in conjunction with the Global Mission Department of the Church of the Nazarene. Our hope is that the data collected in this study will increase our understanding of how a missionary's relationships with God and others (both on and off the mission field) help with adapting to a new cultural environment, providing a greater understanding of how the Church of the Nazarene and other mission organizations can best support missionaries on the field. As a current missionary, you are in an ideal position to give valuable, first-hand information from your personal experiences.

This study is being completed through an online survey, which will take approximately 1 hour to complete. The survey is set up in a way that will allow you the option of completing it in sections if your schedule does not allow for finishing your responses in one sitting. All responses to the questions will be kept confidential, and your personal information will not be given out at any time.

While your participation in this research study would be greatly appreciated, you are under no obligation from the Global Mission Department or the Church of the Nazarene to complete the online survey. Participation is completely voluntary, and the Global Mission Department will not receive any individual information related to missionaries who do or do not chose to complete the survey. If you do chose to participate in the study, you can go to http://louisville.az1.qualtrics.com/jfe/form/SV 54Hvhzd5PWT3ccB to begin the survey. The deadline for completion of the survey will be October 16, 2017.

If you have any questions please do not hesitate to contact me at swarren@extremenazarene.org.

Thank you for your help,

Sarah Warren, MA, LMFT, LCAC 
Appendix E

Demographic Questions

Please answer the following demographic questions

Gender: Male: __ Female:

Age: $18-24: \_$25-44: ___ 45-64:___ 65 years or more:

Race/Ethnicity: American Indian/Alaska Native:____ Asian:

Black/African: ___ Hispanic/Latino: ___ Pacific Islander:

White:

Other:

Marital Status: Divorced:

Married:

Never Married:

Separated:

Widowed:

\section{Country of origin:}

Current country of service:

Length of time in missionary service (years): $0-2$ :

3-5:

6-10:

11-15:

16-20:

21 years or more:

Length of time in current country of service (years): $0-2$ : 3-5: 6-10: 11-15: 16-20: 21 years or more:

How would you rate your socioeconomic status compared with others in your country of service?

$\begin{array}{ccccc}\begin{array}{c}\text { Very } \\ \text { below } \\ \text { average }\end{array} & \begin{array}{c}\text { Somewhat } \\ \text { below } \\ \text { average }\end{array} & \text { Average } & \begin{array}{c}\text { Somewhat } \\ \text { above } \\ \text { average }\end{array} & \begin{array}{c}\text { Very } \\ \text { above } \\ \text { average }\end{array} \\ 1 & 2 & 3 & 4 & 5\end{array}$


Appendix F

Sociocultural Adaptation Scale

Thinking about life in your current country of service, please rate your competence in each of the following areas.

\begin{tabular}{ccc}
\hline & 1 & 5 \\
no & extreme \\
difficulty & difficulty
\end{tabular}

1. Making friends

2. Using the transport system

3. Making yourself understood

4. Getting used to the pace of life

5. Going shopping

6. Going to social events/gatherings/functions

7. Worshipping in your usual way

8. Talking about yourself with others

9. Understanding jokes and humor

10. Dealing with someone who is unpleasant/ cross/aggressive

11. Getting used to the local food/finding food you enjoy

12. Following rules and regulations

13. Dealing with people in authority

14. Dealing with the bureaucracy

15. Adapting to local accommodation

16. Adapting to local etiquette

17. Communicating with people of a different ethnic group

18. Understanding the local accent/language

19. Relating to members of the opposite sex

20. Dealing with unsatisfactory service

21 . Finding your way around

22. Dealing with the climate

$\begin{array}{lllll}1 & 2 & 3 & 4 & 5\end{array}$

$\begin{array}{lllll}1 & 2 & 3 & 4 & 5\end{array}$

$\begin{array}{lllll}1 & 2 & 3 & 4 & 5\end{array}$

$\begin{array}{lllll}1 & 2 & 3 & 4 & 5\end{array}$

$\begin{array}{lllll}1 & 2 & 3 & 4 & 5\end{array}$

$\begin{array}{lllll}1 & 2 & 3 & 4 & 5\end{array}$

$\begin{array}{lllll}1 & 2 & 3 & 4 & 5\end{array}$

$\begin{array}{lllll}1 & 2 & 3 & 4 & 5\end{array}$

$\begin{array}{lllll}1 & 2 & 3 & 4 & 5\end{array}$

$\begin{array}{lllll}1 & 2 & 3 & 4 & 5\end{array}$

$\begin{array}{lllll}1 & 2 & 3 & 4 & 5\end{array}$

$\begin{array}{lllll}1 & 2 & 3 & 4 & 5\end{array}$

$\begin{array}{lllll}1 & 2 & 3 & 4 & 5\end{array}$

$\begin{array}{lllll}1 & 2 & 3 & 4 & 5\end{array}$

$\begin{array}{lllll}1 & 2 & 3 & 4 & 5\end{array}$

$\begin{array}{lllll}1 & 2 & 3 & 4 & 5\end{array}$

$\begin{array}{lllll}1 & 2 & 3 & 4 & 5\end{array}$

$\begin{array}{lllll}1 & 2 & 3 & 4 & 5\end{array}$

$\begin{array}{lllll}1 & 2 & 3 & 4 & 5\end{array}$

$\begin{array}{lllll}1 & 2 & 3 & 4 & 5\end{array}$

$\begin{array}{lllll}1 & 2 & 3 & 4 & 5\end{array}$

$\begin{array}{lllll}1 & 2 & 3 & 4 & 5\end{array}$ 
Thinking about life in your current country of service, please rate your competence in each of the following areas.

\begin{tabular}{ccc}
\hline & 1 & 5 \\
& no & extreme \\
difficulty & difficulty \\
\hline
\end{tabular}

23. Accepting /understanding the local political system

24. Understanding the locals' world view

25. Taking a local perspective on the culture

26. Understanding the local value system

27. Seeing things from the locals' point of view

$\begin{array}{lllll}1 & 2 & 3 & 4 & 5\end{array}$

28. Understanding cultural differences

$\begin{array}{lllll}1 & 2 & 3 & 4 & 5\end{array}$

$\begin{array}{lllll}1 & 2 & 3 & 4 & 5\end{array}$

$\begin{array}{lllll}1 & 2 & 3 & 4 & 5\end{array}$

29. Being able to see two sides of an intercultural issue

$\begin{array}{lllll}1 & 2 & 3 & 4 & 5\end{array}$

$\begin{array}{lllll}1 & 2 & 3 & 4 & 5\end{array}$

$\begin{array}{lllll}1 & 2 & 3 & 4 & 5\end{array}$


Appendix G

Spiritual Assessment Inventory

\section{Instructions}

1. Please respond to each statement below by selecting the number that best represents your experience.

2. It is best to answer according to what really reflects your experience rather than what you think your experience should be.

3. Give the answer that comes to mind first. Don't spend too much time thinking about an item.

4. Give the best possible response to each statement even if it does not provide all the information you would like.

5. Try your best to respond to all statements. Your answers will be completely confidential.

6. Some of the statements consist of two parts as shown here:

[2.1] There are times when I feel disappointed with God.

[2.2] When this happens, I still want our relationship to continue.

Your response to 2.2 tells how true statement 2.2 is for you when you have the experience of feeling disappointed with God described in statement 2.1.

\begin{tabular}{|c|c|c|c|c|c|}
\hline & $\begin{array}{c}1 \\
\text { not at } \\
\text { all true }\end{array}$ & & & & $\begin{array}{c}5 \\
\text { very } \\
\text { true }\end{array}$ \\
\hline 1. I have a sense of how God is working in my life & 1 & 2 & 3 & 4 & 5 \\
\hline 2.1. There are times when I feel disappointed with God & 1 & 2 & 3 & 4 & 5 \\
\hline $\begin{array}{l}\text { 2.2. When this happens, I still want our } \\
\text { relationship to continue }\end{array}$ & 1 & 2 & 3 & 4 & 5 \\
\hline 3. God's presence feels very real to me & 1 & 2 & 3 & 4 & 5 \\
\hline 4. I am afraid that God will give up on me & 1 & 2 & 3 & 4 & 5 \\
\hline $\begin{array}{l}\text { 5. I seem to have a unique ability to influence God } \\
\text { through my prayers }\end{array}$ & 1 & 2 & 3 & 4 & 5 \\
\hline 6. Listening to God is an essential part of my life & 1 & 2 & 3 & 4 & 5 \\
\hline 7. I am always in a worshipful mood when I go to church. & . 1 & 2 & 3 & 4 & 5 \\
\hline 8.1. There are times when I feel frustrated with God & 1 & 2 & 3 & 4 & 5 \\
\hline $\begin{array}{l}\text { 8.2. When I feel this way, I still desire to put effort } \\
\text { into our relationship }\end{array}$ & 1 & 2 & 3 & 4 & 5 \\
\hline 9. I am aware of God prompting me to do things & 1 & 2 & 3 & 4 & 5 \\
\hline 10. My emotional connection with God is unstable & 1 & 2 & 3 & 4 & 5 \\
\hline $\begin{array}{l}\text { 11. My experiences of God's responses to me } \\
\text { impact me greatly }\end{array}$ & 1 & 2 & 3 & 4 & 5 \\
\hline
\end{tabular}




\begin{tabular}{|c|c|c|c|c|c|}
\hline & $\begin{array}{c}1 \\
\text { not at } \\
\text { all true }\end{array}$ & & & & $\begin{array}{c}5 \\
\text { very } \\
\text { true }\end{array}$ \\
\hline 12.1. There are times when I feel irritated at God & 1 & 2 & 3 & 4 & 5 \\
\hline $\begin{array}{l}\text { 12.2. When I feel this way, I am able to come to } \\
\text { some sense of resolution in our relationship }\end{array}$ & 1 & 2 & 3 & 4 & 5 \\
\hline $\begin{array}{l}\text { 13. God recognizes that I am more spiritual } \\
\text { than most people }\end{array}$ & 1 & 2 & 3 & 4 & 5 \\
\hline $\begin{array}{l}\text { 14. I always seek God's guidance for every } \\
\text { decision I make }\end{array}$ & 1 & 2 & 3 & 4 & 5 \\
\hline $\begin{array}{l}\text { 15. I am aware of God's presence in my interactions } \\
\text { with other people }\end{array}$ & 1 & 2 & 3 & 4 & 5 \\
\hline $\begin{array}{l}\text { 16. There are times when I feel that God is } \\
\text { punishing me }\end{array}$ & 1 & 2 & 3 & 4 & 5 \\
\hline $\begin{array}{l}\text { 17. I am aware of God responding to me in a } \\
\text { variety of ways }\end{array}$ & 1 & 2 & 3 & 4 & 5 \\
\hline 18.1. There are times when I feel angry at God & 1 & 2 & 3 & 4 & 5 \\
\hline $\begin{array}{l}\text { 18.2. When this happens, I still have the sense } \\
\text { that God will always be with me }\end{array}$ & 1 & 2 & 3 & 4 & 5 \\
\hline 19. I am aware of God attending to me in times of need & 1 & 2 & 3 & 4 & 5 \\
\hline $\begin{array}{l}\text { 20. God understands that my needs are more important } \\
\text { than most people's }\end{array}$ & 1 & 2 & 3 & 4 & 5 \\
\hline 21. I am aware of God telling me to do something & 1 & 2 & 3 & 4 & 5 \\
\hline 22. I worry that I will be left out of God's plans & 1 & 2 & 3 & 4 & 5 \\
\hline 23. My experiences of God's presence impacts me greatly & y 1 & 2 & 3 & 4 & 5 \\
\hline 24. I am always as kind at home as I am at church. & 1 & 2 & 3 & 4 & 5 \\
\hline $\begin{array}{l}\text { 25. I have a sense of the direction in which } \\
\text { God is guiding me }\end{array}$ & 1 & 2 & 3 & 4 & 5 \\
\hline $\begin{array}{l}\text { 26. My relationship with God is an extraordinary one } \\
\text { that most people would not understand }\end{array}$ & 1 & 2 & 3 & 4 & 5 \\
\hline 27.1. There are times when I feel betrayed by God & 1 & 2 & 3 & 4 & 5 \\
\hline $\begin{array}{l}\text { 27.2. When I feel this way, I put effort into restoring } \\
\text { our relationship }\end{array}$ & 1 & 2 & 3 & 4 & 5 \\
\hline $\begin{array}{l}\text { 28. I am aware of God communicating to me in } \\
\text { a variety of ways }\end{array}$ & 1 & 2 & 3 & 4 & 5 \\
\hline $\begin{array}{l}\text { 29. Manipulating God seems to be the best way } \\
\text { to get what I want }\end{array}$ & 1 & 2 & 3 & 4 & 5 \\
\hline 30. I am aware of God's presence in times of need & 1 & 2 & 3 & 4 & 5 \\
\hline 31. From day to day, I sense God being with me & 1 & 2 & 3 & 4 & 5 \\
\hline
\end{tabular}




$\begin{array}{cc}1 & 5 \\ \text { not at } & \text { very } \\ \text { all true } & \text { true }\end{array}$

32. I pray for all my friends and relatives every day

$\begin{array}{lllll}1 & 2 & 3 & 4 & 5\end{array}$

33.1. There are times when I feel frustrated by God for not responding to my prayers

33.2. When I feel this way, I am able to talk it through with God

34. I have a sense of God communicating guidance to me $\begin{array}{lllllll}1 & 2 & 3 & 4 & 5\end{array}$

35. When I sin, I tend to withdraw from God $\quad \begin{array}{llllll}1 & 2 & 3 & 4 & 5\end{array}$

36. I experience an awareness of God speaking to $\quad \begin{array}{lllllll}1 & 2 & 3 & 4 & 5\end{array}$ me personally

37. I find my prayers to God are more effective than $\quad \begin{array}{llllllll}1 & 2 & 3 & 4 & 5\end{array}$ other people's

38. I am always in the mood to pray.

39. I feel I have to please God or he might reject me

$\begin{array}{lllll}1 & 2 & 3 & 4 & 5\end{array}$

40. I have a strong impression of God's presence

$\begin{array}{lllll}1 & 2 & 3 & 4 & 5\end{array}$

41. There are times when I feel that God is angry at me $\begin{array}{llllll}1 & 2 & 3 & 4 & 5\end{array}$

42. I am aware of God being very near to me $\quad \begin{array}{llllll}1 & 2 & 3 & 4 & 5\end{array}$

43. When I sin, I am afraid of what God will do to me $\quad \begin{array}{lllllll}1 & 2 & 3 & 4 & 5\end{array}$

44. When I consult God about decisions in my life, $\quad \begin{array}{llllll}1 & 2 & 3 & 4 & 5\end{array}$ I am aware to my prayers of his direction and help

45. I seem to be more gifted than most people in $\quad \begin{array}{llllllll}1 & 2 & 3 & 4 & 5\end{array}$ discerning God's will

46. When I feel God is not protecting me, I tend $\quad \begin{array}{lllllll}1 & 2 & 3 & 4 & 5\end{array}$ to feel worthless

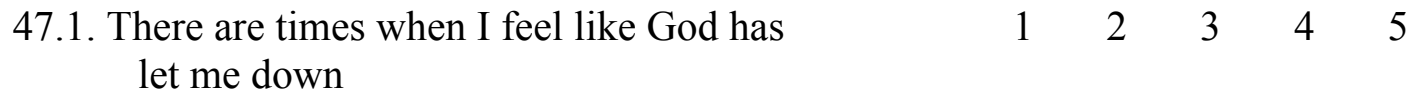

$\begin{array}{lllllll}\text { 47.2. When this happens, my trust in God is } & 1 & 2 & 3 & 4 & 5\end{array}$ not completely broken 


\section{Appendix H}

The 2-Way Social Support Scale

Thinking about your relationships with family and friends in your home country, please rate each of the following areas.

\begin{tabular}{ccc}
\hline & 0 & 5 \\
not at all & always
\end{tabular}

1. There is someone I can talk to about the

$\begin{array}{llllll}0 & 1 & 2 & 3 & 4 & 5\end{array}$
pressures in my life

2. There is at least one person that I can share $\quad \begin{array}{llllllll}0 & 1 & 2 & 3 & 4 & 5\end{array}$ most things with

3. When I am feeling down there is someone I $\quad \begin{array}{lllllll}0 & 1 & 2 & 3 & 4 & 5\end{array}$ can lean on

4. There is someone in my life I can get emotional support from

5. There is at least one person that I feel I can $\quad \begin{array}{lllllllll}0 & 1 & 2 & 3 & 4 & 5\end{array}$ trust

6. There is someone in my life that makes me $\quad \begin{array}{llllllll}0 & 1 & 2 & 3 & 4 & 5\end{array}$ feel worthwhile

7. I feel that I have a circle of people who value $\quad \begin{array}{llllllll}0 & 1 & 2 & 3 & 4 & 5\end{array}$ me

8. I am there to listen to other's problems

$\begin{array}{llllll}0 & 1 & 2 & 3 & 4 & 5\end{array}$

9. I look for ways to cheer people up when they $\begin{array}{lllllllll}0 & 1 & 2 & 3 & 4 & 5\end{array}$ are feeling down

10. People close to me tell me their fears and $\quad \begin{array}{llllllll}0 & 1 & 2 & 3 & 4 & 5\end{array}$ worries

11. I give others a sense of comfort in times of $\begin{array}{llllllll}0 & 1 & 2 & 3 & 4 & 5\end{array}$ need

12. People confide in me when they have problems

13. If stranded somewhere there is someone who $\quad \begin{array}{llllllll}0 & 1 & 2 & 3 & 4 & 5\end{array}$ would get me

14. I have someone to help me if I am physically $\begin{array}{lllllllll}0 & 1 & 2 & 3 & 4 & 5\end{array}$ unwell

15. There is someone who would give me financial assistance

16. There is someone who can help me fulfill my $\quad \begin{array}{lllllllll}0 & 1 & 2 & 3 & 4 & 5\end{array}$ responsibilities when I am unable

17. I help others when they are too busy to get $\quad \begin{array}{llllllllll}0 & 1 & 2 & 3 & 4 & 5\end{array}$ everything done 
18. I have helped someone with their responsibilities when they were unable to fulfill them

19. When someone was sick I helped them

20. I am a person others turn to for help with tasks

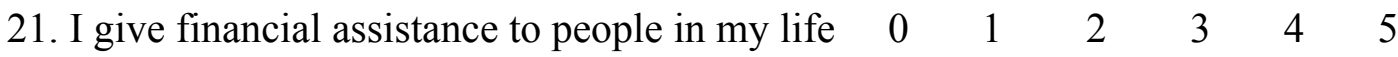




\section{The 2-Way Social Support Scale}

Thinking about your relationships with missionaries on the field, please rate each of the following areas.

\begin{tabular}{ccc}
\hline & 0 & 5 \\
& not at all & always
\end{tabular}

1. There is someone I can talk to about the pressures in my life

2. There is at least one person that I can share $\quad \begin{array}{lllllllll}0 & 1 & 2 & 3 & 4 & 5\end{array}$ most things with

3. When I am feeling down there is someone I $\quad \begin{array}{llllllll}0 & 1 & 2 & 3 & 4 & 5\end{array}$ can lean on

4. There is someone in my life I can get emotional support from

5. There is at least one person that I feel I can $\quad \begin{array}{lllllllll}0 & 1 & 2 & 3 & 4 & 5\end{array}$ trust

6. There is someone in my life that makes me $\quad \begin{array}{llllllll}0 & 1 & 2 & 3 & 4 & 5\end{array}$ feel worthwhile

7. I feel that I have a circle of people who value $\quad \begin{array}{llllllll}0 & 1 & 2 & 3 & 4 & 5\end{array}$ me

8. I am there to listen to other's problems $\quad \begin{array}{lllllll}0 & 1 & 2 & 3 & 4 & 5\end{array}$

9. I look for ways to cheer people up when they $\begin{array}{llllllll}0 & 1 & 2 & 3 & 4 & 5\end{array}$ are feeling down

10. People close to me tell me their fears and $\quad \begin{array}{llllllll}0 & 1 & 2 & 3 & 4 & 5\end{array}$ worries

11. I give others a sense of comfort in times of $\quad \begin{array}{lllllll}0 & 1 & 2 & 3 & 4 & 5\end{array}$ need

12. People confide in me when they have problems

13. If stranded somewhere there is someone who $\quad \begin{array}{llllllll}0 & 1 & 2 & 3 & 4 & 5\end{array}$ would get me

14. I have someone to help me if I am physically $\quad \begin{array}{llllllll}0 & 1 & 2 & 3 & 4 & 5\end{array}$ unwell

15. There is someone who would give me $\quad \begin{array}{lllllllll}0 & & 1 & 2 & 3 & 4 & 5\end{array}$ financial assistance

16. There is someone who can help me fulfill my $\begin{array}{llllllll}0 & 1 & 2 & 3 & 4 & 5\end{array}$ responsibilities when I am unable

17. I help others when they are too busy to get $\quad \begin{array}{llllllll}0 & 1 & 2 & 3 & 4 & 5\end{array}$ everything done

18. I have helped someone with their

$\begin{array}{llllll}0 & 1 & 2 & 3 & 4 & 5\end{array}$
responsibilities when they were unable to fulfill them 
19. When someone was sick I helped them

20. I am a person others turn to for help with tasks

21. I give financial assistance to people in my life $\begin{array}{llllllll}0 & 1 & 2 & 3 & 4 & 5\end{array}$ 


\section{The 2-Way Social Support Scale}

Thinking about your relationships with citizens or residents of your country of service, please rate each of the following areas.

\begin{tabular}{ccc}
\hline 0 & 5 \\
not at all & always
\end{tabular}

1. There is someone I can talk to about the pressures in my life

2. There is at least one person that I can share $\quad \begin{array}{llllllll}0 & 1 & 2 & 3 & 4 & 5\end{array}$ most things with

3. When I am feeling down there is someone I $\quad \begin{array}{llllllll}0 & 1 & 2 & 3 & 4 & 5\end{array}$ can lean on

4. There is someone in my life I can get emotional support from

5. There is at least one person that I feel I can $\quad \begin{array}{lllllllll}0 & 1 & 2 & 3 & 4 & 5\end{array}$ trust

6. There is someone in my life that makes me $\quad \begin{array}{llllllll}0 & 1 & 2 & 3 & 4 & 5\end{array}$ feel worthwhile

7. I feel that I have a circle of people who value $\quad \begin{array}{llllllll}0 & 1 & 2 & 3 & 4 & 5\end{array}$ me

8. I am there to listen to other's problems $\quad \begin{array}{llllllll}0 & 1 & 2 & 3 & 4 & 5\end{array}$

9. I look for ways to cheer people up when they $\begin{array}{llllllll}0 & 1 & 2 & 3 & 4 & 5\end{array}$ are feeling down

10. People close to me tell me their fears and $\quad \begin{array}{lllllllll}0 & 1 & 2 & 3 & 4 & 5\end{array}$ worries

11. I give others a sense of comfort in times of $\quad \begin{array}{lllllll}0 & 1 & 2 & 3 & 4 & 5\end{array}$ need

12. People confide in me when they have problems

13. If stranded somewhere there is someone who $\quad \begin{array}{lllllll}0 & 1 & 2 & 3 & 4 & 5\end{array}$ would get me

14. I have someone to help me if I am physically $\quad \begin{array}{llllllll}0 & 1 & 2 & 3 & 4 & 5\end{array}$ unwell

15. There is someone who would give me $\quad \begin{array}{lllllllll}0 & & 1 & 2 & 3 & 4 & 5\end{array}$ financial assistance

16. There is someone who can help me fulfill my $\quad \begin{array}{llllllll}0 & 1 & 2 & 3 & 4 & 5\end{array}$ responsibilities when I am unable

17. I help others when they are too busy to get $\quad \begin{array}{llllllll}0 & 1 & 2 & 3 & 4 & 5\end{array}$ everything done

18. I have helped someone with their

$\begin{array}{llllll}0 & 1 & 2 & 3 & 4 & 5\end{array}$
responsibilities when they were unable to fulfill them 
19. When someone was sick I helped them

20. I am a person others turn to for help with tasks

21. I give financial assistance to people in my life $\quad \begin{array}{llllllll}0 & 1 & 2 & 3 & 4 & 5\end{array}$ 


\title{
CURRICULUM VITAE
}

\author{
Sarah Warren \\ 412 S. Hickory Lane, Petersburg, IN 47567 \\ warren.sarah@yahoo.com
}

\section{Education}

Doctor of Philosophy, Counselor Education and Supervision, December 2017

University of Louisville, Louisville, KY

Master of Arts, Marriage and Family Therapy/Addictions Counseling/Community Counseling, December 2008

Indiana Wesleyan University, Marion, IN

Bachelor of Arts, Psychology, May 2006

Olivet Nazarene University, Bourbonnais, IL

\section{Licensure and Certification}

Licensed Marriage and Family Therapist, Indiana, Issued 2011

Licensed Clinical Addictions Counselor, Indiana, Issued 2010

\section{Teaching Experience}

Indiana Wesleyan University 05/2011-Present

Adjunct Faculty

Undergraduate Courses: Addictions Counseling Practicum; Addictions Theory; Advocacy in Human Services; Developmental Psychology; Marriage and Family Therapy; Psychopharmacology

Graduate Courses: Counseling Addicted Families; Integrating the Theory and Practice of Christian Counseling; Legal, Ethical, and Professional Issues; Theories and Techniques in the Helping Relationship

University of Louisville

08/2010-06/2013

Graduate Teaching Assistant/Adjunct Faculty

Undergraduate Courses: College of Education New Student Orientation

Graduate Courses: The Prevention of Mental Disorders: Theory, Research, and Practice; Internship in Clinical Mental Health Counseling. 


\section{Supervision Experience}

\section{University of Louisville}

$01 / 2012-12 / 2012$

Doctoral Student Supervisor

Department of Educational and Counseling Psychology

Indiana Wesleyan University

$05 / 2011-06 / 2016$

Practicum Supervisor, Undergraduate Addictions Counseling

College of Adult and Professional Studies

Family Ark

$09 / 2013-01 / 2016$

Home-Based Services Supervisor

\section{Clinical Experience}

Extreme Nazarene Missions

01/2016-Present

Well-Being Manager

Family Ark

09/2013-01/2016

Home-Based Services Supervisor/Therapist

Indiana University Southeast Counseling Center 08/2011-04/2012

Doctoral Intern

Samaritan Behavioral Healthcare

$01 / 2009-10 / 2010$

Clinical Therapist

\section{Additional University Employment}

University of Louisville

Graduate Assistant, Education Advising Center

$08 / 2010-06 / 2013$

Research Assistant, Center for Promoting Recovery and

Resilience of Traumatized Children and Youth

$11 / 2013-05 / 2014$

Indiana Wesleyan University

Graduate Assistant, Division of Graduate Counseling

08/2006-12/2008

\section{Projects/Presentations}

Hudson, D., Chandler, F., Ricci, J., \& Warren, S. (2008) Student perceptions of counseling faculty competency and professional identity based on licensure and participation in practice. Poster presentation at the American Counseling Association's Annual Conference, Honolulu, HI.

\section{Honors and Awards}

Psi Chi (Psychology Honor Society)

Chi Sigma Iota (Counseling Honor Society)

President, Iota Omega Upsilon Chapter 


\section{Professional Memberships}

American Association of Marriage and Family Therapy American Counseling Association

Association for Addiction Professionals (NAADAC) 